\title{
Vascular access in cancer patients - clinical implications
}

\section{Knut Taxbro}

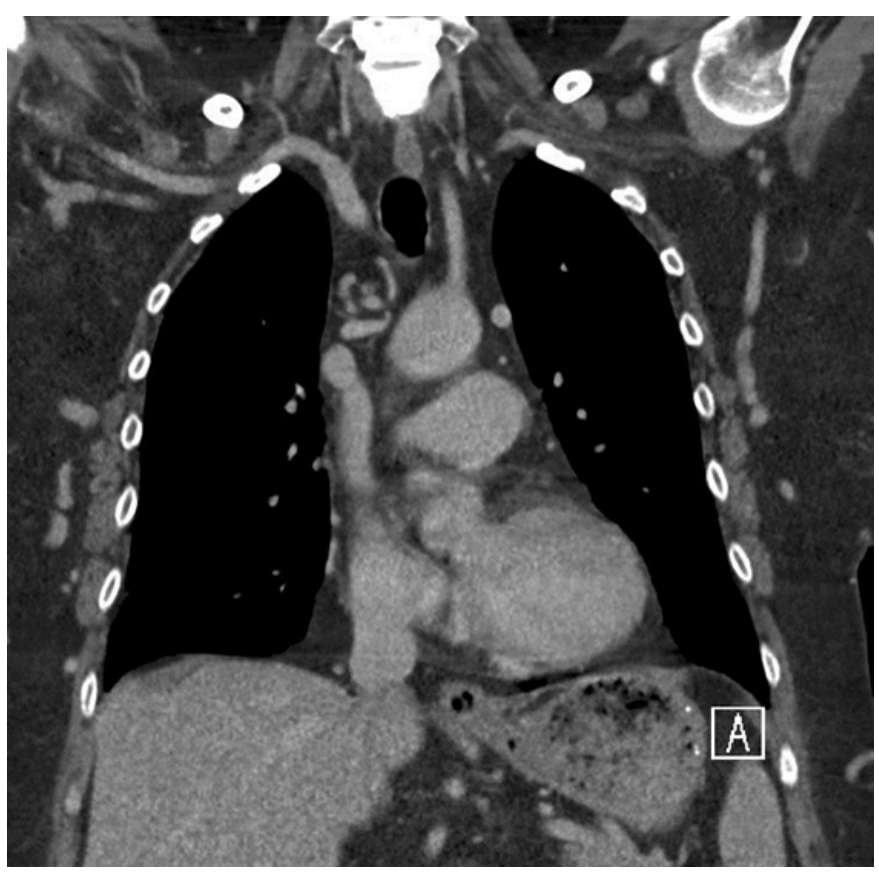

\section{LINKÖPING}


Linköping University Medical Dissertations No. 1693

\section{Vascular access in cancer patients - clinical implications}

Knut Taxbro

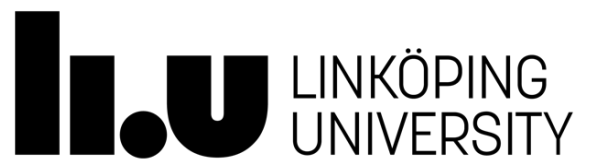

Department of Medical and Health Sciences

Linköping University, Sweden

Linköping 2019 


\section{Principal supervisor:}

Associate Professor Sören Berg, MD, PhD. Linköping University and Department of Cardiothoracic Surgery, Anaesthesia and Intensive Care, Linköping University Hospital, Sweden.

\section{Co supervisors:}

Professor Håkan Hanberger, MD, PhD. Linköping University and Department of Infectious Diseases, Linköping University Hospital, Sweden.

Fredrik Hammarskjöld, MD, PhD. Department of Anaesthesia and Intensive Care, Ryhov County Hospital, Jönköping, Sweden.

\section{Faculty opponent:}

Associate Professor Vineet Chopra, MD, MSc. University of Michigan and Michigan Medicine, Ann Arbor, Michigan, USA

Cover illustration: Computed tomography depicting stenosis in the superior vena cava in a patient with previous long-term central venous catheters.

CKnut Taxbro, 2019

Published articles have been reprinted with the permission of the copyright holder.

Printed in Sweden by LiU-Tryck, Linköping, Sweden, 2019

ISBN 978-91-7685-022-0

ISSN 0345-0082 


\section{CONTENTS}

ABSTRACT

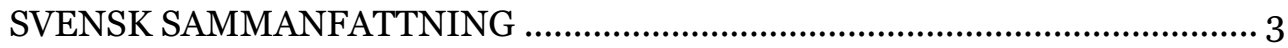

LIST OF PAPERS ……………………………............................................ 5

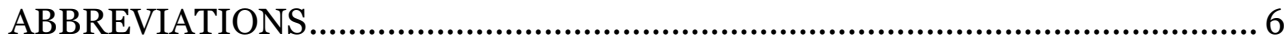

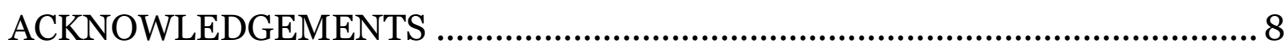

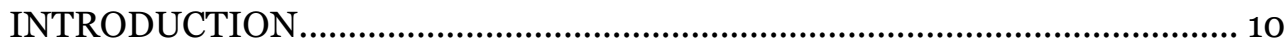

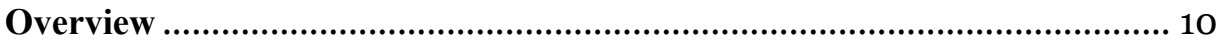

The venous system of the upper limb, neck and thorax..................................10

The history of central venous catheters........................................................... 13

Long-term central venous catheters today .................................................... 14

Indications and catheter selection ...................................................................15

Insertion and implantation of long-term catheters ........................................20

Complications related to catheter insertion, the use of ultrasound and

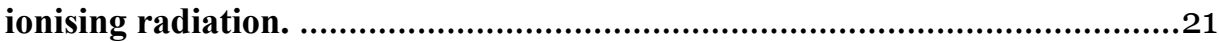

Management of complications during the dwell period. .................................. 29

Venous thrombo-embolic disease in cancer...................................................29

Upper extremity deep vein thrombosis........................................................29

Treatment of catheter-related deep venous thrombosis .....................................32

Prevention of catheter-related deep venous thrombosis (pharmacological

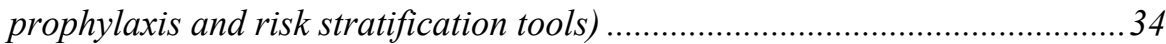

Catheter-related infection ………………….................................................. 39

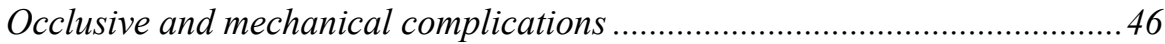

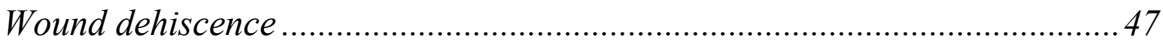

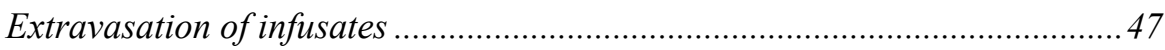

Patient perception ............................................................................................... 49

Aspects of healthcare economy …………......................................................... 50

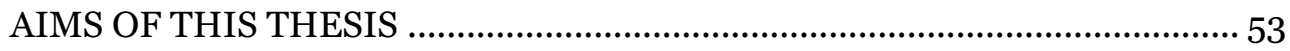

PATIENTS, METHODS AND STATISTICS ……………….............................. 54

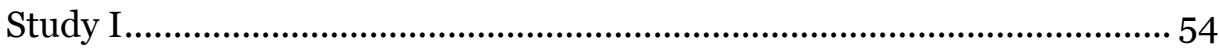




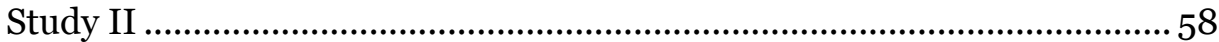

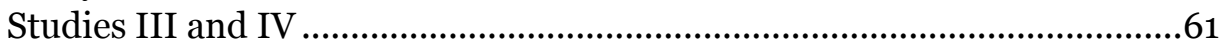

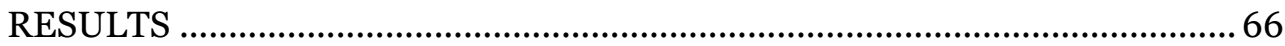

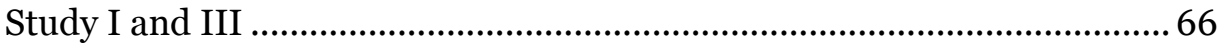

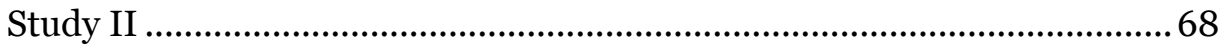

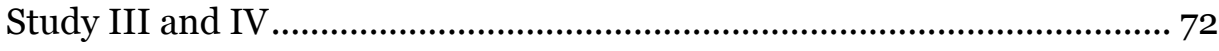

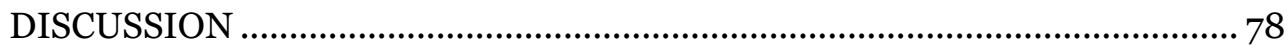

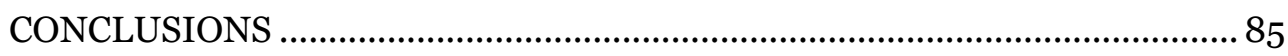

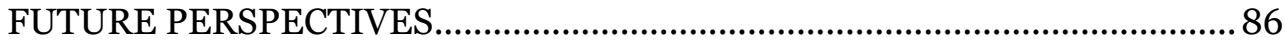

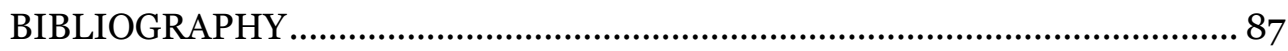




\section{ABSTRACT}

Central venous catheters (CVC) are vital for patients receiving chemotherapy not compatible with peripheral infusion. Thousands of centrally and peripherally inserted central venous catheters are inserted into patients with cancer each year. All types of intravascular catheters are associated with complications. These complications may be divided into infectious, thrombotic, mechanical and occlusive events. All of these events have the potential to harm patients and cause additional expense for the health-care system. Furthermore, the above-mentioned complications are largely avoidable through proper patient selection, insertion technique, hygiene precautions and catheter maintenance.

Catheter-related infections and deep venous thrombosis are the two most common and feared CVC related complications. Infection in a catheter can cause lifethreatening bacteraemia, and thrombosis can lead to pulmonary embolisation, post-thrombotic syndrome and stenosis of the vessel affected. Many studies describing methods to minimise infectious complications associated with central venous catheters have been carried out. These methods appear to have been implemented in most modern advanced healthcare facilities resulting in a continual decrease in catheter-related infections over the last two decades. New implantation techniques, fewer infections and better catheter materials are likely to have contributed to the reduction in the incidence of catheter-related deep venous thrombosis (CR-DVT). Peripherally inserted central venous catheters (PICC) and subcutaneously implanted vascular access ports (PORT) are two very commonly used catheter devices for delivery of chemotherapy. International guidelines are unclear as to which device to choose due to the paucity of controlled trials.

The aim of this thesis was to study complications related to central venous access devices used over long periods of time, usually for the delivery of chemotherapy. 
We prospectively studied PORT complications (Study 1) over a six-month follow-up period. In Study 2, we assessed the number of common CVC-related micro-organisms that are transferred across PORT membrane contaminated by a controlled suspension of micro-organisms when a non-coring access needle is inserted using two different techniques. In the largest randomised controlled trial published on this topic (Study 3), we compared PICC with PORT regarding CRDVT and other catheter-related complications. The economic implications of using PICC or PORT were assessed from health-care system's perspective (Study 4), using data on adverse events and clinical factors (implantation, treatments and dwell-time) from Study 3.

Chemotherapy against various forms of cancer is very common. Implantation of PORT is one of the ten most common surgical procedures in Sweden according to the Swedish Perioperative Register. Hence, the topic in this thesis may be clinically relevant to many patients and their health care providers.

We found that the incidence of catheter-related blood stream infection was very low in the cohorts studied. In general, PICCs are associated with significantly more CR-DVTs and adverse events than PORTs. The cost to the health-care system when using PICC is higher than for PORT when complications are included. Given the choice, patients about to commence chemotherapy appear to prefer PORT to PICC. PORT implantation is more painful than PICC insertion, but PICC appears to influence activities of daily life more than PORT. 


\section{SVENSK SAMMANFATTNING}

En central venkateter (CVK) är en mjuk slang vars spets mynnar i en stor ven inne i bröstkorgen. Centrala venkatetrar är nödvändiga för patienter som får cellgiftsbehandling mot cancer.

De CVKer som i störst utsträckning används inom svensk cancervård är så kallade Perifert Inlagd Central Venkateter (PICC) och venport (PORT). En PICC läggs in via en ven på överarmen och hänger ut ca en decimeter från insticksstället på överarmen. En PORT läggs in via en ven på halsen eller under nyckelbenet och är kopplad till en liten dosa under huden som läggs på bröstkorgen nedanför nyckelbenet.

De två vanligaste komplikationerna till CVK-användning är infektion eller blodproppsbildning i anslutning till katetern. Båda komplikationerna kan leda till allvarliga sjukdomstillstånd (blodförgiftning eller blodpropp i lungan). Det har publicerats flera studier som visar att man med goda rutiner framgångsrikt kan förebygga blodförgiftning med stor framgång. Dessa metoder är på de flesta håll daglig rutin inom svensk sjukvård. Nya inläggningsmetoder, bättre skötsel, färre infektioner och modernt katetermaterial har även lett till en minskad förekomst av blodproppsbildning runt katetern.

Det finns i nuläget inga studier som säkert avgör vilken CVK som lämpar sig bäst vid cellgiftsbehandling. Detta gäller såväl funktionsduglighet, komplikationsrisk och kostnader men även hur varje enskild patient upplever sin CVK. Syftet med denna avhandling har varit att studera förekomsten av komplikationer som kan uppstå när man använder en CVK under lång tid för cellgiftsbehandling och att jämföra komplikationer och kostnader mellan PORT och PICC. I det första arbetet studerades 249 patienter med PORT under sex månader. I det andra arbetet studerade vi risken att föra in bakterier i en PORTs injektionskammare med den nål som sticks igenom huden in i kammaren. Studien genomfördes i en 
laboratoriemiljö genom att nålen stacks in i kammaren efter att kammaren preparerats med olika mängder av bakterier och svampar i olika koncentrationer. I arbete tre och fyra jämfördes PICC och PORT genom att nästan 400 patienter som skulle få cellgiftsbehandling lottades till ett av systemen och därefter följdes upp avseende blodproppsbildning runt kateter och andra komplikationer (Studie 3). Utifrån samma patientergrupp beräknades även hälso-sjukvårdskostnader förknippade med användning och komplikationer av PICC och PORT (Studie 4).

Resultaten visar att risken för blodförgiftning vid användandet av en PORT var $0,8 \%$ i studie 1 och $1,0 \%$ i studie 3 , och vid användandet av en PICC $0 \%$ i studie 3. I jämförelse med internationella studier är detta mycket låga siffror, och det var ingen statistiskt säkerställd skillnad i studie 3 mellan PICC och PORT. Vidare kunde vi i laboratoriemiljö konstatera att väldigt få bakterier och svampar som fanns på PORT-kammarens utsida transporterades in i kammaren vid nålsättning. Man kunde ytterligare minska överföringen genom att spola koksalt i nålen under nålsättningen.

Det viktigaste fyndet i avhandlingen var att blodpropp drabbade $8 \%$ av patienterna med en PICC motsatt till $1 \%$ av patienterna med PORT, vilket statistiskt gav en 10 gånger högre risk för blodproppsbildning för PICC. Det visade sig också att PICC generellt hade fler komplikationer (22,4 \%) än PORT $(13,1 \%)$ vilket gjorde att de totala kostnaderna för PICC-användning var större än för PORT (7883 SEK mot 6332 SEK per katetersystem och 63 SEK mot 29 SEK per kateterdag). Patienterna upplevde att det gjorde mer ont att få en PORT inlagd jämfört med en PICC. Däremot angav patienter med PORT deras kateter påverkade det vardagliga livet mindre jämför med de som hade PICC. Sammanfattningsvis visar avhandlingen att användning av PICC och PORT vid cellgiftsbehandling är förenat med få fall av blodförgiftning men att antalet blodproppar som PICC orsakar är betydligt större än för PORT vilket bör beaktas när man väljer CVK till en patient inför cellgiftsbehandling. 


\section{LIST OF PAPERS}

This thesis is based on the following papers, which will be referred to in the text by their Roman numerals:

I. Taxbro K, Berg S, Hammarskjöld F, Hanberger H, Malmvall B-E. A prospective observational study on 249 subcutaneous central vein access ports in a Swedish county hospital. Acta Oncol. 2013;52:893-901

II. Taxbro K, Mernelius S, Hammarskjöld F, Hanberger H, Berg S. Transfer rate of pathogens through in vitro contaminated venous port membranes varies with species, concentration and injection technique. Journal of the Association of Vascular Access 2019 (Submitted manuscript)

III. Taxbro K, Hammarskjöld F, Thelin B, Lewin F, Hagman H, Hanberger $\mathrm{H}$, Berg S. Clinical impact of peripherally inserted central catheters versus implanted port catheters in patients with cancer: an open-label, randomised two-centre trial. British Journal of Anaesthesia; 2019;122:734-41

IV. Taxbro K, Hammarskjöld F, Juhlin D, Hagman H Bernfort L, Berg S. Cost analysis comparison between peripherally inserted central catheters and implanted chest ports in patients with cancer - a health economic evaluation of the PICCPORT trial. (In manuscript)

All previously published papers are reprinted with permission from the publisher. 


\section{ABBREVIATIONS}

5-FU $\quad 5$ - fluorouracil

AL Antimicrobial lock

APC Activated prothrombin complex

AV Arteriovenous (fistula)

CFU Colony-forming unit

CICC Centrally inserted central catheter

CoNS Coagulase negative staphylococci

CRBSI Catheter-related blood stream infection

CR-DVT Catheter related deep venous thrombosis

CRI Catheter-related infection

CT Computed tomography

CVC Central venous catheter

EUR Euro

HAI Healthcare-associated infection

HCW Health-care worker

IJV Internal jugular vein

ITT Intention-to-treat

LMWH Low molecular weight heparin

MRS Michigan Risk Score

NIM Needleless injection membrane

NRS Numeric rating scale

PE Pulmonary embolism

PICC Peripherally inserted central catheter

PORT Subcutaneous venous port $(=\mathrm{TIVAD},=\mathrm{SVP})$ 
PP Per-protocol

PVC Peripheral venous catheter

RCT Randomised controlled trial

SCV Subclavian vein

SEK Swedish krona

SIRS Systemic inflammatory response system

SVP Subcutaneous venous port $(=$ TIVAD, $=$ PORT $)$

T-CVC Tunnelled-central venous catheter

TIVAD Totally implanted vascular access port $(=\mathrm{SVP}=\mathrm{PORT})$

TNTC Too numerous to count

UEDVT Upper extremity deep vein thrombosis

US Ultrasound

VAD Vascular access device

VKA Vitamin K Antagonist

VTE Venous thrombo-embolism 


\section{ACKNOWLEDGEMENTS}

Sören Berg - My supervisor, for his patience, good spirits, wisdom and for keeping me under appropriate pressure throughout.

Fredrik Hammarskjöld - my co-supervisor who with a big heart, endless support, a hideous red hat, enthusiasm and in-depth catheter knowledge guided me through this project.

Håkan Hanberger - my co-supervisor for pointing out the major findings.

Freddi Lewin - oncology and laughter-master.

Helga Hagman - for her sharp formulations and overall brilliance.

Bosse Thelin and Therese Karlsson- for their endurance and good spirits during the PICCPORT trial.

Bo-Eric Malmvall - for wise supervision during my first paper.

Sara Mernelius - for patiently (and with loads of laughter!) introducing me to pipettes, agar plates and counting CFUs.

Futurum and Margareta Stenmarker - for making this whole project possible.

Peter Cox - for transforming norswenglish into the Queens English.

David Juhlin - for constant positive energy.

Pelle Blomqvist - for precision, diligence and persistence.

Boggis Kiersz - for speed - and momentum.

Joe Woodring - my high-school teacher in the US, for pointing out that the key to success is self-discipline.

Calle Hildebrand - for his remarkable courage during my first CVC insertion and a whole lot more. 
Karin Landen Johansson and Anna Jonsson - for their impressive practical knowledge of $\mathrm{CVC}$ care, and extraordinary resilience during the first study.

Ing-Marie Svensson - for diligence and precision.

Christer Petterson and Thomas Öhman - for much appreciated friendship and for keeping me in contact with the real (clinical) world.

Johan Lidåker - for clean shots and tomato sauce.

Veronica Baumann-Annerhagen - for giving me the opportunity.

Johan Junelind - mountain lion and uphill master.

Hannes Kahlow - the best mentee in the world: period.

My sisters; Trine, Siri and Maria - always a source of inspiration and long phone calls.

Arthur and Filippa - My precious children: the most important persons in the world. I love you both (equally).

Ida - My wife, personifying everything I could ever wish for. I love you. 


\section{INTRODUCTION}

\section{Overview}

\section{The venous system of the upper limb, neck and thorax}

Superficial veins of the upper limb include the cephalic, basilic, median cubital and additional antebrachial veins and their tributaries. ${ }^{1}$

The cephalic vein usually forms in the "anatomical snuff box" and runs along the radial aspect of the forearm ascending the upper arm in a groove lateral to the biceps muscle. After entering the deltoid-pectoral groove, it joins the axillary vein just below the clavicle.

The basilic vein ascends posteromedially on the forearm and joins the median cubital vein between the biceps and pronator teres. It ascends medially and perforates the deep fascia about midway up the upper arm becoming the axillary vein. The deep veins of the upper limb accompany arteries, usually in pairs. Since much blood is returned by the superficial upper extremity veins, the deep veins are usually relatively small. The brachial vein runs parallel to the brachial artery before joining the axillary vein. The axillary vein is the continuation of the basilic and brachial veins and terminates at the first rib where it becomes the SVC. The SCV joins the IJV to form the brachiocephalic (innominate) vein. The IJV receives blood from the skull, brain, face and neck. It begins at the base of the skull descending in the carotid sheath lateral to the vagus nerve and carotid artery. The right brachiocephalic vein is a short, almost vertically descending vessel that joins the longer left brachiocephalic vein to form the SVC. The SVC is about 7 centimetres in length and returns blood to the heart from the upper half of the body, adjoining the upper part of the right atrium. 


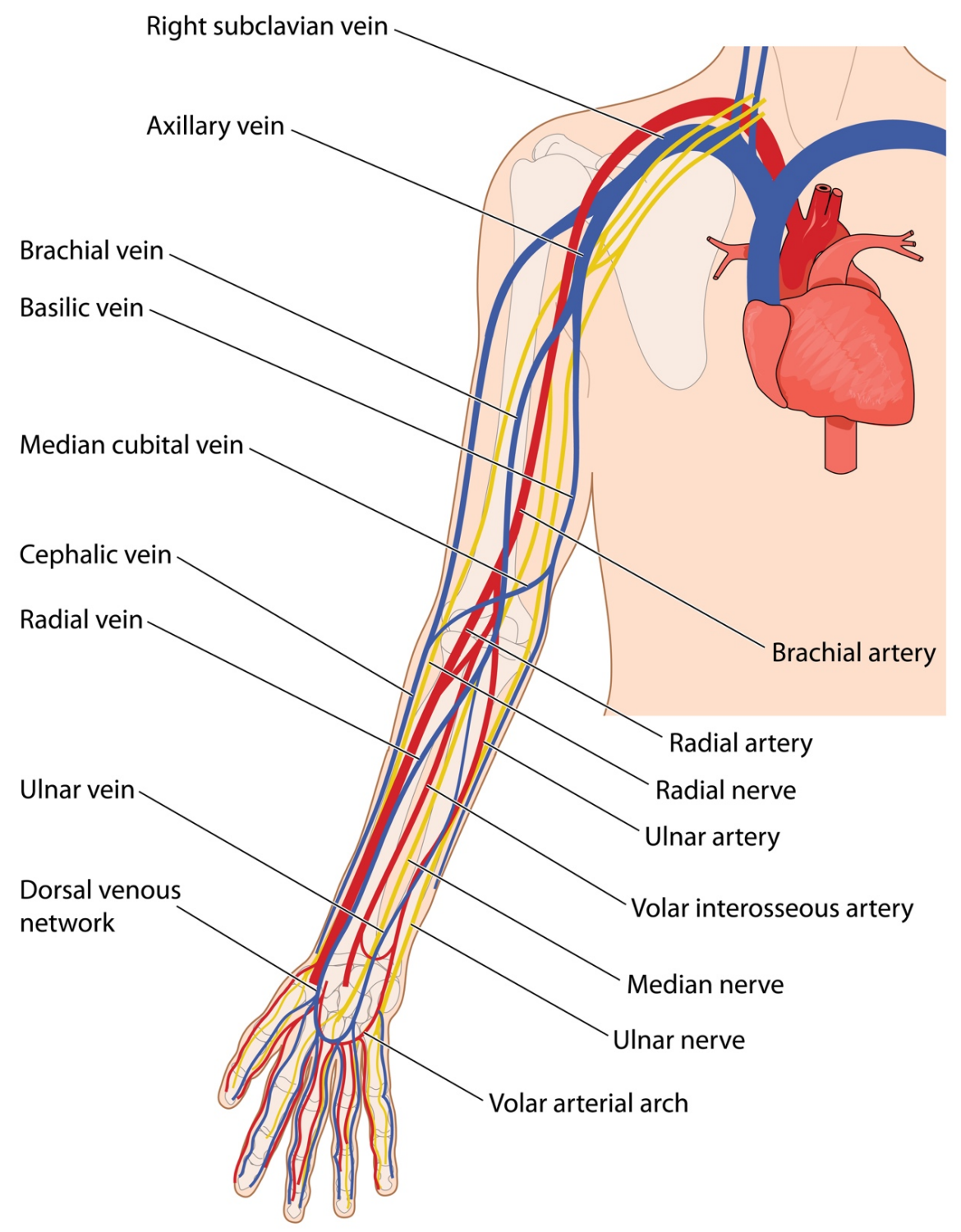

Figure 1 Vessels and nerves of the Upper Limb. Reprinted with permission (Peter Lamb @ http://123rf.com) 


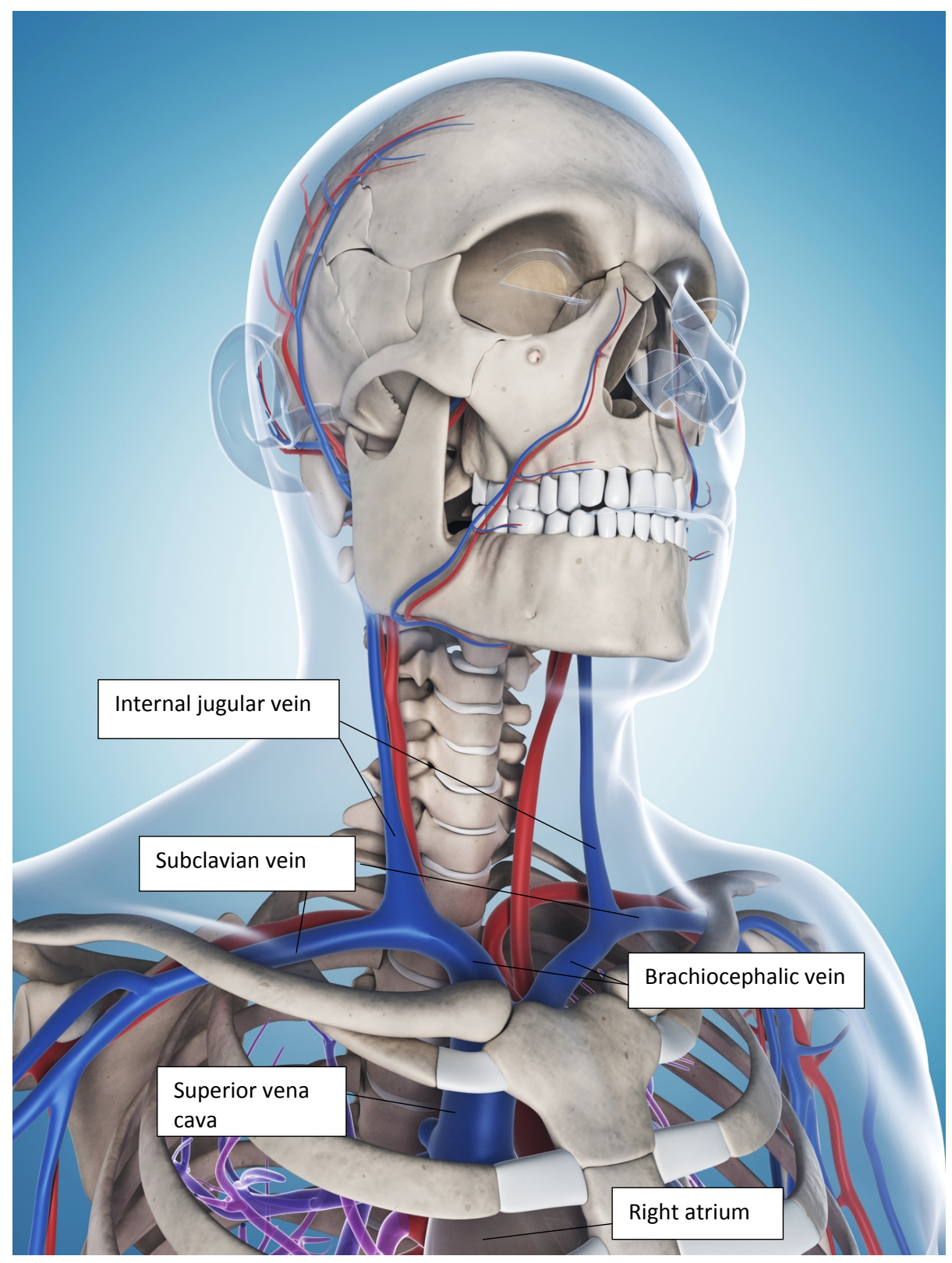

Figure 2 Large veins of the neck and chest. Reprinted with permission (Sebastian Kaulitzki $\odot$ http://123rf.com) 


\section{The history of central venous catheters}

After the first scientific description ${ }^{2}$ of the mammalian circulation by William Harvey (1578-1657), scientists began to experiment on ways to introduce substances to the bloodstream. In 1656, Christopher Wren injected a mixture of wine, ale and opium into dogs. A goose quill or silver cannula was typically connected to a porcine bladder to achieve intravenous injection of various substances. The first xenotransplantation (lamb blood injected into the human bloodstream) was performed in 1667 and due to the inevitable fatal reaction the technique fell into disrepute. ${ }^{3}$ Further blood transfusions were banned until an English obstetrician, using auto transfusion, saved the lives of several women suffering from postpartum haemorrhage in 1818. Bernard cannulated the equine central circulation using long mercury thermometers. Not only could he measure core temperature, but he also described the first serious mechanical side-effect of central venous cannulation when he noted perforation of the heart wall resulting in pericardial haemorrhage.

Nobel laureate Werner Forssmann (1904-1979), a German physician, catheterised his own right heart through cannulation of the antecubital vein. This achievement is regarded as the first PICC insertion. Forssmann was also the first to conceive the idea of administering drugs through a central venous catheter (instead of the more commonly used direct intracardiac injection) in patients suffering from cardiac arrest during surgery. ${ }^{3}$

In the era following the Second World War, flexible polyethylene catheters were introduced into medical practice. However, the introduction and subsequent increased usage was followed by several reports on catheter-related deep vein thromboses. The incidence of thrombosis later decreased due to improvements in catheter materials. In the early 1960's silicone catheters were introduced, and together with polyurethane these materials currently dominate the central venous catheter market.

Prolonged treatment in combination with frequent blood sampling during advanced cancer treatment led to the development of the tunnelled central venous 
catheter. The Hickman silastic catheter was first used in 1975 and it led to a reduction in septicaemia rate and improved patient comfort for those receiving treatment for leukaemia. ${ }^{4}$ The same year, Hoshal published a paper where a 61 $\mathrm{cm}$ long silicone catheter was inserted through the cubital or basilic vein, and was used for long-term intravenous nutrition. ${ }^{5} \mathrm{~A}$ few years later, Niederhuber described the totally implanted central venous access device for use in cancer patients. $^{6}$

\section{Long-term central venous catheters today}

Long-term CVCs are widely used today, each type having its own special qualities. There is no such thing as a "one-device-fits-all-indications" when it comes to vascular access. The clinician together with the patient if possible, must choose the most appropriate device depending on several factors. These include patient factors, anticipated dwell-time, condition specific treatment related factors, and logistics.

According to the Swedish Society of Anaesthesia and Intensive Care Medicine (SFAI), approximately 50.000 central venous catheters are inserted annually in Sweden. ${ }^{7}$ The corresponding figure for the United Kingdom is estimated to be 250000 . The requirement for long-term central venous access is steadily increasing to fulfil the needs of patients receiving cancer chemotherapy, parenteral nutrition, prolonged antibiotic treatment and haemodialysis.

Catheter-related infection (CRI) has been an important problem throughout the world. Over the past decade, substantial scientific and clinical efforts have been made to reduce the rate of HAI. These efforts have resulted in a significant decrease in the number of healthcare-associated central line infections. 


\section{Indications and catheter selection}

Safe and reliable access to the central venous circulation is of great importance for a large number of patients. Patients that require central venous access typically include those who undergo major surgery, require critical care, receive chemotherapy, are on haemodialysis, require total parenteral nutrition or require intravenous antibiotic treatment for several weeks.

The perceived benefits of each type of catheter must be weighed against the risk and cost of complications (insertion-related, infectious and thrombotic) and the cost of management (i.e. dressing changes) and removal.

An array of different central venous vascular access devices exists to meet the specific clinical requirements of different groups of patients. Vascular access devices are generally classified according to the anticipated duration of catheter use (which can range from days to several years), insertion vein (central or peripheral) and the way in which the catheter is fixed (non-tunnelled, tunnelled or totally implanted). 


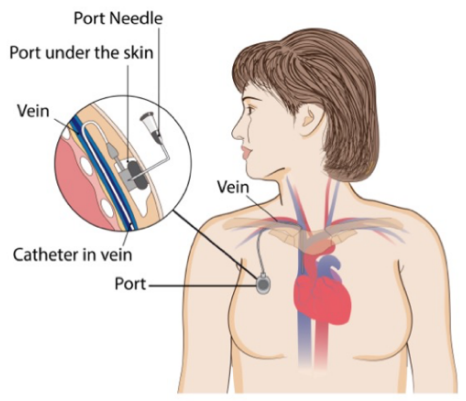

Central venous catheter - Port

Figure 3. Illustration of a totally implanted subcutaneous access port. (Reprinted with permission Maryana Melnyk @ http://123rf.com )

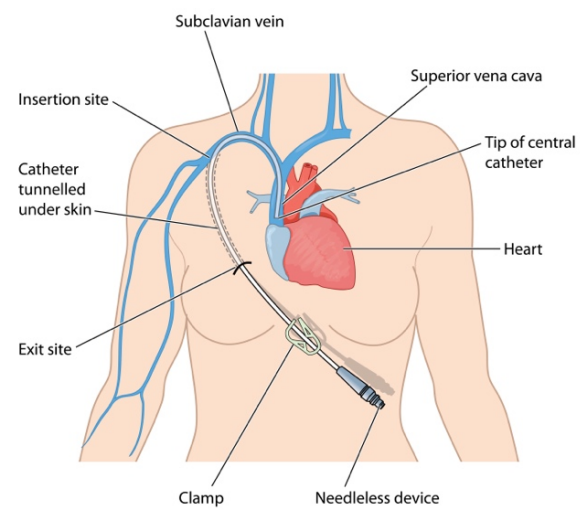

Figure 4 Illustration of a tunnelled (partially implanted) central venous catheter. (Reprinted with permission Peter Lamb C http://123rf.com )

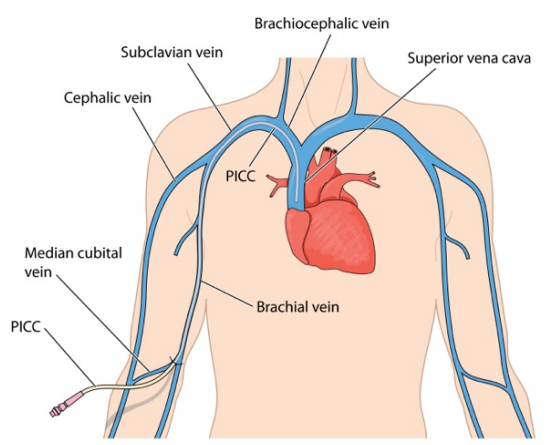

Figure 5 Illustration of a peripherally inserted central venous catheter. (Reprinted with permission Peter Lamb $@$ http://123rf.com) 


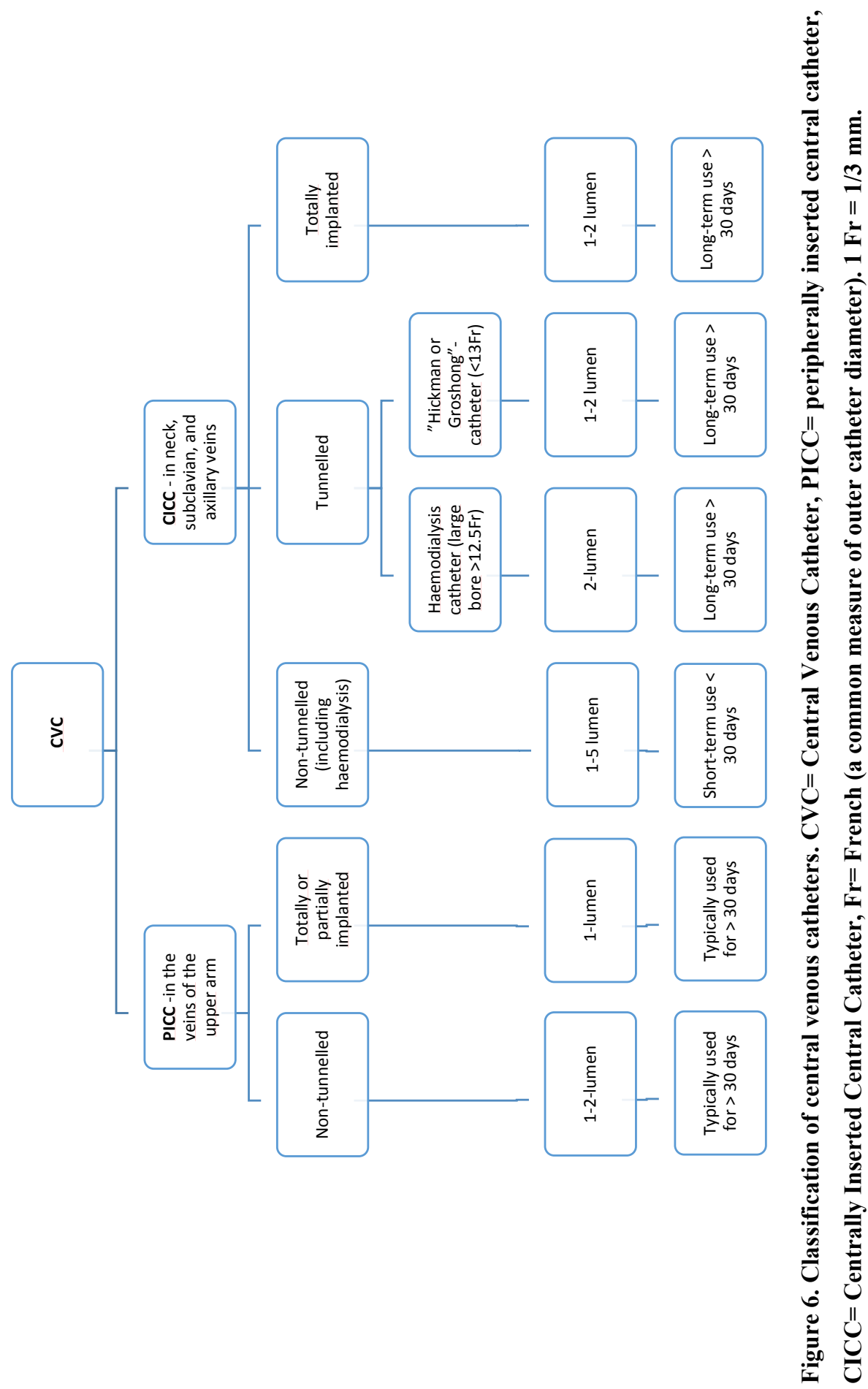


Short-term (up to 30 days dwell-time) CVCs are typically used in the perioperative and critical care setting, mainly for delivering drugs, collecting blood samples and for haemodialysis. Long-term CICCs and PICCs are usually in place for periods longer than 30 days, although PICCs are increasingly used in the intermediate time segment (1 week to 1 month) in hospitalised patients. A group of international experts published guidelines in 2015 to aid clinicians in choosing the most appropriate venous access device (VAD) in various clinical settings. Indications for long-term central venous access include delivery of chemotherapy, parenteral nutrition (as in short bowel syndrome), antibiotics (as in cystic fibrosis), and chronic haemodialysis. More unusual indications include chronic infusion of vasoactive drugs (as in treatment of pulmonary hypertension), prolonged fluid therapy, and in patients with extremely difficult peripheral venous access with an anticipated recurrent need for vascular access.

This thesis focuses on the use of long-term access in cancer patients being treated with chemotherapy. In this setting, patients are eligible for PICC, t-CVC or PORT. Due to the paucity of controlled trials, no major guideline document has been able to give a clear recommendation on which type of catheter is appropriate for patients with cancer (i.e. the largest group of patients requiring long-term central venous access) ${ }^{8-12}$ However, several systematic reviews have raised questions regarding the appropriateness of PICCs in patients with cancer due to the higher incidence of CR-DVT. ${ }^{13-16}$ 


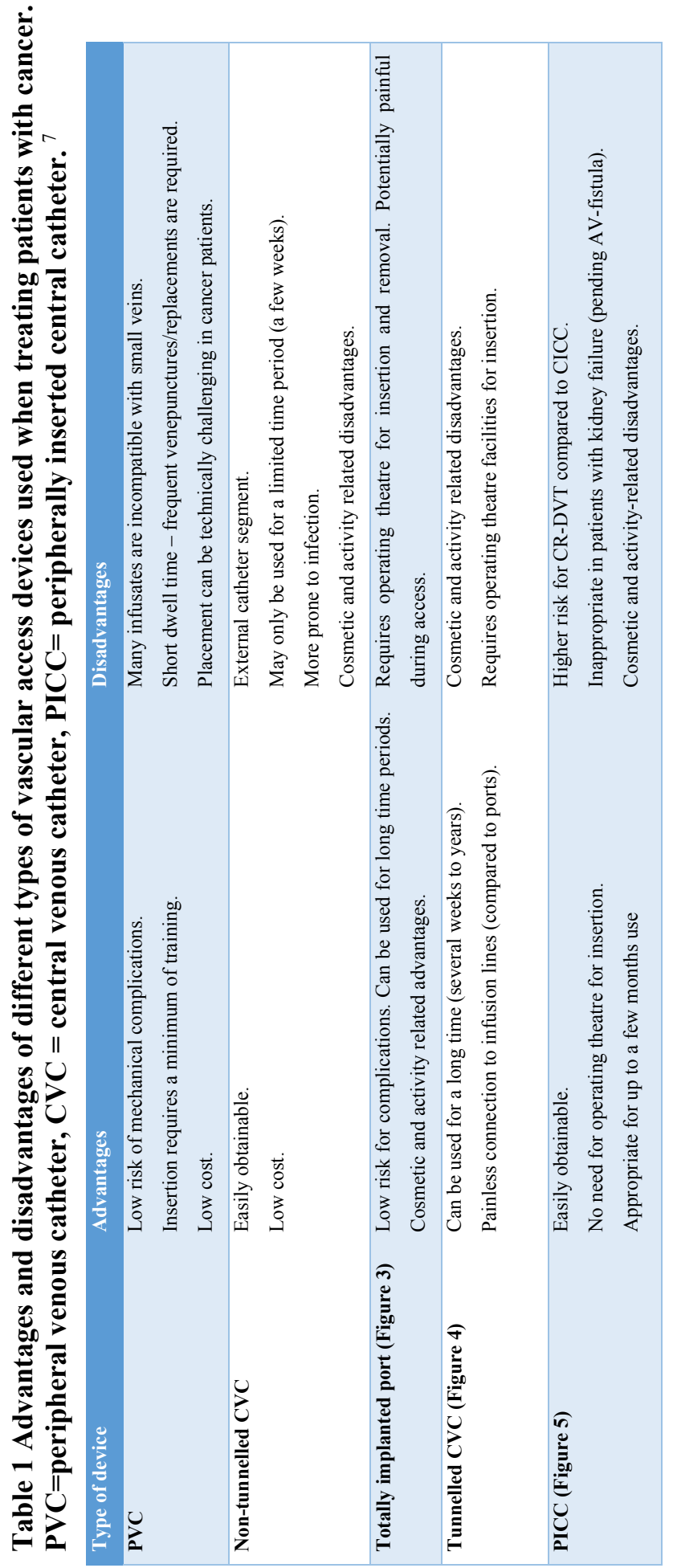




\section{Insertion and implantation of long-term catheters}

In general, there are two different techniques of implanting long-term CVCs based on how access to the central vein is achieved. The percutaneous (Seldinger) technique involves the advancement of a hollow needle towards the vein under ultrasound guidance. Once the needle has reached the vein lumen (blood return) a guidewire is introduced into the vein and advanced towards the superior vena cava. Subsequently, the tissues surrounding the guidewire are dilated to a dimension large enough to accept the catheter. The catheter is positioned in the atriocaval junction, assisted by either fluoroscopy (PORT and t-CVC) or an electromagnetic device (PICC).

The veins of the proximal upper extremity are used for insertion of PICCs (cephalic, brachial or basilic). Once in position, the external part of the PICC is secured to the skin by special anchoring devices, hence, there is no tunnelled segment. In contrast, the PORT catheter is tunnelled from the point of entry to the vein towards a prepared subcutaneous pocket (usually just below the clavicle) on the same side. The tunnelled catheter is attached to the port chamber which is then anchored within the subcutaneous pocket by sutures. The skin is then closed, and the port chamber can be accessed only by puncturing the skin over the port membrane using a specially designed non-coring needle (Huber needle). For t-CVCs the procedure is similar except there is no subcutaneous pocket and the catheter has an external segment. In addition, there is a Dacron ${ }^{\circledR}$ cuff around the catheter just below the skin designed for ingrowth of tissues, thus creating a barrier to skin flora and anchoring the catheter in the correct position.

An alternative method to the percutaneous technique is the open, surgical "cutdown" procedure. Through dissection of the tissues, the vein is identified and accessed through direct incision before positioning the catheter correctly. 
Both surgical and percutaneous techniques are safe and feasible in experienced hands, even though the percutaneous technique is associated with a higher success rate. ${ }^{17} 18$

\section{Complications related to catheter insertion, the use of ultrasound and ionising radiation.}

Although serious insertion-related adverse events are very uncommon during placement of long-term CVCs, we all know these complications exist. Andreas Pikwer's doctoral thesis from 2012 thoroughly discusses several aspects of insertion-related adverse events during central venous cannulation. ${ }^{19}$

Pneumothorax is caused by unintended puncture of lung tissue by the needle, permitting air to escape into the pleural cavity. The volume of air trapped in the pleural cavity can increase due to a valve effect, and may ultimately compress the heart and veins of the chest (tension pneumothorax). A large pneumothorax and especially tension pneumothorax are medical emergencies treated by inserting a chest tube into the pleural cavity enabling the trapped air to escape. However, small $(<3 \mathrm{~cm}$ or $<15 \%)$ and stable asymptomatic pneumothoraxes can be left untreated. ${ }^{70}$

The most severe types of insertion-related complications involve damage to the large vessels of the neck and chest, following accidental perforation, puncture or cannulation of these structures. Accidental arterial cannulation can cause ischaemia through blood flow obstruction or clot embolisation. Damage to a large artery can cause rapid and very significant haemorrhage in a potentially noncompressible area. The haemorrhage can subsequently cause shock, airway obstruction, or haemothorax - all of which are medical emergencies.

Each hemithorax can accommodate 2-3 L of blood and haemothorax is treated by both transfusion and by inserting a large bore chest drain or by thoracotomy if 
the volume of blood exceeds 1.5 L (or if bleeding continues at a rate of 100-200 $\mathrm{ml}$ per hour).

It is essential that the vascular access clinician immediately recognises such complications as soon as they occur - or more importantly, know how to avoid them.

There is good reason to believe that the incidence of insertion-related complications has decreased over time. The use of ultrasound (US)-guided puncture, as opposed to using landmarks, is probably one of the main reasons for this decrease. ${ }^{21-23}$ Due to the relatively scant evidence (particularly regarding the subclavian vein) the use of US has been a matter of some controversy. However, the use of US-guided puncture should be regarded as mandatory in both the elective situation (i.e. when inserting long-term catheters) and the emergency setting. ${ }^{21}$

Table 2 Comparison of studies reporting centrally inserted central venous catheters complications before and after 2010 (early versus modern studies). Studies include heterogeneous patient groups. $\mathrm{cd}=$ catheter days.

\begin{tabular}{|c|c|c|}
\hline Complication & Incidence old studies $(<$ year 2010) & $\begin{array}{l}\text { Incidence modern studies ( } 2010 \\
\text { to present) }\end{array}$ \\
\hline \multirow[t]{2}{*}{ Pneumothorax } & $0-6.6 \%{ }^{22}$ & $0-1.5 \%{ }^{24}$ \\
\hline & $0-3.1 \%{ }^{23}$ & $0-0.1 \%{ }^{21}$ \\
\hline Haemothorax & $0.4 \%-0.6 \%{ }^{23}$ & $0 \%{ }^{21}$ \\
\hline \multirow[t]{2}{*}{ Arterial damage } & $6 \%{ }^{22}$ & $0.1-0.2 \%{ }^{24}$ \\
\hline & $6.3 \%-9.4 \%{ }^{23}$ & $0.1-0.6 \%{ }^{21}$ \\
\hline Nerve damage & $1.7 \%^{22}$ & \\
\hline \multirow[t]{2}{*}{ Thrombosis } & $1.9 \% 1.9-21.2 \%^{22} 23$ & $0.6-1.7 \%{ }^{24}$ \\
\hline & $41 \%$ (Cancerpatients) $^{22}$ & \\
\hline \multirow[t]{2}{*}{ Infection } & 5.3 per $1000 \mathrm{~cd}^{22}$ & $0.5-1.8 \%$ \\
\hline & $1.2-4.5$ per $1000 \mathrm{~cd}^{23}$ & $2.1-13.5$ per $1000 \mathrm{~cd}^{24}$ \\
\hline
\end{tabular}

One of the potential advantages during PICC-insertion is that serious and potentially lethal insertion related complications could be avoided. For this reason, the increased PICC popularity in the pre-US - guided era is reasonable. However, the 
introduction of new medical technology should always be backed by sufficient scientific evidence. Hence, the expansion of the PICC technique in patients with cancer could have occurred for reasons other than patient safety and catheter efficacy.

Post insertion x-ray controls have been routinely used following insertion of both PICC and PORT. Chest x-rays has typically been performed routinely to verify optimal tip-position and to rule out pneumothorax. By performing x-ray controls, the cost of insertion will increase, more time will be consumed (affecting both the patient and staff), and the patient will be exposed to ionising radiation. For both PICC and PORT there are safe alternatives which will save radiation, time and money, and $\mathrm{x}$-rays are required only when complications are suspected. ${ }^{11}$ The PICC tip-position is verified through non-invasive electro-magnetic devices. $^{25-29}$

While inserting PORTs, it is recommended to use of both US and fluoroscopy. ${ }^{7}$ ${ }^{11}$ Fluoroscopy will provide useful information both during guidewire positioning, dilation and catheter advancement. In addition to visualise the needle-vein relationship during puncture, US can be used to verify intravenous guidewire position and to rule out pneumothorax.

The US-technique used to detect pneumothorax offers better sensitivity and specificity when compared to an ordinary antero-lateral chest x-ray. ${ }^{30}$ In the light of the previously mentioned arguments, it is reasonable to abandon the routine use of chest x-rays following both PICC and PORT insertion (or in fact any central venous catheter). ${ }^{71131}$

Venous haemorrhage in the implantation area is usually self-limiting and usually a result of technical difficulties during insertion. ${ }^{32} 33$ Neurological complications following CVC insertion are very rare. They can occur through direct nerve tissue damage, arterial plaque embolisation, nerve compression from an expanding haematoma or through extravasation of chemotherapy near nerve structures. ${ }^{34-39}$ The incidence of air embolisation has been reported to between $0.1-0.5 \%{ }^{7}$ Air can enter the CVC-system and follow the direction of blood flow through the pulmonary circulation. In the presence of cardiac or intrapulmonary shunts, air 
emboli could enter the systemic circulation and subsequently cause end-organ ischemia (i.e. cerebral stroke). ${ }^{40} 41$ 


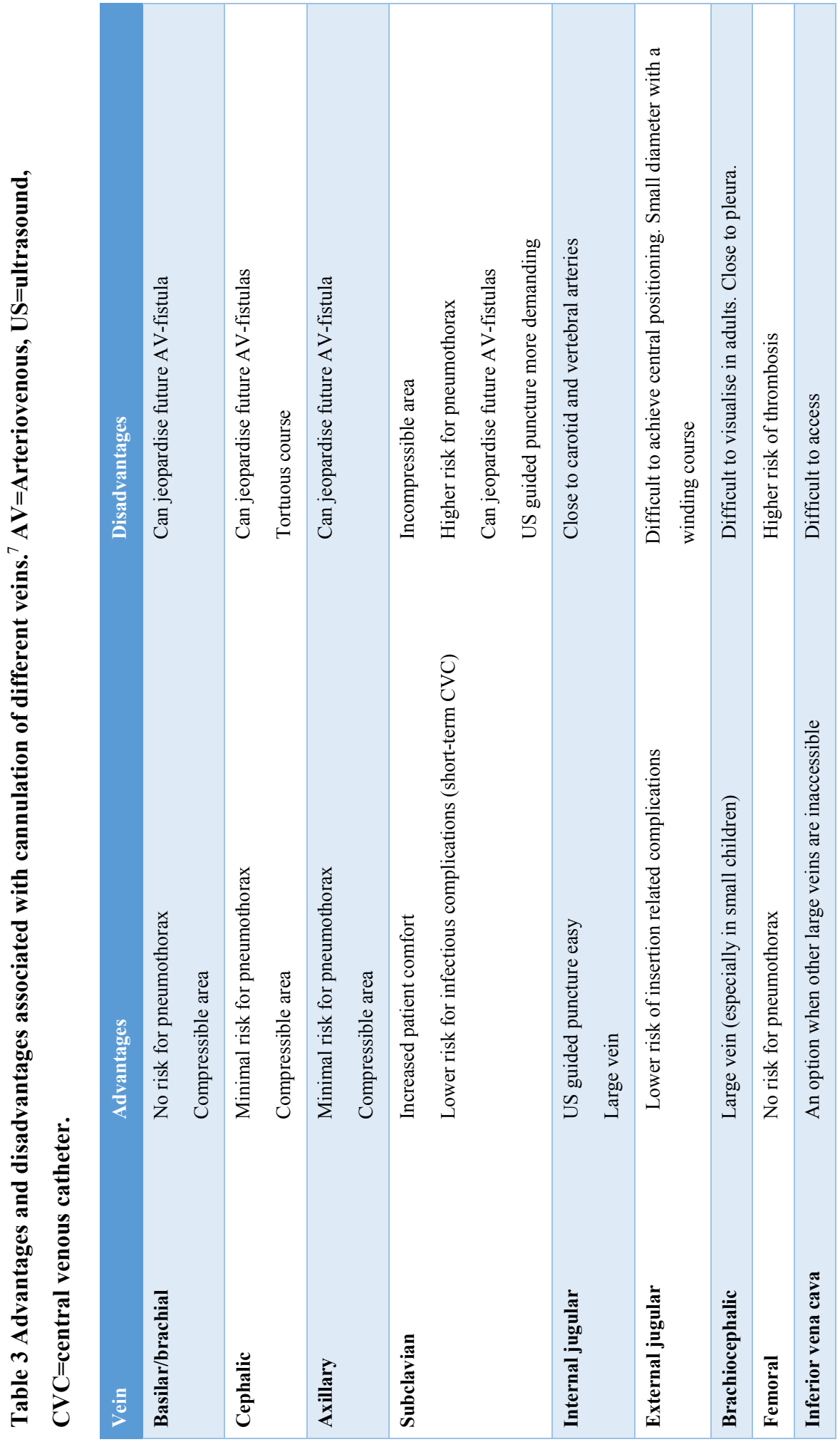




\section{Catheter care and maintenance during the dwell period}

Appropriate care and management are of key importance to keep CVC-related complications to a minimum. To facilitate this, national guidelines are readily available online and free of charge. "Vårdhandboken" (eng: The Handbook for Healthcare) is sponsored by the Swedish Association of Local Authorities and Regions (SKL) and contains several evidence-based up-to-date guidelines. The section on CVCs has several hundred thousand unique hits annually and can be found on www.vardhandboken.se .

In addition, the Swedish Association of Anaesthesia and Intensive Care, SFAI, has recently published an updated version of their guidelines where most aspects of CVC management are covered. ${ }^{7} \mathrm{CVC}$ handling must meet basic hygiene requirements at all times, and infusions and injections must be administered through thoroughly disinfected injection membranes. In hospital patients, dressings, injection membranes and 3-way valves should be changed every 3-5 days, and weekly for patients in the home-care setting. To avoid unnecessary catheter time, it is important that the indication for an indwelling CVC is assessed on a regular basis.

Flushing of the catheter must be performed each time the catheter is used using $0.9 \% \mathrm{NaCl}$ solution, but flushing of a resting catheter is unnecessary. ${ }^{711} 42$

It is imperative to keep track of CVC - related complications when documenting CVC insertion and removal, and this plays a key role in our efforts to increase patient safety.

\section{Pharmacological measures to prevent infection and occlusion.}

\section{The antimicrobial lock}

Prevention of intraluminal catheter colonisation and subsequent infection can be achieved by installation of an antimicrobial solution into the resting catheter lumen (an antimicrobial lock, AL). Localised infections such as exit-site, pocket- 
and tunnel-infections are not affected by an AL. The lock works on the principle that the solution dwells within the catheter lumen thereby preventing the growth of micro-organisms and preventing the development of a biofilm on the internal surface of the catheter. ${ }^{43}$

A meta-analysis of almost 23 studies covering 3000 haemodialysis and cancer patients demonstrated that the use of an AL reduces the number of catheter infections. ${ }^{44}$ A systematic review of 13 studies focusing on adult and paediatric cancer patients concluded that there is a paucity of well-conducted trials addressing the efficacy of prophylactic $\mathrm{AL}$ in adult cancer patients. ${ }^{45}$

Although many agents have been proposed, the optimal solution for a lock has yet to be determined. Antibiotic lock solutions, used alone or in combination, include vancomycin, cefotaxime, gentamycin, minocycline, cefazolin, ciprofloxacin, and linezolid. ${ }^{46}$ It is believed that antibiotic locks have the potential to increase antimicrobial resistance and it could even stimulate biofilm adherence to the internal surface of the catheter. ${ }^{47} 48$ In addition to antibiotics, there is an increasing interest in bactericidal locks. Of these, ethanol, chelators (sodium citrate and EDTA), and taurolidine are the substances most commonly used either alone, or in combination with the above-mentioned antibiotics.

A recently published RCT comparing ethanol AL with heparinised saline including 94 children with cancer, found no difference in central line-associated blood stream infection rates. This trial was stopped due to futility because catheter occlusion (requiring thrombolytic therapy) was more common in the treatment group. ${ }^{49}$

Table 4. Some typical antimicrobial lock agents.

\begin{tabular}{|ll|}
\hline Substance & Mechanism of action \\
\hline Vancomycin & Inhibits cell wall synthesis in gram positive bacteria \\
\hline Minocycline & Inhibits bacterial protein synthesis \\
\hline Ethanol & Denatures protein and dissolves lipids \\
\hline Taurolidine & Denatures cell wall and toxin \\
\hline EDTA (edetic acid) & Chelator \\
\hline Sodium Citrate & Chelator \\
\hline
\end{tabular}




\section{Antibiotic prophylaxis during insertion of ports.}

The routine use of systemic antibiotic prophylaxis during insertion of a long-term CVC is of no benefit and therefore not indicated. ${ }^{74350-52}$

In patients at high risk for infection (i.e. leukopenia and recurrent infections) prophylaxis should be considered.

\section{Measures to minimise catheter occlusion.}

On theoretical grounds, heparin has traditionally been installed in the resting catheter lumen to prevent occlusion. Occlusion can lead to treatment delay or even catheter exchange, and preventing occlusion is an important part of catheter maintenance and care. Heparin has serious side-effects (heparin-induced thrombocytopenia and haemorrhage) and recent studies have shown that normal saline is equally effective in preventing catheter occlusion. Therefore, installation of heparin is not recommended. ${ }^{720} 53-55$ 


\section{Management of complications during the dwell period.}

\section{Venous thrombo-embolic disease in cancer}

The prevalence of venous thromboembolic disease is increased in patients with cancer. ${ }^{56}$ Cancer is associated with a hypercoagulable state due to inflammation (release of cytokines), activation of the coagulation cascade, and cancer treatment itself. One in five patients with cancer will develop venous thromboembolism (VTE) before death, and it has been reported that $50 \%$ of cancer patients have a DVT at autopsy. In addition, VTE is associated with a 2- to 5-fold increased mortality rate in cancer patients. Generally speaking, there are several risk factors for VTE in cancer patients: type of tumour (pancreatic $>$ kidney $>$ ovaries > lung > gastric); age; history of DVT; metastatic disease; type of chemotherapy; and the presence of a central venous catheter. ${ }^{57-60}$

\section{Upper extremity deep vein thrombosis}

Primary upper extremity deep venous thrombosis (UEDVT) is an effort-induced condition known as Paget-Schroetter syndrome which is typically seen in young athletes. ${ }^{61}$ The pathophysiology of this syndrome involves compression of the neurovascular bundle where it exits the thoracic outlet on the affected individual's dominant arm and is by definition not associated with an intravascular catheter.

Secondary UEDVT, on the other hand, is caused by a catheter in the majority ( $>$ 90\%) of cases and the presence of a CVC causes a seven to fourteen-fold increase in the risk for UEDVT. ${ }^{62-64}$

Three factors (hypercoaguability, endothelial damage and reduced blood flow) known to cause venous thrombosis, are usually referred to as Virchow's triad. 
Vascular catheters and substances infused through them can cause damage to the vessel wall (endothelium) with subsequent inflammation. The presence of a catheter can also lead to reduced blood flow in the vessel. These factors together with a hypercoagulable state means that cancer patients with a CVC are exposed to a high risk for thrombosis.

Symptomatic CR-DVT rates of more than $30 \%$ have been reported in patients with cancer. ${ }^{14}$ The smaller the vein-to-catheter ratio is the more stagnant the flow will be. In addition, a small vein-to-catheter ratio could result in catheter induced endothelial trauma. For these reasons the catheter should not occupy more than $33-45 \%$ the vein lumen. ${ }^{65}{ }^{66}$ It is likely that the risk for CR-DVT increases the more distally the catheter is inserted (i.e. smaller veins) which puts cancer patients with a PICC at a particularly high risk for CR-DVT. Several other factors contribute to an increased risk for CR-DVT: catheter-related infection; catheter malposition (i.e. the tip is situated in a position other than the right atrium or distal superior vena cava); previous CR-DVT/VTE; high age; and immobilisation ${ }^{67}$ Furthermore, in patients with factor V Leiden (APC-resistance) or a prothrombin gene mutation, the risk of developing CR-DVT is nearly three-fold. ${ }^{68}$ Technically difficult CVC insertion is also associated with increased risk for CR-DVT. ${ }^{69}$ The internal jugular vein is believed to be the vein associated with the lowest risk for CR-DVT.

As mentioned above, the dimension of the catheter itself plays an important role in the development of CR-DVT. So a triple-lumen PICC increases the risk for symptomatic CR-DVT by a factor of twenty when compared to a single-lumen PICC. $^{70}$

In a recent very large retrospective register study on ports, predictors of CR-DVT included age $<65$ years, comorbidity, lung and gastro-intestinal cancers, metastatic disease, non-white race, and history of VTE. ${ }^{71}$ 
Similarly, a recent report VTE in patients with a PICC named several puncture attempts, male gender, fluoropyrimidine-containing chemotherapy and leucocytosis as risk factors. ${ }^{72}$

Although many patients with CR-DVT are asymptomatic, common presenting symptoms are localised swelling, pain and tenderness/erythema along the course of the affected vein. When there are signs of catheter insertion site infection, the possible presence of a concurrent CR-DVT should be assessed. Another important sign of CR-DVT is catheter malfunction since the catheter tip may be embedded in a DVT that subsequently obstructs flow through the catheter.

Since the relationship between PE and CR-DVT has not been completely clarified, it is reasonable to assess patients with a CVC who suffer PE for a CRDVT. ${ }^{14}$ In a recent retrospective study assessing UEDVT, $17 \%$ of patients with CR-DVT developed a superior vena cava syndrome and post-thrombotic syndrome. ${ }^{73}$ In this series only $54 \%$ of patients with UEDVT had a CVC in place.

The most commonly used diagnostic modality to detect UEDVT is duplex ultrasonography. Ultrasonography is rapid, non-invasive and without ionising radiation. Duplex ultrasonography (US) combines vein compression and colour doppler for the assessment of a suspected UEDVT. Despite the limitations of US in detecting UEDVT in the subclavian and more proximal veins due to clavicle shadowing, the specificity and sensitivity of the method are high. Contrastenhanced computed tomography or magnetic resonance phlebography is indicated if US is inadequate in detecting proximal thromboses.

By combining a clinical decision score, D-dimer levels and US, it is possible to safely and effectively rule out UEDVT. ${ }^{74}$ 
Table 5 Sensitivity and specificity of tests used to assess upper extremity deep vein thrombosis. ${ }^{75} \mathrm{US}=$ ultrasound.

\begin{tabular}{|lll|} 
& \multicolumn{1}{l}{ Sensitivity \% $(95 \%$ CI $)$} & Specificity \% $(95 \%$ CI) \\
\hline Compression US & $97(90-100)$ & $96(86-100)$ \\
\hline Doppler US & $84(72-97)$ & $94(86-100)$ \\
\hline Duplex US & $91(85-97)$ & $93(80-100)$ \\
\hline D-dimer & $100(78-100)$ & $14(4-29)$ \\
\hline
\end{tabular}

\section{Treatment of catheter-related deep venous thrombosis}

For the relief of acute symptoms and the prevention of embolisation, systemic anticoagulation is the cornerstone in the treatment of CR-DVT. A CR-DVT will embolise to the pulmonary circulation at a rate of $6 \%{ }^{76}$ Pulmonary embolisation is a life-threatening medical emergency. Several guidelines recommend that treatment with anticoagulants should be initiated in patients with CR-DVT in axillary and more proximal veins similarly to those with lower extremity DVT. ${ }^{57}$ $77-81$

In patients with cancer, this treatment typically involves parenteral anticoagulants such as LMWH for at least 3 months.

Treatment with LMWH as compared to vitamin K antagonists (VKA) has been shown to reduce the risk of VTE recurrence in patients with cancer and has been the drug of choice during the past decade. A new group of direct oral factor II or Xa-inhibitors (DOAC) could replace LMWH for VTE prophylaxis and treatment in the future. Although rivaroxaban has been suggested for the treatment of CRDVT in a prospective trial, there is currently not enough evidence in support of DOACs. $^{82}$

Raskob et al. recently published results from 1046 patients indicating that treatment with edoxaban (DOAC) is non-inferior to dalteparin (LMWH) for the treatment of cancer-related VTE (HR $0.97 ; 95 \%$ CI 0.70 to 1.36 ). ${ }^{83}$ 


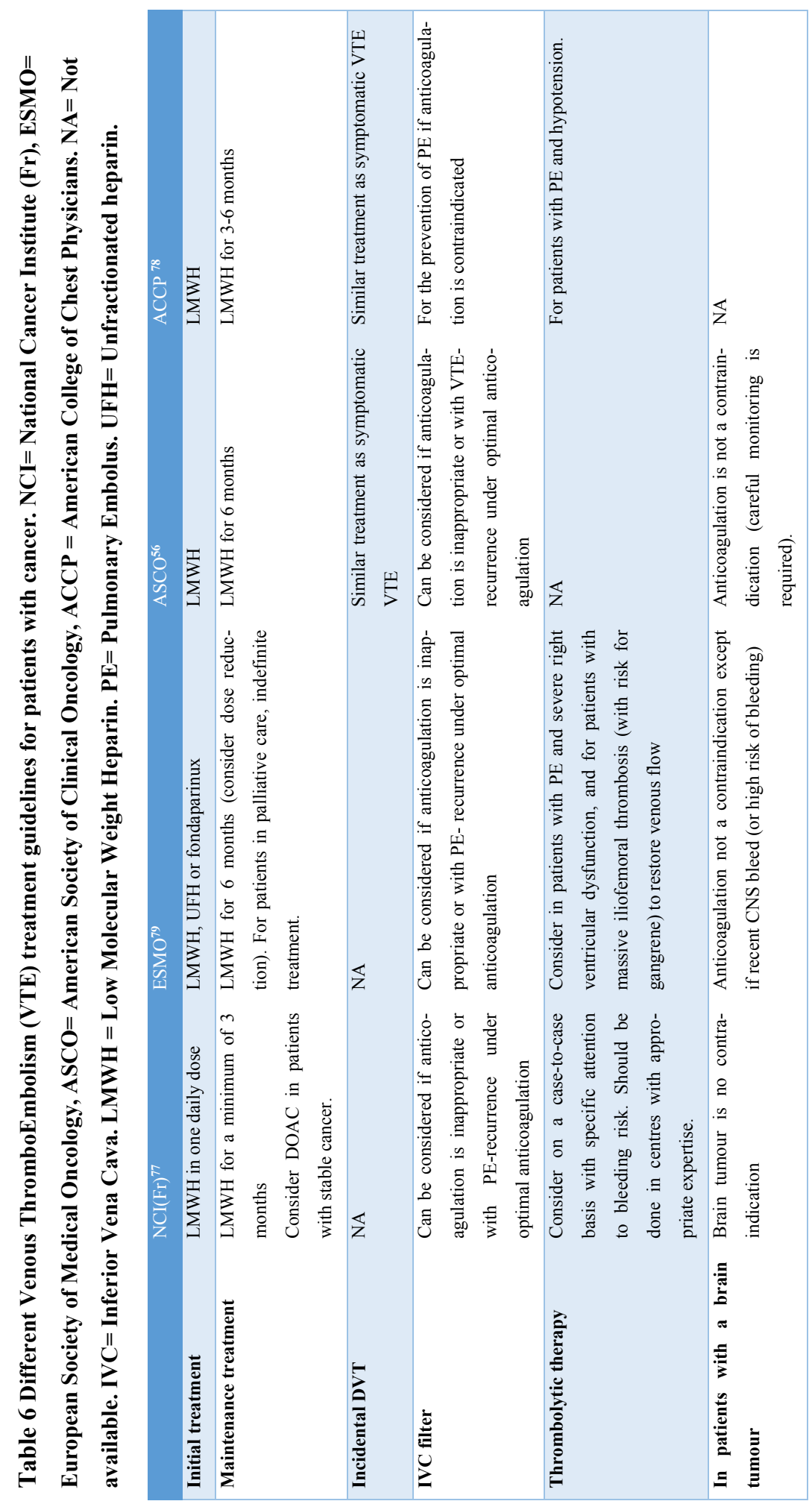


The prevalence of asymptomatic CR-DVT in the presence of a CVC has been reported to be between 2 and $66 \%{ }^{84}$ The treatment of asymptomatic CR-DVTs is more controversial than symptomatic cases. Upper extremity deep venous thromboses embolise in up to eight per cent of cases and may lead to stenosis which is why asymptomatic CR-DVTs should be treated. ${ }^{5678}$ In contrast, superficial catheter-related thromboses are usually treated by discontinuing intravenous infusion and removing the catheter. ${ }^{85}$

In patients with a CR-DVT that need a catheter, given that the function and position of the catheter are acceptable, removal is not required. ${ }^{85}$ Leaving a catheter in situ enable continued cancer therapy and leaves device replacement in excess. This strategy has been shown to be both feasible and safe. In cases where the catheter must be removed, anticoagulant treatment is recommended some days prior to removal. ${ }^{85}$

Directed catheter-guided fibrinolysis should be considered in patients with severe symptoms or without improvement with therapeutic anticoagulation.

\section{Prevention of catheter-related deep venous thrombosis (phar- macological prophylaxis and risk stratification tools)}

Pharmacological VTE prophylaxis is a common medical intervention in hospitalised patients. As stated earlier, cancer patients have an increased risk for VTE compared to the general population, and are therefore often prescribed VTE prophylaxis. Furthermore, the introduction of a CVC increases the risk for VTE putting the cancer patient at particular risk for this complication.

When deciding on VTE prophylaxis in a patient with cancer, the clinician must weigh the potential benefit of preventing VTE against the potential hazards of haemorrhage resulting from anticoagulation.

One of three forms of VTE prophylaxis is usually employed in cancer patients with a CVC:

1. Parenteral (subcutaneous) anticoagulants such as LMWH or fondaparinux;

2. Low dose, oral vitamin-K antagonist; 
3. Direct oral anticoagulants (DOAC) previously called Novel oral anticoagulants (NOAC).

Several studies have evaluated the efficacy of VTE prophylaxis in patients with cancer, and the Cochrane Library recently published a systematic review discussing this topic. ${ }^{86} \mathrm{~A}$ total of 3420 patients from thirteen RCTs were included in the analysis using all-cause mortality as primary outcome. Secondary outcomes included CR-DVT, PE, bleeding, CRI, health-related quality-of-life, premature CVC removal and heparin-induced thrombocytopenia.

The authors found moderate-certainty evidence that LMWH reduces CR-DVT compared to no LMWH. The effect on mortality was inconclusive. However, the majority of these studies were old (reporting large effects sizes, with event rates higher than those in current medical practice). Furthermore, PICCs were not included.

Lately, Carrier et al reported significantly lower rates of VTE in ambulatory cancer patients receiving apixaban (i.e. DOAC) vs. placebo at the start of chemotherapy (hazard ratio $0.41 ; 95 \% \mathrm{CI} 0.26$ to $0.65 ; \mathrm{P}<0.001$ ). However, apixaban was associated with a significantly higher rate of major bleeding (hazard ratio $2.00 ; 95 \% \mathrm{CI}, 1.01$ to $3.95 ; \mathrm{P}=0.046) .{ }^{87}$

In contrast, Khorana et al. reported that rivaroxaban (i.e. DOAC) vs. placebo did not result in a significantly lower incidence of VTE during the 180-day follow-up period (hazard ratio $0.66 ; 95 \% \mathrm{CI}, 0.40$ to 1.09 ). ${ }^{88}$ The rate of major bleeding was not significant (hazard ratio 1.96 ; $95 \%$ CI 0.59 to 6.49 ). This trial randomised 841 cancer patients with a high risk for VTE.

Orally administered DOAC, of course, is more comfortable than subcutaneously injected LMWH.

To identify those patients eligible for CVCs but with a high risk for developing CR-DVT, certain risk stratification protocols have been developed. Examples are 
the Caprini-, Padua-, Khorana- and the Michigan Risk Scores that are used for this purpose ${ }^{86-89}$ The Caprini score is a VTE risk assessment tool validated for surgical patients and may therefore not be applicable to non-surgical oncology patients. Furthermore, the score includes a great number $(>30)$ of potential risk factors and requires direct patient/physician contact to obtain a family history. The Padua score comprises 11 variables and is useful when assessing hospitalised patients not scheduled for surgery. ${ }^{89}$ For patients eligible for a PICC, the MRS includes five risk factors: history of DVT; multilumen PICC; active cancer; presence of another CVC when the PICC was placed; and white blood cell count greater than 12,000. Patients are divided between four risk groups depending on the score. The MRS may not be applicable to patients eligible for centrally inserted CVCs as it is designed for patients with a PICC. 
Table 7 The Caprini score. Variables with scores and interpretation. BMI= Body mass index. VTE = venous thromboembolism.

\begin{tabular}{|c|c|c|c|c|c|}
\hline \multicolumn{3}{|c|}{ Caprini score predictor variables } & Score & Caprini score predictor variables & Score \\
\hline \multicolumn{3}{|c|}{ Age $41-60$ years } & 1 & Cancer & 2 \\
\hline \multicolumn{3}{|c|}{$\mathrm{BMI}>25 \mathrm{Kg} / \mathrm{m} 2$} & 1 & Plaster cast & 2 \\
\hline \multicolumn{3}{|c|}{ Minor surgery } & 1 & Bed bound for more than 72 hours & 2 \\
\hline \multicolumn{3}{|c|}{ Oedema in the lower extremities } & 1 & Central venous access & 2 \\
\hline \multicolumn{3}{|c|}{ Varicose veins } & 1 & Age $\geq 75$ years & 3 \\
\hline \multicolumn{3}{|c|}{ Pregnancy } & 1 & Prior episodes of VTE & 3 \\
\hline \multicolumn{3}{|c|}{ Post-partum } & 1 & Positive family history for VTE & 3 \\
\hline \multicolumn{3}{|c|}{ Oral contraceptive } & 1 & Prothrombin 20210 A mutation & 3 \\
\hline \multicolumn{3}{|c|}{ Hormonal therapy } & 1 & Factor V Leiden & 3 \\
\hline \multicolumn{3}{|c|}{ Unexplained or recurrent abortion } & 1 & Lupus anticoagulants & 3 \\
\hline \multicolumn{3}{|c|}{ Sepsis (in the previous month) } & 1 & Anticardiolipin antibodies & 3 \\
\hline \multicolumn{3}{|c|}{ Serious lung disease such as pneumonia } & 1 & High homocysteine level in the blood & 3 \\
\hline \multicolumn{3}{|c|}{ Abnormal pulmonary function test } & 1 & Heparin induced thrombocytopenia & 3 \\
\hline \multicolumn{3}{|c|}{ Acute myocardial infarction } & 1 & Stroke (in the previous month) & 3 \\
\hline \multicolumn{3}{|c|}{ Congestive heart failure (currently) } & 1 & Congenital or acquired thrombophilia & 5 \\
\hline \multicolumn{3}{|l|}{ Bed rest } & 1 & Fracture of the hip, pelvis, or leg & 5 \\
\hline \multicolumn{3}{|c|}{ Inflammatory bowel disease } & 1 & Elective arthroplasty & 5 \\
\hline \multicolumn{3}{|c|}{ Age: $61-74$ years } & 2 & Acute spinal cord injury & 5 \\
\hline \multicolumn{3}{|c|}{ Arthroscopic surgery } & 2 & Fracture of the hip, pelvis, or leg & 5 \\
\hline \multicolumn{3}{|c|}{ Surgery lasting more than 45 minutes } & 2 & Elective arthroplasty & 5 \\
\hline & & & & $\begin{array}{l}\text { Acute spinal cord injury (in the previous } \\
\text { month) }\end{array}$ & 5 \\
\hline $\begin{array}{l}\text { Caprini } \\
\text { Score }\end{array}$ & Risk category & Risk percent $^{90}$ & \multirow{2}{*}{\multicolumn{2}{|c|}{$\begin{array}{l}\text { Recommended prophylaxis }^{91} \\
\text { Early frequent ambulation only, OR at discretion of surgical team }\end{array}$}} & $\begin{array}{l}\text { Chemoprophy- } \\
\text { laxis }\end{array}$ \\
\hline 0 & Lowest & Minimal & & & $\begin{array}{l}\text { During hospital- } \\
\text { isation }\end{array}$ \\
\hline $1-2$ & Low & Minimal & \multicolumn{2}{|c|}{$\begin{array}{l}\text { Pneumatic compression devices } \pm \text { graduated compression stock- } \\
\text { ings }\end{array}$} & $\begin{array}{l}\text { During hospital- } \\
\text { isation }\end{array}$ \\
\hline $3-4$ & Moderate & $0.7 \%$ & \multicolumn{2}{|c|}{$\begin{array}{l}\text { Pneumatic compression devices } \pm \text { graduated compression stock- } \\
\text { ings }\end{array}$} & $\begin{array}{l}\text { During hospital- } \\
\text { isation }\end{array}$ \\
\hline $5-6$ & High & $1.8 \%$ & \multicolumn{2}{|c|}{$\begin{array}{l}\text { Pneumatic compression devices AND low molecular weight } \\
\text { heparin }\end{array}$} & $7-10$ days total \\
\hline $7-8$ & High & $4.0 \%$ & \multicolumn{2}{|c|}{$\begin{array}{l}\text { Pneumatic compression devices AND low molecular weight } \\
\text { heparin }\end{array}$} & $7-10$ days total \\
\hline$\geq 9$ & Highest & $10.7 \%$ & \multicolumn{2}{|c|}{$\begin{array}{l}\text { Pneumatic compression devices AND low molecular weight } \\
\text { heparin }\end{array}$} & 30 days total \\
\hline
\end{tabular}


Table 8 The Padua score. Variables with scores and interpretation. VTE= venous thromboembolism.

\begin{tabular}{|l|c|}
\hline Padua score predictor variables & Score per variable \\
\hline Prior episode of VTE & $\mathbf{3}$ \\
\hline Thrombophilia & $\mathbf{3}$ \\
\hline Decreased mobility & $\mathbf{3}$ \\
\hline Active malignancy & $\mathbf{2}$ \\
\hline Previous trauma or surgery within the last month & $\mathbf{1}$ \\
\hline Age $\geq 70$ years & $\mathbf{1}$ \\
\hline Heart and/or respiratory failure & $\mathbf{1}$ \\
\hline Ischaemic stroke or acute myocardial infarction & $\mathbf{1}$ \\
\hline Acute rheumatologic disorder and/or acute infection & $\mathbf{1}$ \\
\hline Obesity & $\mathbf{1}$ \\
\hline Hormonal therapy & \\
\hline Padua score & Action required \\
\hline$<\mathbf{4}$ & VTE prophylaxis should be considered \\
\hline$\geq \mathbf{4}$ & VTE prophylaxis is recommended \\
\hline
\end{tabular}

Table 9 The Khorana venous thromboembolism risk score

\begin{tabular}{|c|c|c|}
\hline \multicolumn{2}{|c|}{ Khorana risk score } & Points \\
\hline \multicolumn{3}{|l|}{ Cancer type: } \\
\hline \multicolumn{2}{|c|}{ Stomach or pancreas } & 2 \\
\hline \multicolumn{2}{|c|}{ Lung, lymphoma, gynaecologic, bladder or testicular } & 1 \\
\hline \multicolumn{2}{|l|}{ Other } & 0 \\
\hline \multicolumn{2}{|c|}{ Pre-chemotherapy thrombocytosis $\left(\geq 350 \times 10^{9} / 1\right)$} & 1 \\
\hline \multicolumn{2}{|c|}{ Haemoglobin level $<10 \mathrm{~g} / \mathrm{l}$} & 1 \\
\hline \multicolumn{2}{|c|}{ Pre- chemotherapy leukocyte count $>11 \times 10^{9} / I$} & 1 \\
\hline \multicolumn{2}{|c|}{$\mathrm{BMI} \geq 35 \mathrm{~kg} / \mathrm{m}^{2}$} & 1 \\
\hline Risk group & Score & 2.5 month rate of VTE \\
\hline Low & 0 & $0.3-0.8 \%$ \\
\hline Intermediate & $1-2$ & $1.8-2.0 \%$ \\
\hline High & $\geq 3$ & $6.7-7.1 \%$ \\
\hline
\end{tabular}


Table 10. The Michigan Risk Score for predicting PICC associated thrombosis. $P I C C=$ peripherally inserted central catheter, $C V C=$ central venous catheter, WBC $=$ white blood cell. VTE $=$ Venous thrombo embolism

\begin{tabular}{|c|c|c|}
\hline \multicolumn{2}{|l|}{ Predictor Variable } & \multirow{2}{*}{$\begin{array}{l}\text { Points } \\
+1\end{array}$} \\
\hline Presence of another CVC when PICC is placed & Yes & \\
\hline WBC Count at PICC Insertion $\left(>12.0 \times 10^{9}\right)$ & Yes & +1 \\
\hline \multirow[t]{3}{*}{ Number of PICC lumens } & 1 & 0 \\
\hline & 2 & +1 \\
\hline & $3-4$ & +2 \\
\hline \multirow[t]{4}{*}{ History of VTE } & Never & 0 \\
\hline & $>30$ days prior & +2 \\
\hline & Within 30 days & +3 \\
\hline & No & 0 \\
\hline Active cancer (on chemotherapy) & Yes & +3 \\
\hline Points achieved & Risk class & $\begin{array}{l}\text { Probability } \\
\text { of VTE }\end{array}$ \\
\hline $\mathbf{0}$ & I & $0.9 \%$ \\
\hline 1-2 & II & $1.6 \%$ \\
\hline 3-4 & III & $2.7 \%$ \\
\hline$\geq 5$ & IV & $4.7 \%$ \\
\hline
\end{tabular}

\section{Catheter-related infection}

Infection related to intravascular devices remains a major problem. ${ }^{23} 43$ 92-95 A CRI can pose a threat to patient wellbeing and life itself. Moreover, treatment cycles are interrupted, the need for hospital care increases and costs increase. The various types of intravascular devices are associated with different risks for infectious complications. ${ }^{96} 97$ These differences could be explained by differences in catheter characteristics, but also in which group of patients the catheter is used (e.g. subcutaneous port in a cancer patient vs. short-term haemodialysis catheter in a critical care patient). Systematic reviews suggest that there are no differences in the rate of CRBSI between PICCs and CICCs. ${ }^{13}$ 1597 
Aseptic insertion and strict adherence to hygiene routines during catheter use remains the cornerstone of catheter-related infection prevention. Despite this, infection is a common cause of premature removal of both PICCs and PORTs. ${ }^{92-94}$ 98-101

As depicted in Figure 7, there are four potential mechanisms causing CRI:

1. The dominant mechanism is the migration of skin organisms (i.e. Coagulasenegative staphylococci (CoNS) and S. aureus) along the external surface of the catheter/device;

2. Contaminated injection-hub causing colonisation within the catheter with subsequent spread to the bloodstream.

3. Micro-organisms colonising the external surface of the catheter through haematogenous spread from a distant infection (e.g. bacteria from an abdominal abscess);

4. Colonisation of the catheter due to contaminated infusates.

Figure 7 Mechanisms of CVC infection. ${ }^{102} \mathrm{HCW}=$ health-care worker. ( Reprinted with permission from Springer-Verlag.)

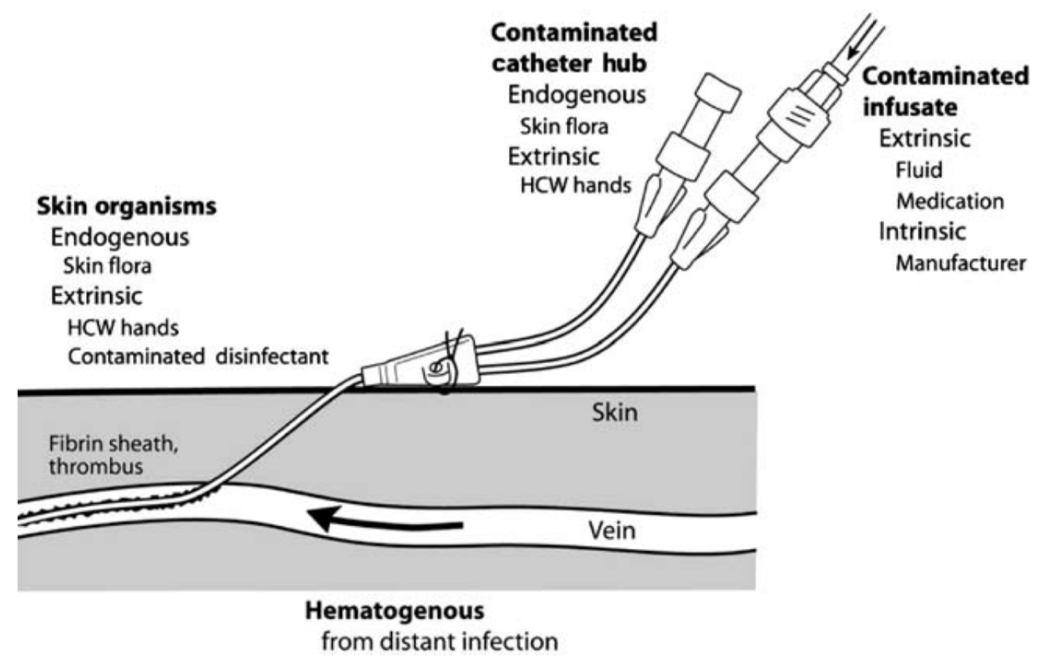

Risk factors for CRI include: coexisting thrombosis; patients on total parenteral nutrition; chronic steroid use; neutropenia; frequent access; insufficient care; metastatic disease; and haematological cancer. ${ }^{92-94}$ 98-101

When assessing potential CRIs there are two important distinctions the clinician must be aware of. On the one hand the potential infection could be clinically obvious (i.e. 
exit-site and localised pocket infections show signs of inflammation or pus). On the other, the only symptom might be fever or non-specific signs of systemic infection (i.e. due to an infected catheter tip). Internationally, systemic infection dominates and some authors state that local infection is present in only $3 \%$ of device-related infections. ${ }^{43}$ Patients with CRBSI usually present without signs of local infection. Diagnostic examination aims at verifying the diagnosis and identifying the micro-organism responsible for the suspected infection. The workup normally consists of paired blood cultures one drawn from (each of) the catheter hubs, and one culture from a peripheral vessel. In addition, local swab cultures from the exit-site or port-pocket are recommended. If the catheter is removed, a positive culture of the catheter tip is required to fulfil the diagnostic criteria of CRBSI. ${ }^{103}$ In contrast, if the catheter is left in situ (i.e. during a catheter salvage attempt), the diagnosis CRBSI can be made based on paired blood cultures only.

To prove that the catheter is the source of infection it is necessary to (Table 11):

- $\quad$ see higher colony counts ( $\geq 3$ times) in quantitative analysis in the blood from the catheter compared to that of peripheral blood, or

- shorter time ( $\geq 2$ hours difference) to positivity for blood drawn through the catheter compared to that of the peripherally drawn blood. The latter method is usually referred to as "DTP" (Differential Time to Positivity). ${ }^{103}$

The blood culture method has several limitations.

- Micro-organisms can be released intermittently to the bloodstream.

- The culture results can be influenced by antimicrobial treatment, culture technique and transportation time. ${ }^{104} 105$

- There are limited data on cut-off limits for different microorganisms regarding analyses of time to positivity or CFU per ml.

- Micro-organisms found on the tip and blood cultures are regarded as indistinguishable if phenotype and antibiograms are the same. This may not be correct since different genotypes of the same phenotype could have the same antibiogram. 
Figure 8. The diagnosis of catheter-related blood stream infection (CRBSI) can be made using different methods. DTP $=$ differential time to positivity, CFU $=$ colony forming unit.

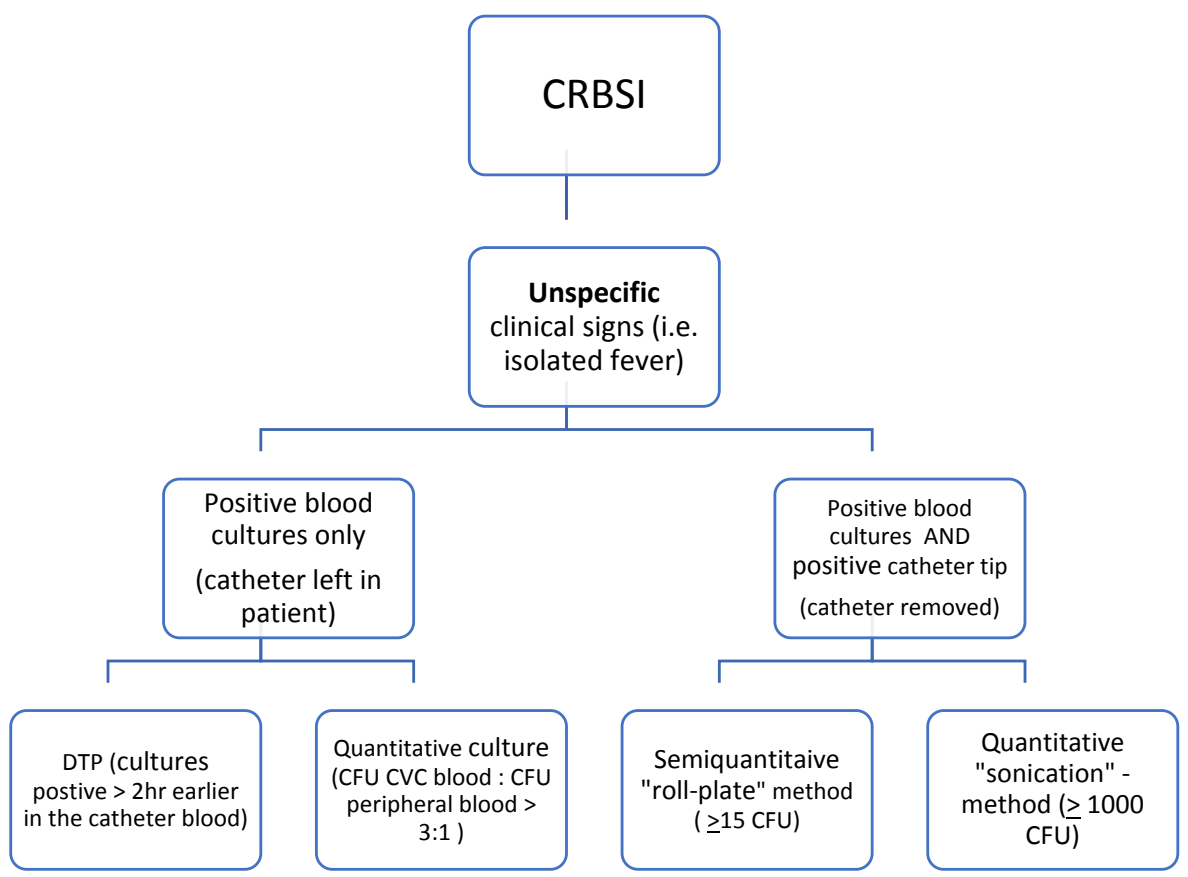



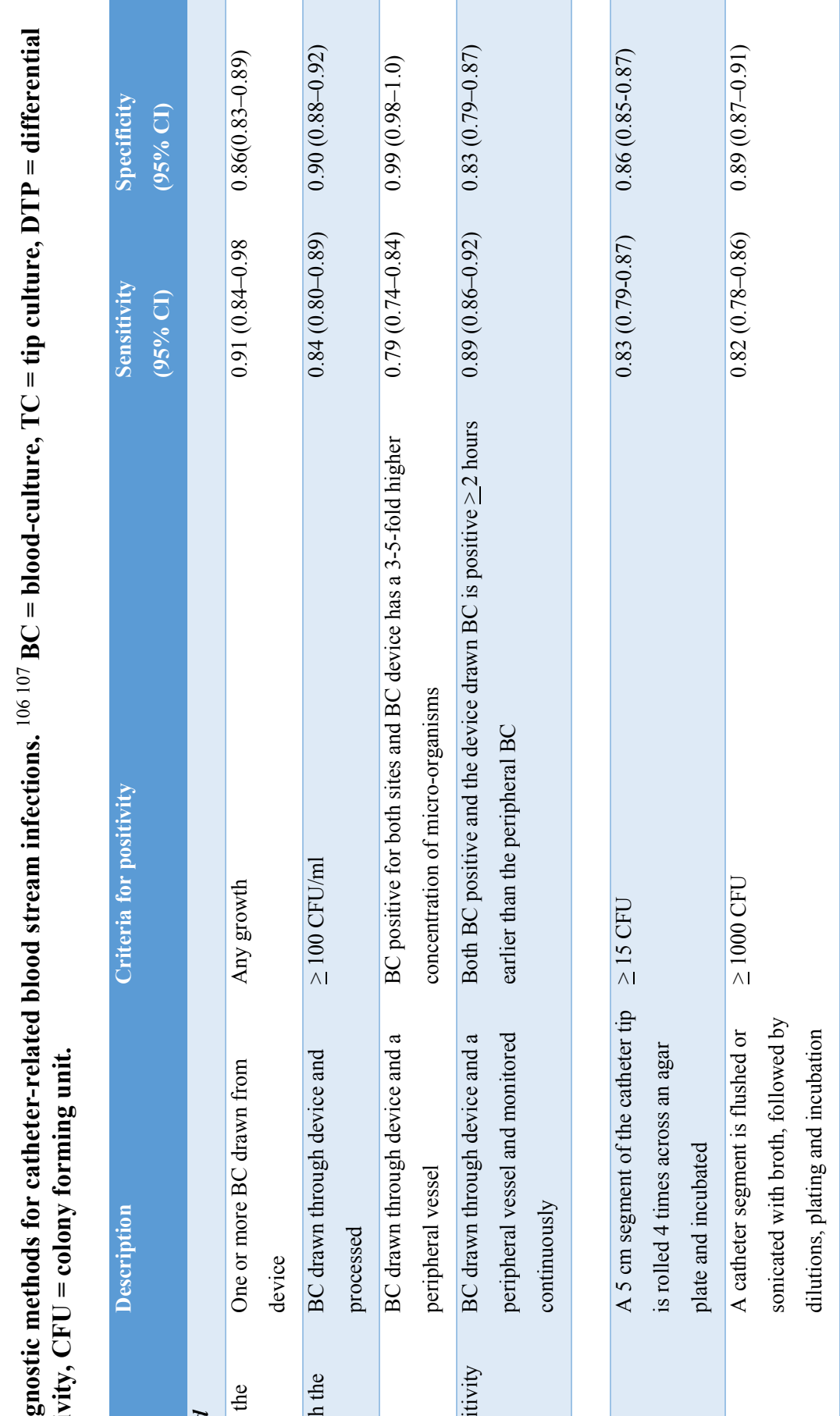

$\stackrel{8}{\Xi}$

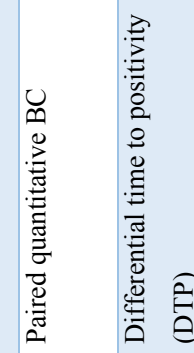



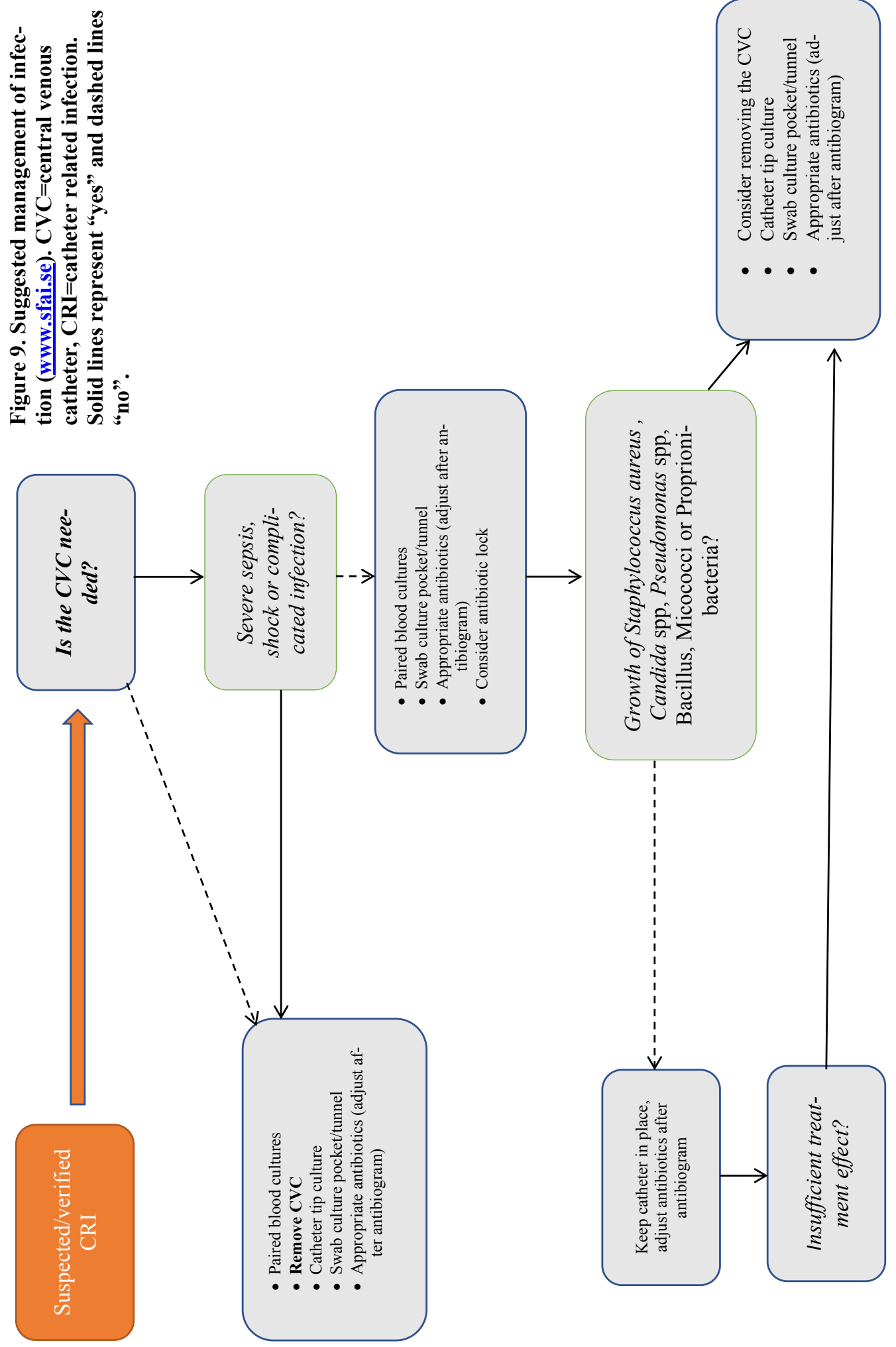


\section{Treatment}

Whenever the clinician suspects that the catheter is the source of a bloodstream infection, the catheter/device should be removed promptly in the presence of severe sepsis, septic shock, endocarditis, substantial local infection or metastatic infection. The device should also be removed if there is an infected CR-DVT or if bacteraemia persists after 3 days of appropriate antibiotic therapy. ${ }^{43} 103108$

Empiric antibiotic therapy is started after the appropriate cultures have been secured. Gram-positive infection is usually the culprit, but in severely compromised patients (with sepsis, short-bowel syndrome or leukopenia) antibiotics with activity against gram-negatives and fungi must be considered. ${ }^{20} 43$ The antibiotic treatment should be adjusted according to resistance pattern when it becomes available.

In the absence of the conditions listed above, a decision whether to remove or retain the device must be made. Catheters without proper indication should be removed.

Whenever an approach including the retention of an infected catheter is chosen, a catheter salvage attempt should be made. The salvage attempt consists of two interventions: first, the administration of systemic antibiotics in order to eradicate any bacteria from the bloodstream and catheter/device external surface; and second, the installation of an antimicrobial substance within the catheter lumen (ie. an "antimicrobial lock"). It is reasonable to use the catheter for the administration of antibiotics.

This conservative (catheter retention) treatment of catheter-related infection is associated with high (>80\%) cure rates avoiding unnecessary catheter removal. ${ }^{43} 109$ However, some micro-organisms (i.e. S.aureus and Candida spp) have lower antibiotic lock success rates $(<50 \%)$ which should prompt device removal under most circumstances. $^{43} 109$

In exceptional cases where the infected device is irreplaceable, salvage therapy could be warranted despite evidence of S.aureus or Candida spp catheter infection. ${ }^{110-112}$ All cases of salvage attempts require a close follow-up protocol.

Totally implanted PORTs pose a particular challenge as regards suspected local infection. There are many reasons as to why the skin surrounding the reservoir and tunnel could exhibit signs mimicking an infection (i.e. chafing, allergic reactions and non- 
infectious skin conditions). It is unfortunate to have to remove a PORT due to a suspected local infection without prior proper diagnostic work-up.

It is crucial to understand that the key to success in reduction of catheter-related infection is prevention. The risk for infection can be based on several determinants: the anatomical insertion site; type of catheter; appropriate catheter removal; and most importantly - adherence to basic hygiene principles during insertion, care and maintenance of the catheter. ${ }^{7}$

In cancer patients receiving chemotherapy over long periods of time, only a few access devices (PICC, PORT and tunnelled CVC) are relevant. This makes comparison of data from a wide range of catheter types more commonly seen in other settings (i.e. intensive care and haemodialysis), challenging.

The use of chlorhexidine containing solutions for skin disinfection has been shown to reduce the incidence of CRBSI when compared with pivodine-iodine or alcohol alone.

${ }^{113}$ However, reports have recently been published of bacterial chlorhexidine resistance which must be taken into consideration in the future. ${ }^{114}$

During catheter implantation, maximum sterile precautions (proper hand disinfection, sterile gloves, surgical gown, mask, hat and a large sterile surgical drape) must be taken. ${ }^{7112043115}$

\section{Occlusive and mechanical complications}

Failure to aspirate blood or infuse fluids through the CVC is a common sign of catheter occlusion. The underlying cause can lie within or without the catheter itself. There may be clotting or accumulation of infusates (lipids) within the catheter lumen, both typically caused by insufficient flushing of the catheter. Thrombotic occlusions can usually be resolved through installation of a fibrinolytic agent. ${ }^{116}$ Occlusions due to accumulation of lipids can appropriately be managed by intraluminal installation of a solvent (ethanol for lipids, hydrochloric acid for calcium phosphate). ${ }^{117} 118$

For catheters inserted via the subclavian vein it is possible for the catheter to be "pinched-off" between the clavicle and the first rib. The "pinched-off" syndrome is reported to occur in $0.1-2.1 \%$ of subclavian catheters. ${ }^{119}$ In long-term subclavian CVCs, "pinched-off" syndrome can be easily mistaken for an intraluminal catheter occlusion and the syndrome is worth bearing in mind when treatment options for catheter occlu- 
sion have failed. ${ }^{120}$ "Pinched-off" syndrome is diagnosed using contrast-enhanced $\mathrm{x}$ rays and it should be noted that the pinched catheter is prone to fracture and subsequent embolisation.

Failure to aspirate blood can also be present if the catheter is fractured, or if the PORT reservoir is disconnected from the catheter. Catheter fracture and disconnection can occur regardless of the vein catheterised.

Pain (and possibly swelling) during injection can also be the result of catheter fracture. The same symptomatology can be seen when a retrograde infusion between the catheter exterior and a fibrin sheet occurs. Both catheter fracture and retrograde infusion are diagnosed with contrast-enhanced radiology.

\section{Wound dehiscence}

This complication can be related to technical misfortune during insertion or secondary to an impaired wound healing process. Impaired wound healing could be due to immunocompromise from cancer, malnutrition or to the chemotherapy itself. Recent studies suggest that the monoclonal antibody bevacizumab (an angiogenesis inhibitor) could be a risk factor for developing wound dehiscence, particularly if implantation occurred within 2 weeks prior to treatment with bevacizumab. ${ }^{121} 122$

\section{Extravasation of infusates}

Leakage of chemotherapeutic agents into tissues surrounding the access device can cause severe necrosis and ulceration. The rate of local extravasation is reported to be $0.1 \%$ to $6 \% .^{123} 124$ Dislodgement or rupture of the PORT septum, catheter fracture or disconnection and retrograde infusion because of a fibrin sleeve can all result in local extravasation. Extravasation of chemotherapeutic agents can cause horrific injuries. It is important to bear in mind that an extravasation injury can mimic symptoms of local infection (pain, swelling, redness). It is imperative to always assess catheter integrity and function (i.e. through aspiration of blood) before administering vesicants/irritants in order to prevent extravasation injuries (see Table 12).

Management of extravasation injury can be complex and there are a few general considerations to be taken as well as several specific actions against the chemotherapeutic agent. First, recognition and termination of infusion is of key importance. Whenever 
possible, attempts to aspirate the infusate should be made. There are a number of chemotherapy-specific antidotes available (see Table 13).

Table 12 Classification of chemotherapy agents according to their ability to cause local damage after extravasation. ${ }^{125} \mathrm{DNA}=$ deoxyribonucleic acid

\begin{tabular}{|c|c|c|}
\hline Vesicants & Irritants & Non-vesicants \\
\hline DNA-binding compounds & Alkylating agents & Aresenic trioxide \\
\hline Alkylating agents & Carmustine & Asparaginase \\
\hline Mechloretamine & Ifosfamide & Bleomycin \\
\hline Bendamustine & Streptozocin & Bortezomib \\
\hline Anthracyclines & Dacarbazine & Cladribine \\
\hline Doxorubicin & Melphalan & Cytarabine \\
\hline Daunorubicin & Anthracyclines (other): & Etoposide phosphate \\
\hline Epirubicin & Liposomal doxorubicin & Gemcitabine \\
\hline Idarubicin & Liposomal Daunorubicin & Fludarabine \\
\hline Others (antibiotics) & Mitoxantrone & Interferons \\
\hline Dactinomycin & Topoisomerase II inhibitors & Interleukin-2 \\
\hline Mitomycin C & Etoposide & Methotrexate \\
\hline Mitoxantrone & Teniposide & Monoclonal antibodies \\
\hline Non-DNA-binding compounds & Antimetabolites & Pemetrexed \\
\hline Vinka alkaloids & Fluorouracil & Raltitrexed \\
\hline Vincristine & Platin salts & Temsirolimus \\
\hline Vinblastine & Carboplatin & Thiothepa \\
\hline Vindesine & Cisplatin & Cyclophosphamide \\
\hline Vinorelbine & Oxaliplatin & \\
\hline Taxanes & Topoisomerase I inhibitors & \\
\hline Docetaxel & Irinotecan & \\
\hline Paclitaxel & Topotecan & \\
\hline Others & Others & \\
\hline Trabectedin & Ixabepilone & \\
\hline
\end{tabular}


Table 13 Chemotherapy-specific antidotes. DMSO = Dimethyl sulfoxide (a topically applied solvent with free-radical scavenging properties. ${ }^{125}$

\begin{tabular}{|c|c|c|}
\hline Extravasated drug & Suggested antidote & $\begin{array}{l}\text { Level of } \\
\text { evidence }\end{array}$ \\
\hline Anthracyclines & $\begin{array}{l}\text { Dexrazoxane i.v. Start as soon as possible (no later than } 6 \mathrm{~h} \text { ) at a } \\
1000 \mathrm{mg} / \mathrm{m}^{2} \text { dose on day } 1 \text { and day } 2 \text { and at } 500 \mathrm{mg} / \mathrm{m}^{2} \text { on day } 3 \text {. }\end{array}$ & III-B \\
\hline Anthracyclines & $\begin{array}{l}\text { Topical DMSO }(99 \%) \text {. Start as soon as possible (preferably within } \\
10 \mathrm{~min}) . \text { It should be applied every } 8 \mathrm{~h} \text { for } 7 \text { days. }\end{array}$ & IV-B \\
\hline Mytomicin C & $\begin{array}{l}\text { Topical DMSO }(99 \%) \text {. Start as soon as possible (preferably within } \\
10 \mathrm{~min}) \text {. It should be applied every } 8 \mathrm{~h} \text { for } 7 \text { days. }\end{array}$ & IV-B \\
\hline Mechlorethamine & $\begin{array}{l}\text { Sodium thiosulfate } 0.17 \mathrm{M} \text { as a subcutaneous injection. Start im- } \\
\text { mediately. Subcutaneous injection of } 2 \mathrm{ml} \text { of solution made from } \\
4 \mathrm{ml} \text { sodium thiosulfate }+6 \mathrm{ml} \text { sterile water. }\end{array}$ & $\mathrm{V}-\mathrm{C}$ \\
\hline Vinka alkaloids & $\begin{array}{l}\text { Hyaluronidase as a subcutaneous injection. Administer 150-900 } \\
\text { IU around the area of extravasation. }\end{array}$ & V-C \\
\hline Taxanes & $\begin{array}{l}\text { Hyaluronidase as a subcutaneous injection. Administer 150-900 } \\
\text { IU around the area of extravasation. }\end{array}$ & $\mathrm{V}-\mathrm{C}$ \\
\hline
\end{tabular}

\section{Patient perception}

How the patient perceives their vascular access device is of great interest and importance to the clinician. In order to best inform a patient eligible for chemotherapy through a central line, we rely on information from well-conducted, relevant clinical trials. However, there is little evidence from studies assessing quality-of-life during chemotherapy, especially ones with special attention paid to the means of access,. A systematic review by Robinson et al regarding patients with breast cancer, was published in $2018 .{ }^{15}$ This review identified three papers using questionnaires to examine quality-of-life in patients with breast cancer and a vascular access device. The authors concluded that the use of a PORT is generally well accepted.

Kang et al published a pilot study in 2017 involving 357 patients with different cancer forms treated via a PICC. ${ }^{126}$ The authors concluded that quality-of-life measures vary according to the type of cancer and that a PICC probably has a low impact on overall quality-of-life. In another small Italian study describing patients receiving palliative home-care, PICCs appeared to cause little pain and distress. ${ }^{127}$ Paràs-Bravo et al conducted a qualitative study interviewing 18 patients with cancer. ${ }^{128}$ They concluded that the benefits of PICCs include reduction in number of venepunctures, rapid insertion and 
absence of symptoms. In contrast, disadvantages include pain and discomfort related to the device, lack of information, as well as the PICC's impact on daily activities and the need for adaptation.

In a study on patient-reported complications, Krein et al recently published interesting work indicating that more than $60 \%$ of hospital patients with a PICC reported signs of at least one complication during the time they had their PICC in place. ${ }^{129}$ One in four patients in in this cohort experienced that the catheter restricted their activities of daily life.

In the randomised controlled trial by Patel et al from 2014, data on quality-of-life were available in $53 \%$ of patients, and indicated that there was no difference in preference between PICCs and PORTs. ${ }^{130}$ In summary, from the patient's perspective, current scientific evidence gives us no real guidance in the choice of vascular access system for chemotherapy. It is obvious that more well-conducted controlled trials and qualitative studies reporting patient-reported outcome and quality- of-life are warranted in order to assist us in future decision-making.

\section{Aspects of healthcare economy}

There has been an increase in the use of PICCs in recent decades due to the apparently lower costs, insertion availability, perceived patient safety and ease of removal compared to other implanted central venous access devices such as t-CVCs and PORTs. ${ }^{122}$ 123 The insertion and removal of a PORT must be performed by a physician in an operating theatre (OT) or interventional radiology (IR) suite, whereas PICCs are typically inserted by a specialist nurse in locations outside OT and IR- suites.

The only RCTs addressing the cost of vascular access devices in patients with cancer, questioned the apparently lower cost of PICC. ${ }^{130}$ Comparing costs of access devices between different healthcare systems can be challenging. ${ }^{131}$ Other studies are mainly retrospective and only a few have a relevant control group (Table 14). ${ }^{132-143}$ All of these studies differ regarding the access device used, implantation techniques, definitions used, and how clinical outcomes were assessed. Furthermore, they were conducted in healthcare systems with different tariffs for implantation, maintenance, staff and complication management. These differences make any meaningful comparison between trials very difficult. Health-economic trials comparing relevant VADs in similar patient groups would be of interest to practice in order to inform decisions. In 
conclusion, the impact of CVCs on healthcare costs very much depends on where the studies are conducted and which perspectives are used. 


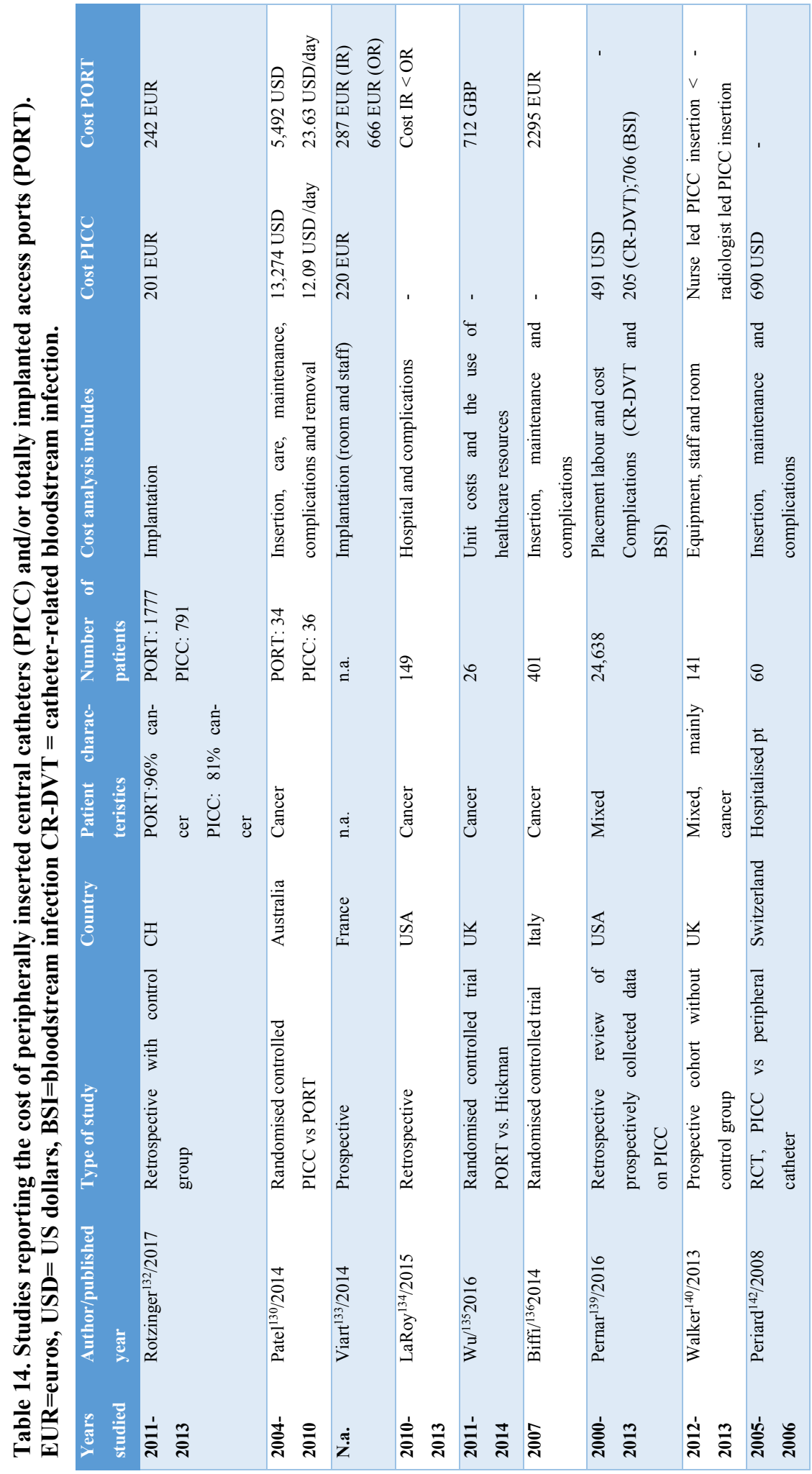




\section{AIMS OF THIS THESIS}

The overall aim of this thesis was to examine patient safety, patient satisfaction and cost to the healthcare system regarding the use of long-term vascular access devices in patients with cancer.

In Study I, we conducted a prospective audit of PORTs implanted at our hospital, to evaluate the incidence of complications and patient satisfaction.

In Study II, we investigated whether micro-organisms can be transmitted into a PORT chamber by injection through a PORT membrane contaminated with micro-organisms, and if so, to what extent. Furthermore, we evaluated if flow through the needle during insertion could reduce the number of bacteria transported across the membrane.

Study III was designed to answer the question: Which of the two commonly used long-term CVCs used in cancer therapy (PICC and PORT) is associated with the least number of complications (i.e. safest for the patient). In addition, we evaluated how patients perceive their CVC.

Based on the results from Study III, the aim of Study IV was to perform a healthcare cost analysis and examine the actual costs associated with PICC and PORT from the healthcare system's perspective. 


\section{PATIENTS, METHODS AND STATISTICS}

\section{Study 1}

In Study I, we prospectively enrolled patients eligible for PORT implantation and followed them for up to six months. Follow-up included chart reviews and interviews.

Setting: The hospital is a 500-bed general county hospital including most medical, oncological and surgical specialties except neurosurgery and cardiac surgery. No solid organ or stem cell transplantations are performed. All nursing staff handling central vein access ports receive special training, and about 150-200 ports are implanted each year by the Department of Anaesthesia and Intensive Care.

Patients: Patients $\geq 18$ years of age and with a predicted survival of more than 6 months were invited to take part in the study. Exclusion criteria were: ongoing severe infection; severe coagulation disorder at the time of implantation; or inability to communicate in English or a Scandinavian language.

Port implantation: Two different central vein port systems where used; the Bard $\AA$ port with a silicone Groshong catheter and B.Brauns Celsite $\AA$ port ST301 with an open-ended silicone catheter. Prior to surgery the patients received a total body wash using a sponge containing 4\% chlorhexidine. Antibiotic prophylaxis was not routinely administered. All port systems were implanted in an operating theatre with maximal sterile precautions (cap, mask, gown, gloves and a large drape). The implanting physician was assisted by a theatre nurse. The surgical area was prepared with a solution containing $70 \%$ ethanol and $0,5 \%$ chlorhexidine, and the skin passively dried for 1-2 minutes before sterile draping. All pro- 
cedures were carried out by either a resident or specialist anaesthesiologist using the Seldinger percutaneous technique. The procedure was routinely carried out under local anaesthesia, but in some cases propofol sedation was also used. Ultrasound-guided venepuncture and fluoroscopy was used, and the internal jugular vein was the first choice because of the minimal risk for pinch-off syndrome and its good ultrasound accessibility compared to the subclavian vein. The catheter was then tunnelled towards the infraclavicular area where a pocket just large enough for the port reservoir was prepared using a single sharp skin incision and subsequent blunt dissection. After correct tip positioning, with the help of fluoroscopic guidance, in the right atrium or distal superior vena cava, the catheter was connected to the port reservoir. The port reservoir was then punctured, and system function verified by aspirating blood. Post-implantation chest $\mathrm{x}$-rays were not routinely performed and the patient was able to use the port immediately after implantation.

Port care: All port handling was carried out by nursing staff with specific training in port handling stressing the importance of good adherence to hygiene precautions. Written instructions for port care and problem-solving were easily available through the hospital IT-system. Access-team support (anaesthesiologist/intensive care nurse) was available on a 24-hour basis from the Department of Anaesthesiology and Intensive Care. Prior to puncture of the reservoir membrane, the skin was disinfected with a solution containing $70 \%$ ethanol and 0.5 $\%$ chlorhexidine. During this procedure, sterile or high purity gloves were used. Intravenous positioning was verified by blood aspiration prior to use. After use, $40 \mathrm{ml}$ of $0,9 \%$ saline was flushed through the system. When the port needle was left in situ, it was covered with a semi-permeable transparent dressing (Tegaderm $^{\mathrm{TM}} \mathrm{HP}$ ). During continuous use intravenous positioning was verified once a day. When indwelling, the port needle was changed once a week. Intermittent injections were performed through a NIM attached to the needle (Smartsite ${ }^{\circledR}$ ). NIMs were disinfected with ethanol/chlorhexidine solution before use. Dressing and NIMs were changed and the area around the puncture site disinfected every 3 
days and weekly in the home-care setting. Resting ports were not routinely flushed. Antithrombotics and intraluminal or subcutaneous heparin was not routinely used.

Port problem-solving: When catheter occlusion occurred the first step was to try to flush the system with a $10 \mathrm{ml}$ syringe containing isotonic saline. If this failed, a $2,5-5 \mathrm{ml}$ syringe was tried with caution by an anaesthesiologist. Alteplase $0,2 \mathrm{mg} / \mathrm{ml}$, ethanol $70 \%$ or hydrochloric acid $1 \mathrm{mmol} / \mathrm{ml}$ was used to restore catheter patency if flushing with saline was unsuccessful, depending on the probable cause of occlusion. Prior to installation of ethanol or hydrochloric acid, a chest x-ray was taken to rule out catheter fracture or disconnection.

Data collection: Patients were invited to take part in the study on the day of scheduled surgery. Written and verbal information about the study was provided and patient consent obtained. At implantation we collected the following data: patient characteristics (age, gender, disease, laboratory results); implantation characteristics (vessel choice, procedural time, use of antibiotics, anaesthetic method, implantation difficulties, use of ultrasound/fluoroscopy, anaesthetist training level); and patient perception during the procedure. One week after port implantation patients were interviewed and the information cross-checked with the patient's notes as regards port-related complications. Interviews were performed by telephone. This procedure was repeated once a month for the entire 6month follow-up period. All interviews and chart reviews followed a specific protocol. Two research nurses and the first author conducted the interviews and chart reviews.

Microbiological methods: When an infection was suspected, swab cultures from the area around the reservoir and tunnel as well as blood cultures drawn from the port and a peripheral vein, were obtained. Swabs were transported in Amies medium with charcoal. Identification and antibiotic susceptibility testing were performed using standard methods at our local microbiology laboratory 
(www.srga.org accessed January 1, 2007). A culture from the reservoir pocket, and the catheter tip were taken from all systems removed. The tip was then cultured using a standardised semiquantitative method for up to 2 days. ${ }^{103}$ The tip culture results were categorised as follows: $>15 \mathrm{CFU}$; $1-15 \mathrm{CFU}$; and negative culture. When blood cultures were performed, a minimum of $10 \mathrm{ml}$ blood was injected into an aerobic and an anaerobic bottle, respectively. The bottles were incubated for up to six days using an automated blood culture system (BacT/ALERT, bioMe'rieux, Inc., Durham, NC). Identification and antibiotic susceptibility testing were performed using standard methods for all colonies detected.

Definitions: Catheter colonisation was defined as a positive tip culture in the absence of clinical symptoms of SIRS. ${ }^{144}$ Port pocket and/or tunnel infection was defined as local signs of inflammation around the port/tunnel with culturepositive fluids from the port pocket/tunnel. ${ }^{144} \mathrm{~A}$ CRI, was defined as a positive tip culture in a patient with at least two of four SIRS symptoms and no other source of infection. ${ }^{145}$ A CRBSI was defined as isolation of the same microorganism from tip culture and from a blood- culture drawn from another vessel, together with at least two of the four SIRS criteria. ${ }^{144}$ The criteria for "difficult implantation" were: more than four attempts to puncture the vessel and/or necessity to change access vein. ${ }^{146}$ Catheter-related DVT, was defined as occlusion (partial or total) of the vein into which a catheter had been placed. Catheter occlusion was defined as inability to aspirate or flush via the catheter. Procedural time was defined as the time from the application of local anaesthetic to completion of the last suture.

Statistical methods: Descriptive analyses were performed to characterise the patient population. The significance of differences between groups was determined using the $\chi 2$-test for categorical variables and Student's t-test for continuous variables. Two-tailed tests of significance were used. A number of univariate 
logistic regression analyses were performed to estimate the risk for port-related colonisation and infection. We used multivariable regression models controlling for catheterisation time. All analyses were conducted using a statistical software package (SPSS, version 13.0. for Windows, SPSS Inc., Chicago, IL, USA).

Ethics: The study was approved by the Regional Ethics Review Board at the University of Linköping (reference number: M207-07).

\section{Study II}

In Study I, we found that the number of suspected local PORT infections was causing concern among patients and staff. Therefore, in Study II we investigated the extent to which micro-organisms can be transmitted across a PORT injection membrane, and if there is a way to reduce such transmission. Our hypothesis was that micro-organisms from the PORT exterior would be transmitted via the cavity of the needle-tip. Furthermore, when flushing the needle during insertion, the number of micro-organisms transferred would decrease.

Figure 10 Schematic drawing of the non-coring needle-tip and its corresponding volume. (Reprinted with the permission of B.Braun Medical).

\section{NEEDLE 22G}

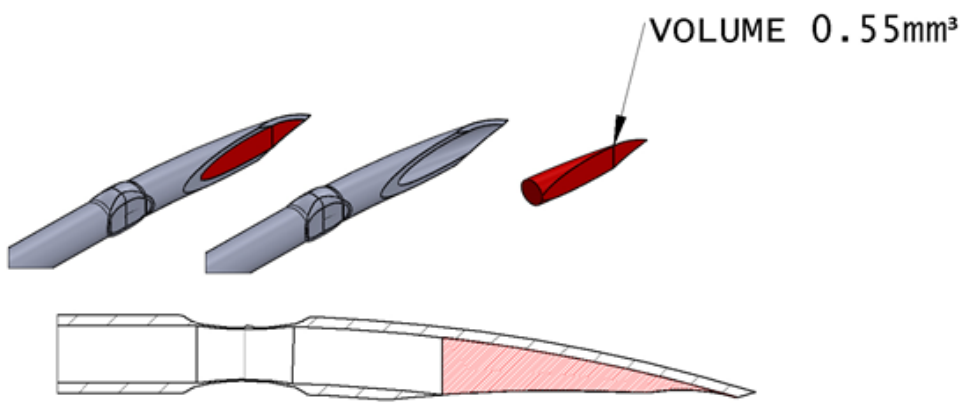




\section{Microbial strains, preparation of contaminated solutions and PORT materi-} al

Four different microbiological species, typically isolated from venous port infections, were examined: Staphylococcus aureus strain ATCC 29213; Staphylococcus epidermidis strain CCUG 21989; Candida albicans strain CCUG 19915; and Klebsiella pneumoniae strain CCUG 4521.

We prepared three different suspensions of S. epidermidis, S. aureus and C. albicans with concentrations mimicking various levels of contamination: very high level (undiluted cultured microbial mass); high level (pus-equivalent) ${ }^{147}$ and low level. For K. pneumoniae only the high-level concentration was used.

The undiluted preparation of micro-organisms supplied was used as the very high-level concentration. The micro-organisms were then suspended in $3 \mathrm{ml}$ of $0.9 \% \mathrm{NaCl}$ to a concentration of $0.5 \mathrm{McFarland}$ (primary dilution; high-level). The suspensions were further diluted in $0,9 \% \mathrm{NaCl} 1: 10.000$ for $S$. epidermidis and S. aureus, and 1:1000 for C. albicans (secondary dilution; low-level). In order to quantify the number of CFUs transmitted during puncture using the standard puncturing technique, thirty PORTs were used in ten different combinations of micro-organism and concentration ( $\mathrm{n}=3$ in each). Using three individual PORTs for each experimental condition $100 \mu \mathrm{l}$ samples of the very high-level (undiluted microbial mass), of the primary dilution (high-level suspension) and of the secondary dilution (low-level suspension) of $S$. epidermidis, S. aureus, $C$. albicans was spread across the PORT membrane. For K. pneumoniae, only the high-level primary dilution solution was used on three PORTs.

The BBraun Celsite ${ }^{\circledR}$ (Boulonge, France) 301 PORT including a 22G needle with an inner diameter of $0.47 \mathrm{~mm}$ was used. The needle tip volume is $5.5 \times 10^{-4}$ ml. Figure 10.) The experiments were conducted in a Laminar Air Flow working station. 


\section{Comparison of bacterial transport through the PORT membrane with or without the use of flow through the non-coring needle}

The aim was to investigate if transmission of micro-organisms could be reduced by changing the puncture technique by maintaining a low positive pressure flow through the non-coring needle during insertion. A total of 40 PORTs were prepared, 10 each with very high-level concentration of $S$. epidermidis and S. aure$u s$, and 10 each with the high-level concentrations. Five PORTs of each preparation were then subjected to injection with a constant low flow and 5 served as controls with no flow applied during membrane puncture.

The low positive pressure injection was accomplished by puncturing the membrane with a preset flow rate through the needle of $250 \mathrm{ml}$ per hour $(0.07 \mathrm{ml}$ per second) $0.9 \% \mathrm{NaCl}$. The infusion rate was controlled by a standard syringe driver (Perfusor ${ }^{\circledR}$ BBraun, Melsungen AG, Germany). Immediately following puncture, the flow was stopped to prevent dilution of the sample. Thereafter, $1.5 \mathrm{ml}$ of $0.9 \% \mathrm{NaCl}$ was manually flushed through the needle into the chamber using a prefilled syringe. The control "no-flow" ports were handled the same way except for not being attached to a syringe with flow during puncture.

\section{Culture and Colony-Forming Unit counts}

Fluid from the outlet metal nipple of the PORTs was collected in a sterile container and duplicate $100 \mu \mathrm{l}$ samples were incubated on human blood agar plates (S. aureus, S. epidermidis, K. pneumoniae) and sabouraud agar plates (C. albicans) at $37^{\circ} \mathrm{C}$ for 24 and 48 hours, respectively. After incubation, the number of CFU was counted manually and estimates of the concentration in CFUs/ml and the mean number of CFUs introduced to the chamber were made.

Cultures and CFU counts were performed on the applied suspensions in order to verify viability of the contaminants and to determine the actual concentrations of the suspensions. 


\section{Statistical analysis}

Numbers are presented as medians with ranges. Comparisons between no-flow and flow groups were performed with the Mann-Whitney test. P-value $<0.05$ was regarded as significant. Analyses were performed using IBM $®$ SPSS ver. 24.

\section{Studies III and IV}

\section{Study design and participants:}

The PICC versus PORT trial (PICCPORT) was a pragmatic, open-labelled, randomised clinical trial evaluating adverse events, patient perception and health economics with two types of CVC (PICC and PORT) in patients with nonhaematological cancer. Patients were randomised in a 1:1 allocation ratio at two oncology centres (Ryhov and Växjö County Hospitals, Sweden). These hospitals have catchment area populations of 360000 and 196000 respectively. Ethics approval was granted by the Regional Ethics Committee in Linköping, Sweden (reference number: EPN 2013/56-31). The trials registration was accepted after the inclusion of 22 patients at www.clinicaltrials.gov (NCT0197102). The trial was conducted according to the principles of the International Council for Harmonisation - Good Clinical Practice and the Helsinki Declaration, and adheres to the CONSORT statements including several features of a pragmatic approach (the selection of participants being practical and sequential and that the outcome is directly relevant to patients, care-givers, and practice). ${ }^{148}$ Patients $\geq 18$ years-of-age with a life-expectancy longer than 4 weeks and planned for chemotherapy through a CVC, were eligible for inclusion. Exclusion criteria were: ongoing severe systemic infection; clinically significant upper extremity/central deep venous thrombosis; severe coagulopathy; inability to communicate; or an imminent need for a dialysis fistula. Printed information was given, and all participants gave informed consent before randomisation. 


\section{Randomisation and masking:}

Patients were screened for eligibility by the nursing staff at both in- and outpatient clinics. Eligible patients were subsequently informed and included by a physician at the Department of Oncology. The randomisation sequence was computer-generated and prepared by an independent statistician using a block size of four with stratification to the two recruiting centres. It was not feasible to blind the patient, clinician or trial assessors to the arm allocated due to the obvious nature of the devices. Data on randomisation, after implantation and at follow-up after one, three, six, and 12 months were collected and registered by staff in the clinical trial unit.

\section{Definitions}

A CR-DVT was defined as symptoms or clinical signs of a DVT (pain, redness, swelling, tenderness in a relevant area) confirmed by ultrasound or computed tomography, or a DVT incidentally detected on imaging for other reasons. Evaluation of clinical signs leading to imaging was at the discretion of the treating physician. No periodic imaging was carried out to identify silent thrombosis. Catheter occlusion was defined as the inability to aspirate or flush via the catheter and was included in the analysis only if alteplase or ethanol instillation was required to resolve the occlusion. Catheter-associated infections were defined according to Infectious Diseases Society of America. ${ }^{103}$

\section{Outcomes}

The primary outcome was a clinically significant CR-DVT verified by US and/or CT. We chose CR-DVT as our primary outcome because meta-analyses have shown this complication to be more frequent in patients with a peripherally inserted central catheter than those with a centrally inserted port. ${ }^{13} 16$ Secondary outcomes defined a priori, were a composite end-point describing the occurrence of catheter-related adverse events requiring intervention (thrombotic, occlusive, infectious, mechanical), patient satisfaction and health economics. Pain was graded according to the NRS. 


\section{Cost evaluation and cost definitions}

Costs were divided according to the following categories: implantation (staff, catheter, equipment, pharmaceuticals and materials); catheter maintenance (staff cost, dressing, needle and hub changes); complication (diagnostic assessments, out-patient consultations, hospitalisation, staff, medications); and removal (staff, equipment, cultures and materials).

Staff cost per minute was derived from hourly gross wages (stratified per staffcategory) and subsequently multiplied by the duration of staff involvement to yield the total staff cost per patient. Data regarding staff involvement during device insertion and PORT removal were based on prospectively collected data from the hospital patient data management system (MetaVision $\left.{ }^{\circledR}\right)$. The time consumed during catheter care (e.g. dressing changes), catheter complication-related problem solving (e.g. catheter occlusion and suspected infection) or PICC removal were retrospectively estimated by four nurse experts at the oncology department.

Insertion time was defined as the time the patient spent in the room where the catheter was inserted (preparation, procedure and post-procedural actions). The insertion time was estimated using data from the local booking system (PICCgroup) or actual data from the operating theatre patient data management system (MetaVision ${ }^{\circledR}$ ). Procedural time was defined as the time from the injection of local anaesthetic to anchoring of the catheter device with skin sutures in place (= labour time for the inserting clinician).

The cost of fluoroscopy (Philips Veradius Unity ${ }^{\circledR}$ ), tip-location (Sherlock 3G ${ }^{\circledR}$ ) and ultrasound (Secma SonoSite ${ }^{\circledR}$ ) equipment was estimated using a per catheter-based cost including purchase and depreciation costs. Depreciation was calculated based on ten (tip-locating and ultrasound equipment) or seven (fluoroscopy) years of use in a linear depreciation model. The cost of this equipment was also 
based on the proportion of annual use for PICC and PORT procedures in relation to their annual total use.

The routines for catheter maintenance and care differ between PICCs and PORTs. PICC dressings are changed weekly regardless of whether they are in active use or not. For PORTs there is no requirement for regular dressing changes (the systems are totally implanted) thus dressings are only changed when the catheter is in active use. In order to estimate the cost for PORT maintenance, we randomly selected one in five patients in the PORT-arm and did a separate retrospective electronic chart review (Cambio Cosmic ${ }^{\mathrm{TM}}$ ) to reveal how often the PORT dressings actually were changed.

The cost estimate for catheter-related complications (CR-DVT, infection, occlusion and mechanical) was based on the cost for diagnostic assessment, nurse assessment, out-patient consultations, hospitalisation, drug therapy and removal (staff and disposables). For the price of antibiotics in the cost estimation model, we calculated the mean cost of the various antibiotics used. In the analysis we included the cost of access devices removed due to both complication and at cessation of treatment.

Analyses were from the healthcare system's perspective and did not estimate any home-care or indirect costs. Pricing information regarding the cost of staff, medicines and diagnostic tools were acquired from the Ryhov County Hospital personnel department, hospital pharmacy and hospital economy department. All costs were calculated in SEK and converted to EUR using a fixed rate of 100 $\mathrm{SEK}=9.56 \mathrm{EUR}$.

\section{Statistical analyses}

With a two-tailed alpha of 0.05 and a power of 0.80 , the trial was estimated to detect a difference between groups of at least 7\% in CR-DVT rate. The estimated incidence of PICC CR-DVT (8\%) was gathered from systematic reviews. ${ }^{13} 16$ 
The estimated incidence of CR-DVT in the PORT group (1.6\%) was based on data from Paper I in this thesis. ${ }^{33}$ Estimated incidences indicated that 174 patients were required per group. To have margin for patients leaving the trial after randomisation we aimed at including 200 patients in each group. We stratified for oncology centre since PORT implantation procedures differed.

Pearson's Chi ${ }^{2}$, Fisher's, Mann-Whitney U and Student t-tests were used to test for differences between groups as appropriate. Analyses on primary and secondary outcomes were performed on the intention-to-treat (ITT) and per-protocolpopulations (PP). Multivariable Cox proportional hazard models were used to identify independent predictors (centre, catheter type, treatment goal, sex, age, bevacizumab and continuous 5-FU treatment) of CR-DVT and catheter-related adverse events (thrombosis, occlusion, infection, mechanical issues or death) during follow-up period. Predictors with p-values $>0.5$ were stepwise manually removed from the model. An adjustment for the futility analysis (the first 100 patients) was made. Analyses of CR-DVT-free catheter patency (primary endpoint) and adverse event-free catheter patency (secondary endpoint) were performed using the Kaplan-Meier method and the log rank test. These analyses were planned a priori. Data on the use of either continuous 5-FU or bevacizumab were compared with other regimens in a post-hoc analysis. Two sensitivity analyses were performed: one assuming that patients dropping out all had CR-DVT, and the second by only including patients with symptomatic CR-DVT. All $\mathrm{p}$ values were two-tailed, a value $<0.05$ was considered statistically significant. Statistical analyses were performed using IBM ${ }^{\circledR}$ SPSS version 24. Data on health care expenditure was compiled using Microsoft Excel®. 


\section{RESULTS}

\section{Study I and III}

\section{Patient and PORT-catheter characteristics}

Four-hundred and forty seven patients were included. The median patient age was 62 years (range 20-88) in Study I and 65 (30-89) in Study III and 60\% of patients were female. A total of 81454 PORT catheter days were studied and the median follow-up time was 180 days (Study I) and 220 days (Study III). Eightyone patients with PORT (18\%) died during the follow-up period. No patient death could be related to access port complications.

\section{Implantation characteristics}

Antibiotic prophylaxis was administered in 36 cases (8\%) and an additional five patients were under antibiotic treatment at the time of port implantation. In 405 cases (90\%) the inserting physician was a specialist anaesthesiologist. Median procedure time was 25 minutes (range 9-75). Three hundred thirty ninepatients $(75 \%)$ received local anaesthetic only, 111 patients $(24 \%)$ received light propofol sedation in addition to the local anaesthetic. In three cases $(0.7 \%)$ general anaesthesia was required. The proportion of patients with moderate to severe procedural discomfort was $25 \%$ in both the group receiving local anaesthetic only and the propofol sedation group.

Arterial puncture occurred eight times (1.8\%), but no intra-arterial guidewire or dilator placement occurred.

\section{Early mechanical (up to one month after implantation) complications}

No case of pneumo- or haemothorax was recorded. One patient had a port-related haematoma appearing a few hours after surgery that was treated conservatively. Two systems $(0.8 \%)$ had to be removed due to suspected disconnection between 
the catheter and reservoir; in one case a faulty radiological diagnosis led to port removal and in the other case suspected handling error during implantation caused disconnection - both cases during Study I.

\section{Occlusive and thrombotic complications}

In Study I we registered 36 occasions (0.95/1000 catheter days) of catheter occlusion and/or failure to draw blood through the catheter. In Study III, alteplase was required once to restore catheter patency. No catheter had to be removed because of occlusion. In all PORTs studied, six $(1.3 \%$ or $0.07 / 1000$ catheter days) clinically apparent CR-DVT were diagnosed by CT, ultrasound or phlebography. All these patients received anticoagulant therapy and three patients required catheter removal because of their CR-DVT. In patients with PORTs, no clinically evident pulmonary embolisation occurred in patients with a CR-DVT.

\section{Catheter colonisation and port-related infections}

In $30 / 447$ (6.7\% or $0.36 / 1000$ catheter days), local pocket infection was verified by culture. Staphylococcus aureus and CoNS were the most common microorganisms responsible for local pocket infections. A CRBSI was recorded on four occasions $(0.9 \%$ or $0.05 / 1000$ catheter days $)$. Two patients had local signs of infection around the reservoir, and verified $S$. aureus sepsis. These patients had their port removed immediately and the infections were successfully treated with antibiotics. Two PORT patients from Study III experienced CRBSI, one with a potential bacterial translocation from the gut and one with a CR-DVT infected by CoNS.

Table 15 Adverse events in the 447 PORTs studied. CR-DVT = catheter related deep venous thrombosis, $\mathrm{CRBSI}=$ catheter related bloodstream infection.

\begin{tabular}{|llll|} 
& CR-DVT & CRBSI & Local infection \\
\hline $\mathbf{N}(\%)$ & $6(1.3)$ & $4(0.9)$ & $30(6.7)$ \\
\hline Per 1000 catheter days & 0.07 & 0.05 & 0.36 \\
\hline
\end{tabular}




\section{Patient perception}

During the implantation procedure in Study I, 25\% of patients experienced moderate $(23.4 \%)$ to severe discomfort (2.6\%). There were no significant differences between patients receiving local anaesthetic only or with propofol sedation. The vast majority of patients $(202 / 249$ (81\%)) felt that the access port facilitated their treatment. One hundred and eighty-two (73\%) patients reported that the port had little or no effect on their daily living.

In Study III, one of four patients with PORT reported implantation related pain NRS $\geq 4$. Similarly, $25 \%$ of patients in Study I experienced moderate to severe implantation related discomfort.

\section{Study II}

\section{Microbial transmission through the contaminated injection membrane}

The results from the cultures in the first part of the experiment are shown in Table 16. The control cultures of the contaminant suspension confirmed that the pathogens applied to the PORT membrane surface were viable. In general, CFU concentrations in the saline flushed through the port were much lower than the applied contaminant suspension. Depending on the microbial concentration on the PORT membrane, the number of $\mathrm{CFU} / \mathrm{ml}$ flushed saline from the outlet sample ranged between zero and numbers TNTC. Generally, the number of microorganisms was reduced by a factor of $10^{3}-10^{4}$ during the passage through the membrane.

When using low-level contamination dilutions $\left(\sim 10^{3-4} \mathrm{CFU} / \mathrm{ml}\right)$ of $S$. epidermidis and $C$. albicans, no CFUs were grown from the samples flushed through the PORT. The low-level contamination dilution of S. aureus gave 15 CFUs in the outlet sample.

When puncturing the membrane through the high-level contamination smear $\left(\sim 10^{6-7} \mathrm{CFU} / \mathrm{ml}\right)$ the number of microbes isolated from the PORT chamber sample increased to $2.6-3.4 \times 10^{3} \mathrm{CFU}$ for the bacteria and $8 \mathrm{CFU}$ for C. albicans. 
Puncture through a very high-level contamination smear $\left(\sim 10^{11} \mathrm{CFU} / \mathrm{ml}\right)$ resulted in an outlet sample CFU TNTC for S. aureus, $3.0 \times 10^{3} \mathrm{CFU}$ for C. albicans, and $5.4 \times 10^{3} \mathrm{CFU}$ for $S$. epidermidis.

\section{The effect of continuous flow through the non-coring needle on bacterial transmission across the injection membrane}

Data from the transmission when using a modified injection technique are shown in Table 17 and Figure 11. As seen, there was a significant reduction in the number of CFUs transported across the injection membrane when a continuous flow was applied at the high-level concentration of both S. epidermidis (1750 vs. 20) and $S$. aureus (1420 vs.130), respectively. This number corresponds to approximately a volume of $10^{-4} \mathrm{ml}$ of contaminant fluid being transmitted through the silicone membrane (Figure 10). The number of bacteria transported across the membrane when using the flow technique was approximately $1 \%$ of that using the standard no-flow technique.

When using the very high-level concentration this effect could not be evaluated because the number of CFUs were TNTC in both the experimental and control groups. 


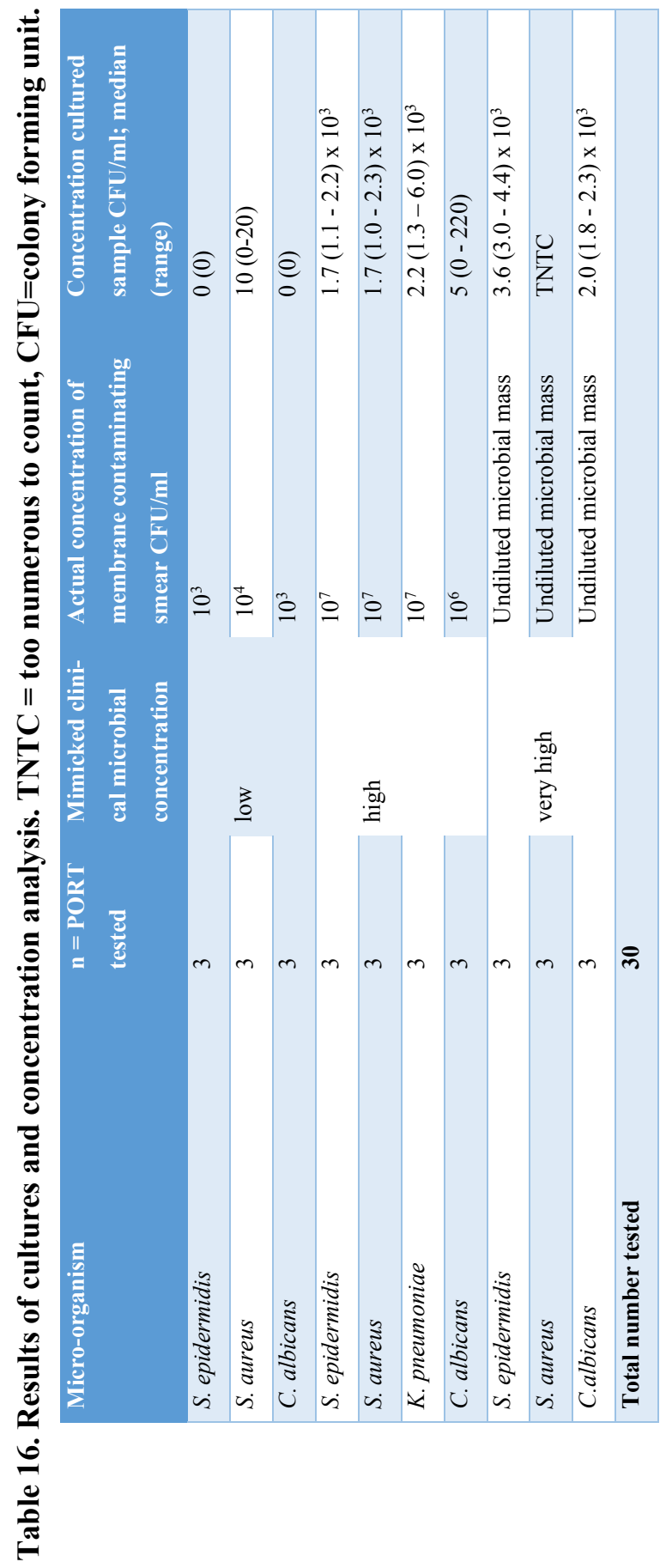




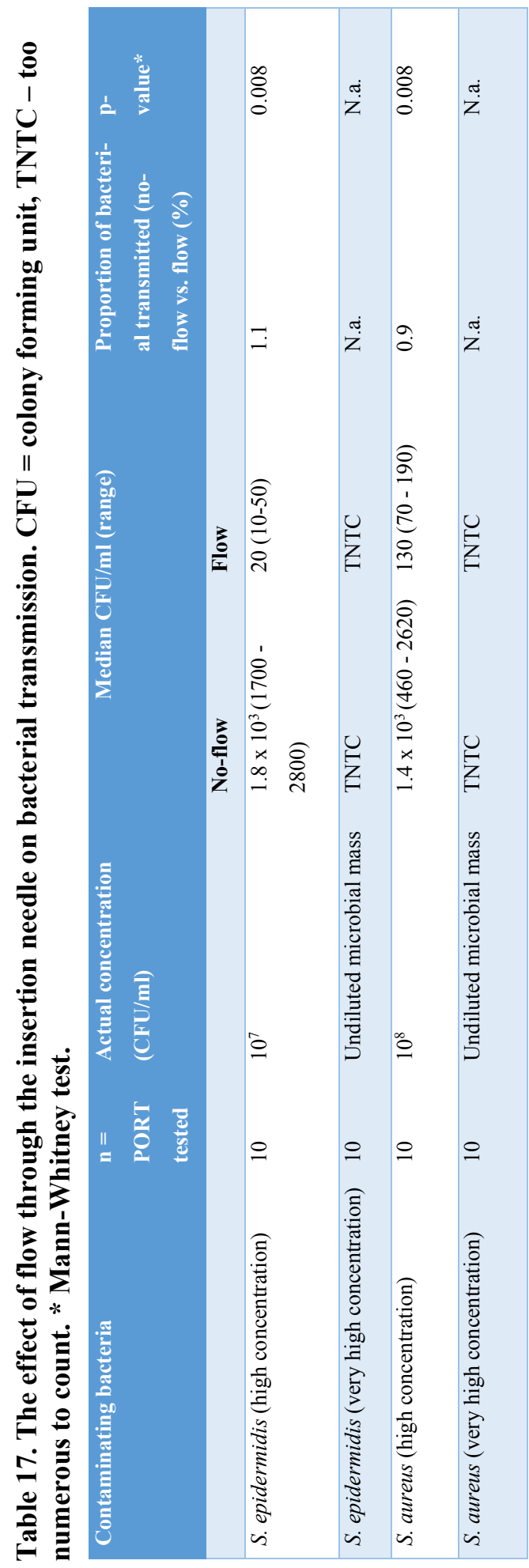


Figure 11. Boxplot showing the bacterial counts of the fluid in the port using two different injection methods (no flow vs. flow) for the high concentration of Staphylococcus epidermidis and Staphylococcus aureus applied on the membrane. $\mathrm{CFU}=$ colony forming unit

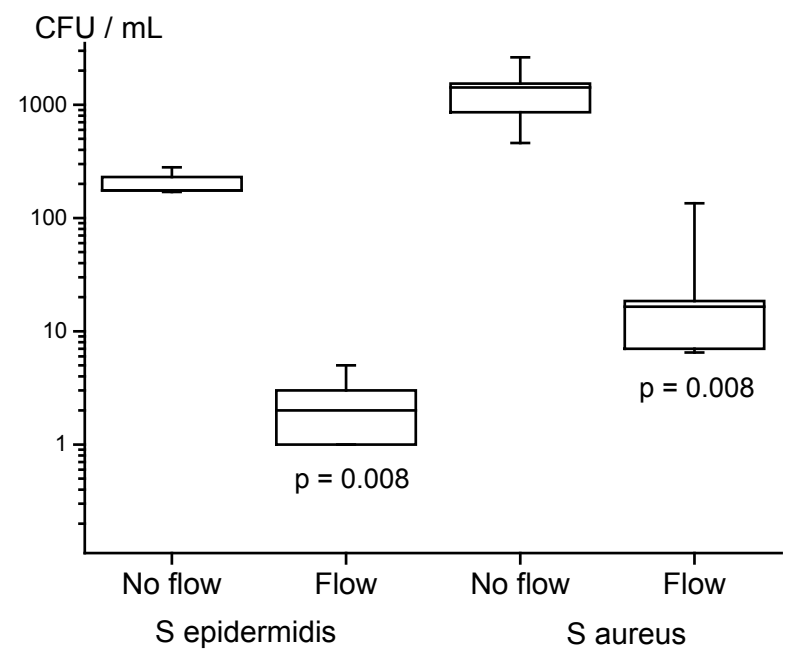

\section{Study III and IV}

Participants were recruited between the $13^{\text {th }}$ of March 2013 and the $16^{\text {th }}$ of February 2017 . The final date for data cut-off was the $16^{\text {th }}$ of February 2018. Of 1597 patients eligible according to screening, 807 declined participation due to device preference $(61.5 \%$ and $35.7 \%$ requested PORT or PICC, respectively, and reason unknown 2.9\%) and 391 failed to meet the inclusion criteria. Of the 399 enrolled and randomised participants, 201 were assigned to the PICC group and 198 to the PORT group. Following randomisation, 10/201 (5\%) patients in the PICC group and 5/198 (2.5\%) in the PORT group declined further participation (Figure 12). 


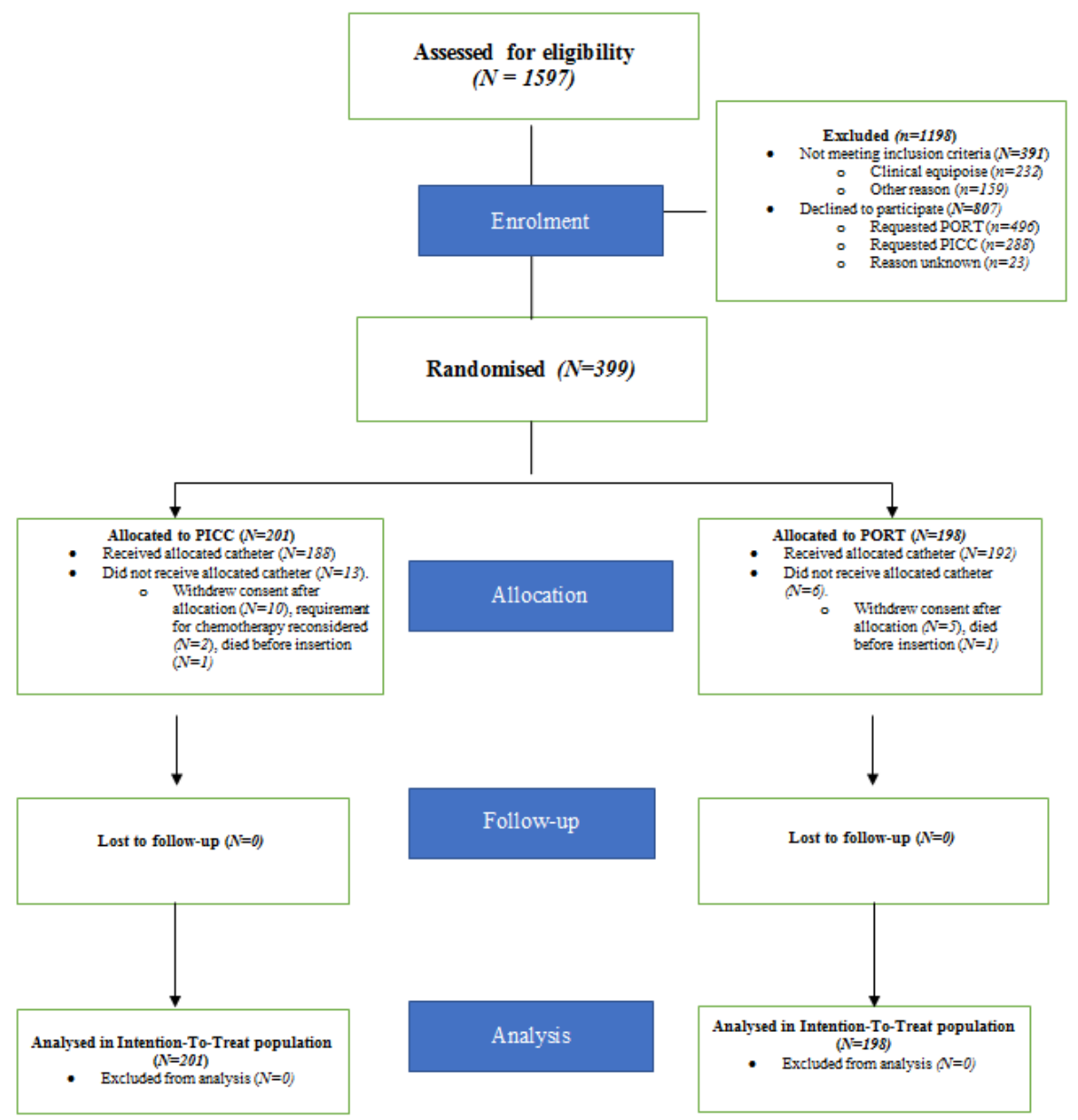

Figure 12. CONSORT- diagram outlining the patient flow in Study III.

In the ITT- population, 16 patients $(8 \%)$ in the PICC group developed CR-DVT compared to $2(1 \%)$ in the PORT group. With an absolute risk reduction for CRDVT of $7 \%$ between the groups, 14 patients would need to receive a PORT instead of a PICC in order to avoid one CR-DVT. The CR-DVT-free Kaplan-Meier time-to-event differed significantly between the two groups (HR 10.2 95\% CI 2.3 - 44.6, $p=0.001$ by the log rank test) (Figure 13). Several potential risk factors for CR-DVT (oncology centre, type of catheter, tip position, age, sex, type of cancer, metastatic disease, and treatment with 5-FU infusion- or bevacizumab-containing 
therapy) were analysed using a Cox regression model. In this analysis catheter type was the only significant risk factor.

Catheter-related thrombotic events occurred between days 4 and 142. Six of 18 (33\%) CR-DVTs were diagnosed during the first month after implantation, all of them in the PICC group. The catheters were left in situ despite CR-DVT in 14 of 18 (77.8 \%) patients, all of whom received treatment with LMWH. Median time to CR-DVT was for PICC 55 and for PORTs 93 days. Three of 18 CR-DVTs were diagnosed incidentally when a CT-scan was performed for reasons not related to the catheter. One PICC patient with CR-DVT and subsequent pulmonary embolisation had a lethal cerebral haemorrhage two days after LMWH treatment was initiated. There was a reasonable causal relationship between the cerebral haemorrhage and treatment with LMWH. One PORT patient with an infected CR-DVT and mechanical problems experienced septic embolisation to lumbar vertebrae. The CoNS infection originated in the PORT pocket and the patient had recurrent bacteraemia after the PORT had been removed. The significant difference in the incidence of CR-DVT remained after performing sensitivity analyses. When combining catheter-related adverse events (CR-DVT, exit site or pocket infection, CRBSI and occlusion), and mechanical problems (including insertion failure and accidental removal) into a composite variable, 45 (22.4 \%) PICC patients compared to $26(13.1 \%)$ in the PORT group experienced an adverse event (HR 2.7 (95\% CI $1.6-4.6, P<0.001)$ as seen in Figure 14. Analyses on primary and secondary outcomes on both the ITT and PP populations gave the same results.

In the PORT group, 49/190 (25\%) of the patients answering the questionnaire one month after insertion said that they experienced pain (NRS $\geq 4$ ) during catheter insertion. The corresponding number in the PICC group was 14/176 $(8 \%), p<0.001$. At both 1- and 3-month follow-ups, fewer patients reported that the PORT interfered with daily activities (showering and taking a bath) than did PICC patients, but not with other activities. 
Figure 13. Kaplan-Meier curves showing the cumulative catheter related deep venous thrombosis (CR-DVT) free time period for peripherally inserted catheters (PICC) and implanted port catheters (PORT): HR= hazard ratio, $\mathbf{C I}=$ confidence interval.

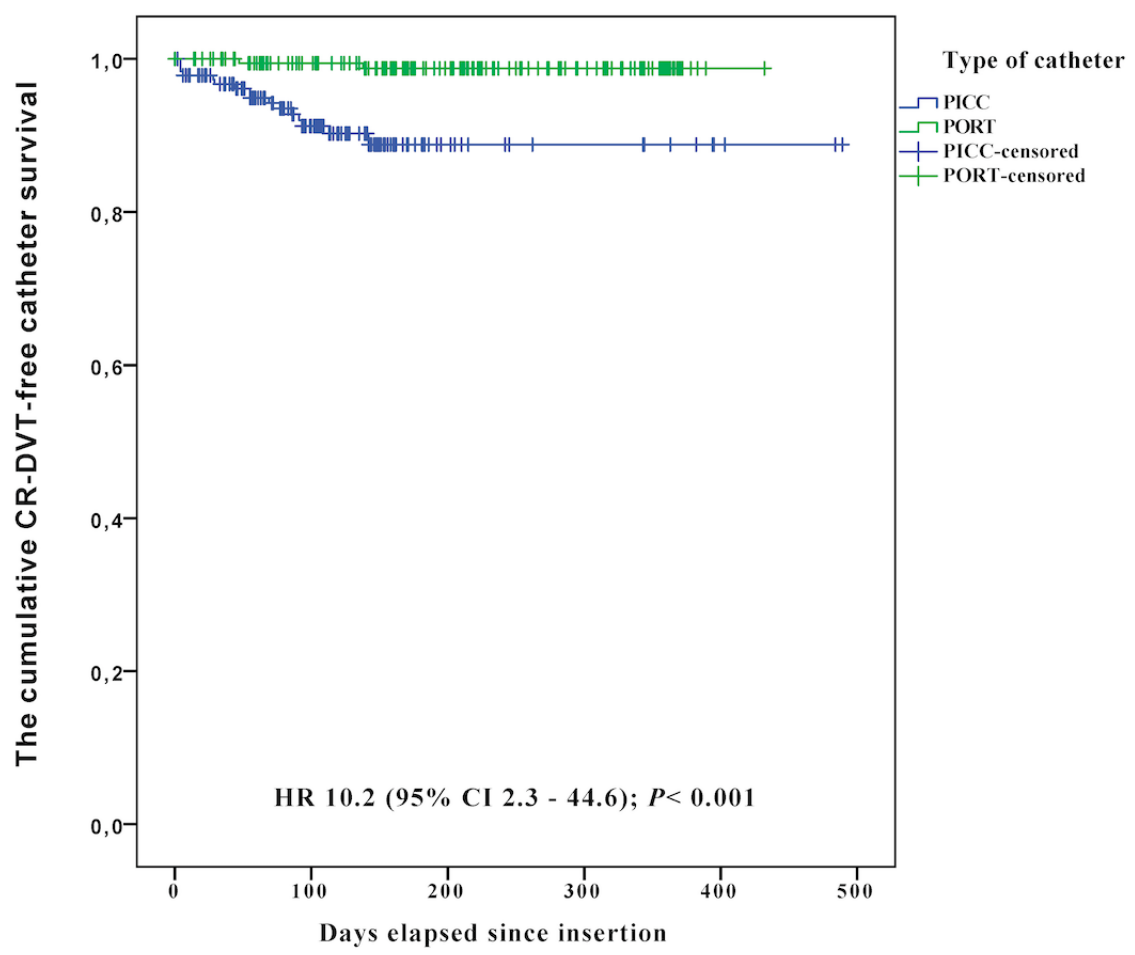

Number at risk

$\begin{array}{lllccll}\text { PICC } & 201 & 111 & 18 & 10 & 3 & 0 \\ \text { PORT } & 198 & 158 & 107 & 65 & 1 & 0\end{array}$


Figure 14. Kaplan-Meier curves showing the cumulative adverse event free time period for peripherally inserted catheters (PICC) and implanted port catheters (PORT): $\mathrm{HR}=$ hazard ratio, $\mathrm{CI}=$ confidence interval.

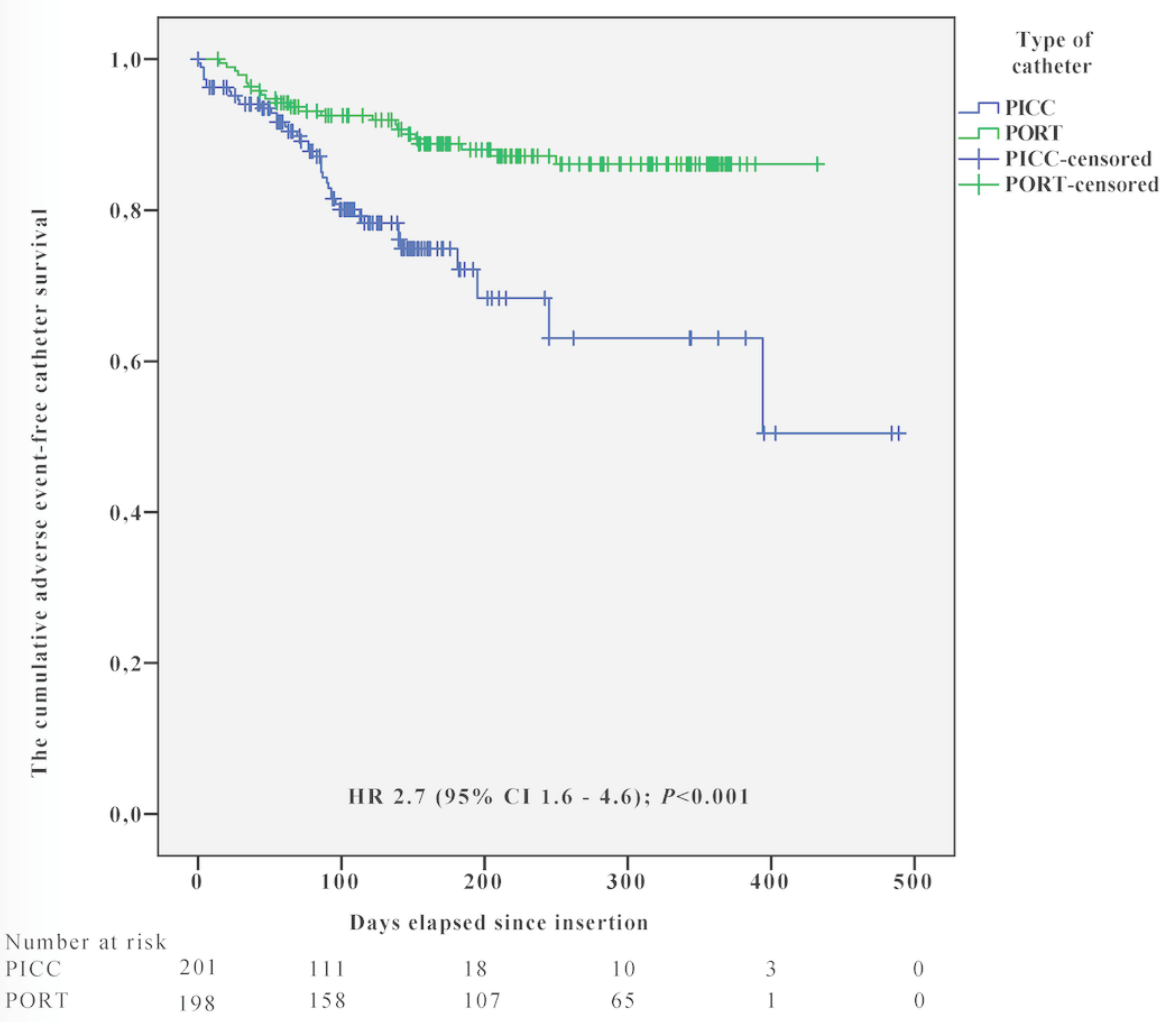

\section{Costs}

Dressing changes occurred on average 18 times per PICC and 15 times per PORT. The time consumed during PICC and PORT maintenance, nurse-led complication assessment and removal, was 10 minutes for dressing changes, 30 minutes for occlusion assessment and installation of fibrinolytics, 15 minutes for infection assessment and culturing, and 15 minutes for PICC removal. The corresponding median time consumption for PORT removal was 23 minutes (interquartile range 14). 
Combining the costs of all categories, the price per inserted device was 824.58 EUR for PICC and 662.34 EUR for PORT. When adjusting for total catheter dwell time the price was 6.58 EUR/day for PICC and 3.01 EUR/day for PORT.

Table 18 Cost related to PICC and PORT from a health-care perspective. PICC $=$ peripherally inserted central catheter, PORT $=$ implanted port catheter. $\mathbf{N}=$ Euro

\begin{tabular}{|lll|}
\hline Cost group & PICC & PORT \\
\hline Implantation & 384 & 331 \\
\hline Maintenance & 143 & 148 \\
\hline Complication & 272 & 128 \\
\hline Removal & 25 & 63 \\
\hline Total & 825 & 662 \\
\hline
\end{tabular}

Figure 15. Estimated cost in SEK and EUR per patient in the PICC and PORT group. $\mathrm{PICC}=$ peripherally inserted central catheter. $\mathrm{PORT}=\mathrm{Im}$ planted port catheter. $\mathbf{S E K}=$ Swedish krona. $\mathbf{E U R}=$ Euro

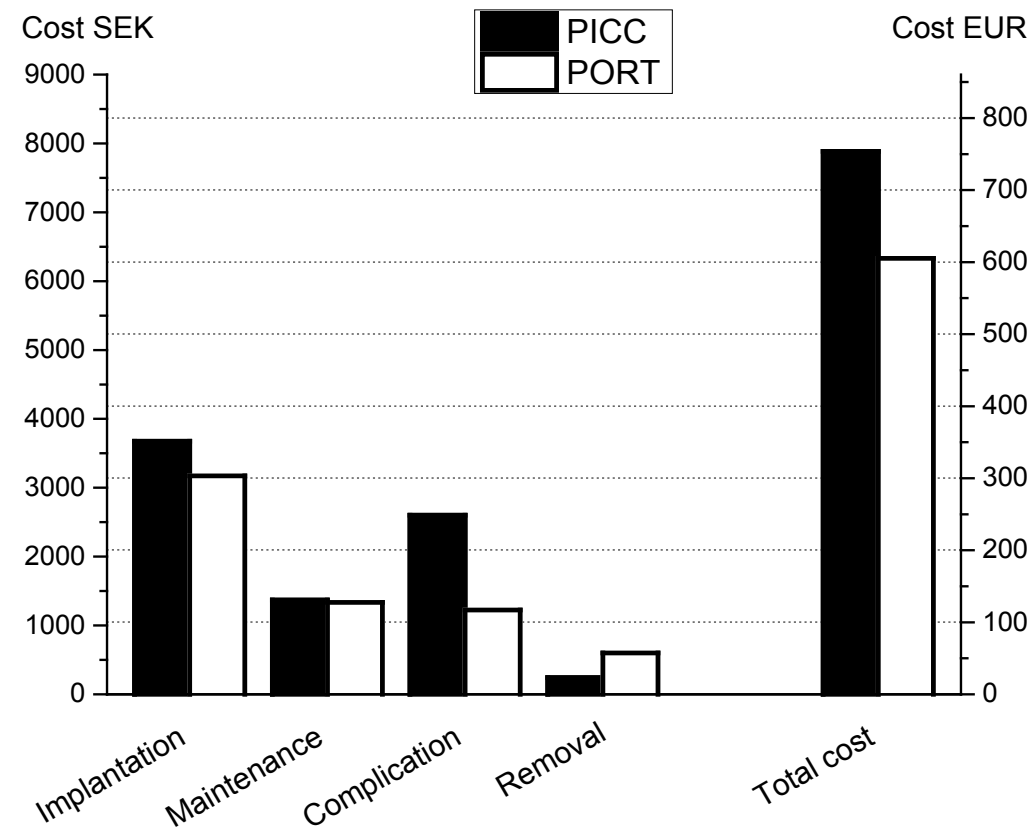




\section{DISCUSSION}

The main finding in this thesis was that a low overall complication rate may be achieved when evidence-based guidelines concerning the implantation and care of vascular access devices are implemented. Furthermore, the use of PICC is an independent risk factor for developing CR-DVT in patients with solid tumours.

Recent studies on cancer patients have shown CR-DVT rates of $4.3-11.7 \%$ for those with a PICC and $1.6-3.3 \%$ for those with a PORT. 336972 149-151 Three systematic reviews including cancer patients have concluded that PICCs are associated with an increased risk for CR-DVT compared to traditional CVCs. ${ }^{131416}$ Results from the small underpowered randomised trial by Patel et al are similar to the findings in the present thesis. ${ }^{130}$ Hence, available evidence supports our finding that CR-DVT is more common in cancer patients with a PICC when compared to those with a PORT.

The pathogenesis of CR-DVT is multifactorial and several risk factors have been suggested. ${ }^{84} 152$ The insertion of a venous catheter produces vascular injury at the site of insertion, and shortly after insertion fibrin deposits adhere to the thrombogenic surface of the catheter. ${ }^{153}$ The blood flow in a catheterised vein is reduced depending on the diameter ratio of the vein to the catheter. ${ }^{154}$ Stagnant flow, vascular injury and the hypercoagulability associated with both malignant disease and the catheter itself are classic contributors (Virchow's triad) to venous thrombosis.

In a systematic review, the incidence of CRBSI in patients with a PICC has been reported to be $1.8-7.7$ per 1000 catheter days. ${ }^{155}$ In another systematic review including 57250 patients comparing PICCs with CVCs, the relative risk for central line-associated blood stream infection was reported to be 0.9 (95\% CI 0.3 to 
2.6) for PICCs in patients with cancer. ${ }^{97}$ Lebeaux et al reported a PORT-related infection incidence of $0.1-1.5$ per 1000 catheter days in oncology patients. ${ }^{95}$ In this thesis (Studies I and III) we found a very low incidence of CRBSIs in both PICC and PORT patients of 0 to 0.05 per 1000 catheter days. During recent years, extensive programs related to catheter infection prevention have been introduced at our department resulting in a consistently low rate of catheter-related infections. ${ }^{33}{ }^{156-158}$ Hence, it is reasonable to believe that there is good adherence to basic hygiene precautions in our hospital. In addition, other factors that could have influenced the low infection rate is the appropriate utilisation of CVCs catheters are inserted with the correct indications and removed when no longer needed.

It should be emphasised that the argument for choosing a PICC instead of a PORT because of its easy removal if an infectious complication occurs, is not justified due to the very low incidence of CRBSI in both groups. The choice of device must therefore be based on its optimal properties not because of ease of removal due to possible CRBSI, especially if the catheter increases the risk for thrombosis.

We experienced more local infections in the PORT group. This difference was not significant when dwell-time was taken into account. We believe that the difference in median dwell-time between the two systems (126 vs 220 days) was probably the result of catheter survival bias i.e. PICCs are more often removed when treatment is discontinued.

Our incidence of local PORT infection was higher (6.7\% vs. 1.2\%) than in the Lebeaux et al. prospective observational study from $2012 .{ }^{95}$ However, it is important to notice that the Lebeaux-group only followed patients for 12 weeks compared to our one-year follow-up. It is reasonable to believe that this explains some of the difference. 
Early infection (within 30 days after implantation) suggest an implantation related infection, whereas late infection is linked to maintenance flaws. Since the median time to infection in the PORT group was 54 days (i.e. late infections) and caused by skin flora, it is reasonable to believe that there is room for further improvement in basic hygiene precautions during PORT management in the dwellperiod. Addition of chlorhexidine dressings and consistent use of sterile gloves may decrease the local infection rate.

Local PORT pocket infection may occur at any time posing both clinical and logistic challenges. ${ }^{33}{ }^{159-164}$ When suspecting PORT pocket infection as one of several possible causes of local inflammation, the clinician responsible must decide on whether or not the PORT membrane may safely be penetrated with the noncoring needle and used for infusion. The alternative is postponement of treatment pending further investigation, and possibly removal of the PORT system altogether. The risk of puncturing the PORT membrane through possibly infected tissues, leading to contamination of the PORT interior and subsequent bacteraemia, must be weighed against the risks and disadvantages of postponing cancer treatment or establishing an alternative intravenous access.

The main finding of Study II was that when puncturing a contaminated PORT membrane with a non-coring needle, a small fraction of the micro-organisms present on the membrane outside are transported through the membrane. The concentration of micro-organisms cultured from the outlet of the PORT system was only a fraction of the concentration on the outer side of the membrane $\left(10^{3}\right.$ - to $10^{4}$ - fold reduction). This number of micro-organisms can be significantly reduced by applying a continuous positive pressure flow through the non-coring needle during insertion. We believe that bacterial transmission occur within the cavity of the needle-tip itself (Figure 10) and not by adherence to the needle exterior. Hence, by applying flow in the non-coring needle, bacterial transmission was reduced to approximately $1 \%$ of that with puncture without flow. To the best of our knowledge such data have not previously been published. In extension, 
potentially infected PORTs could safely be accessed and thereby limiting interruptions in chemotherapy.

In recent years, PICCs have gained increased popularity. The reason for this may be that insertion can be done without delay by specially trained nursing teams on the ward, and that the capacity for insertion of PORTs is limited in many hospitals. ${ }^{165}$ However, the increase in the use of PICCs has taken place with little high-quality evidence regarding its safety compared to traditional central catheters. It has been noted in several papers that despite the frequent use of central vein access devices in oncology practice, there are few controlled trials comparing the quality and risk profiles of devices currently available. ${ }^{13141672} 130166$

Several vascular access-related features must be taken into consideration by the treating physician when discussing intravenous cancer treatment with the patient. The decision to use a particular central venous access device should involve a risk-benefit analysis including the risk for an adverse event, device availability, expected time on the waiting list for implantation, patient preference and cost. When assessing clinically relevant adverse events as a whole, the risk is almost three times higher with a PICC than with a PORT.

Several authors have stated that PICC is the cheaper vascular access alternative for patients with cancer. In Study IV, we demonstrate that PICCs are associated with a higher cost to the healthcare system compared to PORTs, when including clinically relevant dimensions of catheter insertion, care and removal. The difference in cost is mainly caused by costs related to the management of adverse events. Adverse events are potentially avoidable by limiting the use of PICCs in favour of PORTs in patients with cancer. Hence, both our patients and the healthcare system stand to benefit from a change in practice by choosing the central venous catheter that is the most appropriate for the delivery of chemotherapy. 
Our findings are comparable to those reported by Patel et al in 2014 i.e. higher costs with PICCs due to catheter related complications. ${ }^{130}$ In our material, PORT implantation costs were marginally smaller than PICCs, mainly due to the price difference in the pre-packed PICC kits. In contrast, implantation cost has been reported to be lower for PICCs by both Patel, Rotzinger and Viart. ${ }^{130} 133167$ When analysing costs from a healthcare system's perspective, it is important to include all relevant factors involved in insertion, maintenance and adverse event-related expenditure.

Several studies have investigated costs associated with both PICCs and PORTs focusing on different perspectives and patient categories. Notably, only a few of these have used a prospective study design with a control group. There are large differences in calculated costs in previously published studies (Table 14). The differences in the cost of long-term vascular access devices between studies could be explained by several factors including differences in salary between countries, different thresholds for hospital admission during treatment of adverse events, material pricing and differences in healthcare systems.

At many oncology centres (ours included), the use of a PICC for chemotherapy has been an integral and well-functioning part of day-to-day clinical practice for many years. However, the results of the present study raise questions regarding the appropriateness of the use of PICCs in cancer patients. On the other hand, a shift toward increased utilisation of PORTs might delay start of treatment in many cases due to the limited access to operating theatres. Meanwhile we believe that the PICC has a role to play in the treatment of cancer patients. It must be stressed that logistic challenges must be solved so that more patients will have access to PORTs within a reasonable time. When assessing the situation as a whole, more attention should be paid to selecting the best vascular access device alternative for each individual, possibly guided by CR-DVT risk- assessment tools. ${ }^{152}$ In light of the available evidence regarding safety, patient preference, 
and health economy more effort should be made in making PORTs available for patients with cancer.

Based on data from the screening process of Study III, patients appeared to prefer PORT over PICC when given the choice before starting their chemotherapy. This observation is prone to bias from several sources including other patients, staff and the internet. However, it is an interesting observation that needs further exploration.

In the randomised controlled trial by Patel et al from 2014, data on quality of life were available in $53 \%$ of patients. These indicated that there was no difference in preference between PICCs and PORTs. ${ }^{130}$ In our first study, PORTs were generally well accepted. ${ }^{33}$ In our randomised controlled trial, the implantation procedure was less painful in the PICC group, but PORTs interfered less with activities of daily life. ${ }^{164}$ It is obvious that more well-conducted controlled trials investigating patient-reported outcome measures and quality-of-life assessments are warranted in order to provide the information we require to be able to inform our patients and make the best decisions in the future.

This thesis has strengths that need to be mentioned. Data from the two clinical trials (Study I and III) are both prospective, with the latter being a RCT. In fact, Study III is the largest published RCT assessing differences between PICC and PORT in a cancer population. Thus, the internal and external validity of our results is likely high.

There are limitations that must be discussed. First, the health-economic evaluation may be of limited value in health-care systems very different from the Nordic countries due to different reimbursement models, other wages and different pricing. Second, we used a non-validated patients perceptions questionnaire during Study I and III. During Study I, patients were interviewed over the telephone 
which could have led to bias. Third, we included a wide range of cancer diagnoses which make interpretation in regard to specific subgroups difficult.

When recommending vascular access device to cancer patients, the avoidance of harmful adverse events and maximum patient satisfaction must be the priority of all clinicians. 


\section{CONCLUSIONS}

- The overall risk for vascular access device related adverse events is low in patients with cancer.

- The risk for CR-DVT is higher in cancer patients with a PICC when compared to cancer patients with a PORT.

- The risk for adverse events as a whole is higher with PICC.

- The incidence of CRBSI is very low in both PICCs and PORTs.

- Local infection is a major reason for premature PORT removal.

- The incidence of insertion-related complications, and mechanical complications during the indwelling period is very low for both PICC and PORT.

- Patients experience more pain during the insertion of a PORT than a PICC, but PICCs interfere with activities of daily life more than PORTs.

- Patients tend to prefer a PORT over a PICC when given the choice before starting chemotherapy

- The cost of a PICC is higher than that of a PORTs from the health-care system's perspective. The difference in cost is mainly caused by complications associated with PICCs.

- Micro-organisms can be transported across the PORT injection membrane when injecting through infected areas. The number of CFUs transported is dependent of the concentration outside the PORT membrane and the contaminating species.

- The number of transported CFUs into the PORT interior can be reduced by applying a positive-pressure flow through the needle when puncturing the PORT membrane. 


\section{FUTURE PERSPECTIVES}

- The use of antibiotic prophylaxis during PORT insertion should be studied further in well-designed prospective RCTs.

- The use of chlorhexidine-containing dressings around PORT needles should be evaluated in well-designed prospective RCTs.

- To clinically evaluate the safety and feasibility of anti-thrombotic PICCs, and in the extension perform controlled trials comparing traditional PICCs with anti-thrombotic PICCs.

- Qualitative research to further explore which device related factors are important to cancer patients. 


\section{BIBLIOGRAPHY}

1. Ellis H. Gray's anatomy. 37th ed. P. L. Williams, R. Warwick, M. Dyson, L. H. Bannister. Churchill Livingstone;1989 ISBN13:9780443025884

2. Ribatti D. William Harvey and the discovery of the circulation of the blood. J Angiogenes Res 2009;1:3

3. Hamilton H, Bodenham A. Central Venous Catheters. Wiley-Blackwell 2009;1-268 ISBN:9780470750186

4. Hickman RO, Buckner CD, Clift RA, Sanders JE, Stewart P, Thomas ED. A modified right atrial catheter for access to the venous system in marrow transplant recipients. Surg Gynecol Obstet 1979;148:871-5

5. Hoshal VL. Total intravenous nutrition with peripherally inserted silicone elastomer central venous catheters. Arch Surg 1975;110:644-6

6. Niederhuber JE, Ensminger W, Gyves JW, Liepman M, Doan K, Cozzi E. Totally implanted venous and arterial access system to replace external catheters in cancer treatment. Surgery 1982;92:706-12

7. Pikwer A, Acosta S, Granath A, et al. Riktlinjer för central venkateterisering. [Internet]. 2018 Dec p. 1-98 Available from: https://sfai.se/wpcontent/uploads/2015/02/CVK_riktlinjer-inkl-Appendix.pdf

8. Schiffer CA, Mangu PB, Wade JC, et al. Central Venous Catheter Care for the Patient With Cancer: American Society of Clinical Oncology Clinical Practice Guideline. Journal of Clinical Oncology 2013;31:1357-70

9. Bodenham A, Babu S, Bennett J, et al. Association of Anaesthetists of Great Britain and Ireland. Safe vascular access 2016. Anaesthesia 2016;71:573-85

10. Sousa B, Furlanetto J, Hutka M, et al. Central venous access in oncology: ESMO Clinical Practice Guidelines. Ann. Oncol. 2015;26:152-68 (supplement 5)

11. Frykholm P, Pikwer A, Hammarskjöld F, et al. Clinical guidelines on central venous catheterisation. Swedish Society of Anaesthesiology and Intensive Care Medicine. Acta Anaesthesiol Scand 2014;58:508-24

12. Chopra V, Flanders SA, Saint S, et al. The Michigan Appropriateness Guide for Intravenous Catheters (MAGIC): Results From a Multispecialty Panel Using the RAND/UCLA Appropriateness Method. Ann Intern Med 2015;163:S1-48

13. Pikwer A, Akeson J, Lindgren S. Complications associated with peripheral or central routes for central venous cannulation. Anaesthesia 2012;67:65-71 
14. Chopra V, Anand S, Hickner A, et al. Risk of venous thromboembolism associated with peripherally inserted central catheters: a systematic review and meta-analysis. Lancet 2013;382:311-25

15. Robinson A, Souied O, Bota AB, et al. Optimal vascular access strategies for patients receiving chemotherapy for early-stage breast cancer: a systematic review. Breast Cancer Res Treat 2018;171:607-20

16. Johansson E, Hammarskjöld F, Lundberg D, Arnlind MH. Advantages and disadvantages of peripherally inserted central venous catheters (PICC) compared to other central venous lines: a systematic review of the literature. Acta Oncol 2013;52:88692

17. Hsu CC-T, Kwan GNC, Evans-Barns H, Rophael JA, van Driel ML. Venous cutdown versus the Seldinger technique for placement of totally implantable venous access ports. Cochrane Vascular Group, editor. Cochrane Database Syst Rev 2016;20:CD008942

18. Nocito A, Wildi S, Rufibach K, Clavien P-A, Weber M. Randomized clinical trial comparing venous cutdown with the Seldinger technique for placement of implantable venous access ports. Br J Surg 2009;96:1129-34

19. Pikwer A. Clinical aspects on central venous cannulation. Lund University, Faculty of Medicine Doctoral Dissertation 2012. ISSN: 1652-8220, ISBN: 978-91-86871-70-3

20. Tabatabaie O, Kasumova GG, Eskander MF, Critchlow JF, Tawa NE, Tseng JF. Totally Implantable Venous Access Devices: A Review of Complications and Management Strategies. Am J Clin Oncol 2017;40:94-105

21. Shin H-J, Na H-S, Koh W-U, et al. Complications in internal jugular vs subclavian ultrasound-guided central venous catheterization: a comparative randomized trial. Intensive Care Med 2019;348:1-9

22. Kusminsky RE. Complications of central venous catheterization. J Am Coll Surg 2007;204:681-96

23. McGee DC, Gould MK. Preventing Complications of Central Venous Catheterization. $N$ Engl J Med 2003;348:1123-33

24. Parienti J-J, Mongardon N, Megarbane B, et al. Intravascular Complications of Central Venous Catheterization by Insertion Site. N Engl J Med 2015;373:1220-9

25. Yamagishi T, Ashida H, Igarashi T, et al. Clinical impact of the Sherlock $3 C^{\circledR}{ }^{\circledR}$ Tip Confirmation System for peripherally inserted central catheters. $J$ Int Med Res 2018;46:5176-82

26. Rosche N, Stehr W. Evaluation of a Magnetic Tracking and Electrocardiogram-based Tip Confirmation System for Peripherally Inserted Central Catheters in Pediatric Patients. J Infus Nurs 2018;41:301-8

27. Bedford E, Waterhouse D. Service development of a nurse-led community-based PICC insertion service. Br J Nurs 2017;26:S22-7 
28. Tomaszewski KJ, Ferko N, Hollmann SS, et al. Time and resources of peripherally inserted central catheter insertion procedures: a comparison between blind insertion/chest X-ray and a real time tip navigation and confirmation system. Clinicoecon Outcomes Res 2017;9:115-25

29. Dale M, Higgins A, Carolan-Rees G. Sherlock 3CG(®) Tip Confirmation System for Placement of Peripherally Inserted Central Catheters: A NICE Medical Technology Guidance. Appl Health Econ Health Policy 2016;14:41-9

30. Ebrahimi A, Yousefifard M, Mohammad Kazemi H, et al. Diagnostic Accuracy of Chest Ultrasonography versus Chest Radiography for Identification of Pneumothorax: A Systematic Review and Meta-Analysis. Tanaffos 2014;13:29-40

31. Pikwer A, Acosta S, Frykholm P et al. Riktlinjer för central venkateterisering. [Internet]. 2010 1-62 Available from: https://sfai.se/wpcontent/uploads/2015/02/CVK_riktlinjer-inkl-Appendix.pdf

32. Turker G, Kaya FN, Gurbet A, Aksu H, Erdogan C, Atlas A. Internal jugular vein cannulation: an ultrasound-guided technique versus a landmark-guided technique. Clinics (Sao Paulo) 2009;64:989-92

33. Taxbro K, Berg S, Hammarskjöld F, Hanberger H, Malmvall B-E. A prospective observational study on 249 subcutaneous central vein access ports in a Swedish county hospital. Acta Oncol 2013;52:893-901

34. Topaz O, Sharon M, Rechavia E, Mager A, Chetboun I. Traumatic internal jugular vein cannulation. Annals of Emergency Medicine 1987;16:1394-5

35. Mandala M, Ciano C, Ghilardi M, Cremonesi M, Cazzaniga M, Barni S. Acute dyspnea due to right phrenic palsy during infusional chemotherapy. Ann Oncol 2004; 15:691-2

36. Akata T, Noda Y, Nagata T, Noda E, Kandabashi T. Hemidiaphragmatic paralysis following subclavian vein catheterization. Acta Anaesthesiol Scand 1997;41:1223-5

37. Taskapan H, Oymak O, Dogukan A, Utas C. Horner's syndrome secondary to internal jugular catheterization. Clin Nephrol 2001;56:78-80

38. Salman M, Potter M, Ethel M, Myint F. Recurrent laryngeal nerve injury: a complication of central venous catheterization-a case report. Angiology 2004;55:345-6

39. Whittet HB, Boscoe MJ. Isolated palsy of the hypoglossal nerve after central venous catheterization. Br Med J (Clin Res Ed) 1984;288:1042-3

40. Vesely TM. Air embolism during insertion of central venous catheters. $J$ Vasc Interv Radiol 2001;12:1291-5

41. Ploner F, Saltuari L, Marosi MJ, Dolif R, Salsa A. Cerebral air emboli with use of central venous catheter in mobile patient. The Lancet 1991;338:1331 
42. Ignatov A, Ignatov T, Taran A, Smith B, Costa S-D, Bischoff J. Interval between port catheter flushing can be extended to four months. Gynecol Obstet Invest 2010;70:914

43. Lebeaux D, Fernández-Hidalgo N, Chauhan A, et al. Management of infections related to totally implantable venous-access ports: challenges and perspectives. Lancet Infect Dis 2014;14:146-59

44. Zacharioudakis IM, Zervou FN, Arvanitis M, Ziakas PD, Mermel LA, Mylonakis E. Antimicrobial lock solutions as a method to prevent central line-associated bloodstream infections: a meta-analysis of randomized controlled trials. Clin Infect Dis 2014;59:1741-9

45. Norris LB, Kablaoui F, Brilhart MK, Bookstaver PB. Systematic review of antimicrobial lock therapy for prevention of central-line-associated bloodstream infections in adult and pediatric cancer patients. Int J Antimicrob Agents 2017;50:308-17

46. Niyyar VD, Lok CE. Pros and cons of catheter lock solutions. Curr Opin Nephrol Hypertens 2013;22:669-74

47. Shanks RMQ, Sargent JL, Martinez RM, Graber ML, O'Toole GA. Catheter lock solutions influence staphylococcal biofilm formation on abiotic surfaces. Nephrol Dial Transplant 2006;21:2247-55

48. Hoffman LR, D'Argenio DA, MacCoss MJ, Zhang Z, Jones RA, Miller SI. Aminoglycoside antibiotics induce bacterial biofilm formation. Nature 2005;436:1171-5

49. Wolf J, Connell TG, Curtis N, Flynn PM. Ethanol lock therapy. Lancet Infect Dis 2018;18:1306

50. Karanlik H, Kurul S, Saip P, et al. The role of antibiotic prophylaxis in totally implantable venous access device placement: results of a single-center prospective randomized trial. The American Journal of Surgery 2011;202:10-5

51. van de Wetering MD, van Woensel JBM, Lawrie TA. Prophylactic antibiotics for preventing Gram positive infections associated with long-term central venous catheters in oncology patients. Cochrane Database Syst Rev 2013;CD003295

52. Johnson E, Babb J, Sridhar D. Routine Antibiotic Prophylaxis for Totally Implantable Venous Access Device Placement: Meta-Analysis of 2,154 Patients. J Vasc Interv Radiol 2016;27:339-43

53. Goossens GA. Flushing and Locking of Venous Catheters: Available Evidence and Evidence Deficit. Nurs Res Pract 2015;2015:1-12

54. Goossens GA, Jérôme M, Janssens $\mathrm{C}$, et al. Comparing normal saline versus diluted heparin to lock non-valved totally implantable venous access devices in cancer patients: a randomised, non-inferiority, open trial. Ann Oncol 2013;24:1892-9

55. Goh LJ, Teo HS, Masagoes M. Heparinised Saline versus Normal Saline in Maintaining Patency of Arterial and Central Venous Catheters. Proceedings of Singapore Healthcare 2011;20:190-6 
56. Lyman GH. Venous thromboembolism in the patient with cancer: focus on burden of disease and benefits of thromboprophylaxis. Cancer 2011;117:1334-49

57. Lyman GH, Bohlke K, Falanga A. Venous Thromboembolism Prophylaxis and Treatment in Patients With Cancer: American Society of Clinical Oncology Clinical Practice Guideline Update. Journal of Oncology Practice 2015;11:442-4

58. Louzada ML, Majeed H, Dao V, Wells PS. Risk of recurrent venous thromboembolism according to malignancy characteristics in patients with cancer-associated thrombosis: a systematic review of observational and intervention studies. Blood Coagulation \& Fibrinolysis 2011;22:86-91

59. Garcia D, Quintana D. Thrombosis and malignancy: a case-based review. Semin Hematol 2011;48:259-63

60. Venous thromboembolic events with chemotherapy plus bevacizumab: a pooled analysis of patients in randomized phase II and III studies. J Clin Oncol 2011;29:1757-64

61. Engelberger RP, Kucher N. Management of deep vein thrombosis of the upper extremity. Circulation 2012;126:768-73

62. Joffe HV, Kucher N, Tapson VF, Goldhaber SZ, Deep Vein Thrombosis (DVT) FREE Steering Committee. Upper-extremity deep vein thrombosis: a prospective registry of 592 patients. Circulation 2004;110:1605-11

63. Winters JP, Callas PW, Cushman M, Repp AB, Zakai NA. Central venous catheters and upper extremity deep vein thrombosis in medical inpatients: the Medical Inpatients and Thrombosis (MITH) Study. J Thromb Haemost 2015;13:2155-60

64. Lee J-A, Zierler BK, Zierler RE. The risk factors and clinical outcomes of upper extremity deep vein thrombosis. Vasc Endovascular Surg 2012;46:139-44

65. Sharp R, Cummings M, Fielder A, Mikocka-Walus A, Grech C, Esterman A. The catheter to vein ratio and rates of symptomatic venous thromboembolism in patients with a peripherally inserted central catheter (PICC): a prospective cohort study. Int $J$ Nurs Stud 2015;52:677-85

66. Gorski LA. The 2016 Infusion Therapy Standards of Practice. Home Healthc Now 2017;35:10-8

67. van Rooden CJ, Tesselaar MET, Osanto S, Rosendaal FR, Huisman MV. Deep vein thrombosis associated with central venous catheters - a review. J Thromb Haemost 2005;3:2409-19

68. Van Rooden CJ, Rosendaal FR, Meinders AE, Van Oostayen JA, Van Der Meer FJM, Huisman MV. The contribution of factor V Leiden and prothrombin G20210A mutation to the risk of central venous catheter-related thrombosis. Haematologica 2004;89:201-6 
69. Lee AYY, Levine MN, Butler G, et al. Incidence, risk factors, and outcomes of catheter-related thrombosis in adult patients with cancer. American Society of Clinical Oncology; 2006;24:1404-8

70. Evans RS, Sharp JH, Linford LH, et al. Risk of symptomatic DVT associated with peripherally inserted central catheters. Chest 2010;138:803-10

71. Tabatabaie O, Kasumova GG, Kent TS, et al. Upper extremity deep venous thrombosis after port insertion: What are the risk factors? Surgery 2017;162:437-44

72. Jones D, Wismayer K, Bozas G, Palmer J, Elliott M, Maraveyas A. The risk of venous thromboembolism associated with peripherally inserted central catheters in ambulant cancer patients. Thrombosis $J$ 2017;15:25

73. Mansour A, Saadeh SS, Abdel-Razeq N, Khozouz O, Abunasser M, Taqash A. Clinical Course and Complications of Catheter and Non-Catheter-Related Upper Extremity Deep Vein Thrombosis in Patients with Cancer. Clin Appl Thromb Hemost 2018;24:1234-40

74. Kleinjan A, Di Nisio M, Beyer-Westendorf J, et al. Safety and Feasibility of a Diagnostic Algorithm Combining Clinical Probability,d-Dimer Testing, and Ultrasonography for Suspected Upper Extremity Deep Venous Thrombosis. Ann Intern Med 2014;160:451

75. Di Nisio M, Van Sluis GL, Bossuyt PMM, BÜLLER HR, Porreca E, Rutjes AWS. Accuracy of diagnostic tests for clinically suspected upper extremity deep vein thrombosis: a systematic review. J Thromb Haemost 2010;8:684-92

76. Owens CA, Bui JT, Knuttinen MG, Gaba RC, Carrillo TC. Pulmonary embolism from upper extremity deep vein thrombosis and the role of superior vena cava filters: a review of the literature. J Vasc Interv Radiol 2010;21:779-87

77. Farge D, Bounameaux H, Brenner B, et al. International clinical practice guidelines including guidance for direct oral anticoagulants in the treatment and prophylaxis of venous thromboembolism in patients with cancer. The Lancet Oncology 2016;17:452-66

78. Guyatt GH, Akl EA, Crowther M, Gutterman DD, Schuünemann HJ. Executive Summary: Antithrombotic Therapy and Prevention of Thrombosis, 9th ed: American College of Chest Physicians Evidence-Based Clinical Practice Guidelines. Chest Elsevier; 2012;141:7S-47S

79. Mandala M, Falanga A, Roila F. Management of venous thromboembolism (VTE) in cancer patients: ESMO Clinical Practice Guidelines. Ann. Oncol. 2011;21 85-92

80. Kearon C, Akl EA, Ornelas J, et al. Antithrombotic Therapy for VTE Disease: CHEST Guideline and Expert Panel Report. Chest. 2016;149:315-52

81. Debordeau P, Farge D, Beckers M, et al. International clinical practice guidelines for the treatment and prophylaxis of thrombosis associated with central venous catheters in patients with cancer. Journal of Thrombosis and Haemostasis 2013;11:71-80 
82. Davies GA, Lazo-Langner A, Gandara E, et al. A prospective study of Rivaroxaban for central venous catheter associated upper extremity deep vein thrombosis in cancer patients (Catheter 2). Thromb Res 2018;162:88-92

83. Raskob GE, Büller HR, Segers A. Edoxaban for Cancer-Associated Venous Thromboembolism. N Engl J Med 2018;379:95-6

84. Geerts W. Central venous catheter-related thrombosis. Hematology Am Soc Hematol Educ Program 2014;2014:306-11

85. Baskin JL, Pui C-H, Reiss U, et al. Management of occlusion and thrombosis associated with long-term indwelling central venous catheters. Lancet 2009;374:159-69

86. Kahale LA, Tsolakian IG, Hakoum MB, et al. Anticoagulation for people with cancer and central venous catheters. Cochrane Database Syst Rev 2018;6:CD006468

87. Carrier M, Abou-Nassar K, Mallick R, et al. Apixaban to Prevent Venous Thromboembolism in Patients with Cancer. N Engl J Med 2019;380:711-9

88. Khorana AA, Soff GA, Kakkar AK, et al. Rivaroxaban for Thromboprophylaxis in High-Risk Ambulatory Patients with Cancer. N Engl J Med 2019;380:720-8

89. Barbar S, Noventa F, Rossetto V, et al. A risk assessment model for the identification of hospitalized medical patients at risk for venous thromboembolism: the Padua Prediction Score. J Thromb Haemost 2010;8:2450-7

90. Pannucci CJ, Swistun L, MacDonald JK, Henke PK, Brooke BS. Individualized Venous Thromboembolism Risk Stratification Using the 2005 Caprini Score to Identify the Benefits and Harms of Chemoprophylaxis in Surgical Patients: A Meta-analysis. Annals of Surgery 2017;265:1094-103

91. Bahl V, Hu HM, Henke PK, Wakefield TW, Campbell DA, Caprini JA. A validation study of a retrospective venous thromboembolism risk scoring method. Annals of Surgery 2010;251:344-50

92. Fischer L, Knebel P, Schröder S, et al. Reasons for explantation of totally implantable access ports: a multivariate analysis of 385 consecutive patients. Ann Surg Oncol 2008;15:1124-9

93. Hsieh C-C, Weng H-H, Huang W-S, et al. Analysis of risk factors for central venous port failure in cancer patients. World J Gastroenterol 2009;15:4709-14

94. Narducci F, Jean-Laurent M, Boulanger L, et al. Totally implantable venous access port systems and risk factors for complications: a one-year prospective study in a cancer centre. Eur J Surg Oncol 2011;37:913-8

95. Lebeaux D, Larroque B, Gellen-Dautremer J, et al. Clinical outcome after a totally implantable venous access port-related infection in cancer patients: a prospective study and review of the literature. Medicine (Baltimore) 2012;91:309-18 
96. Maki DG, Kluger DM, Crnich CJ. The risk of bloodstream infection in adults with different intravascular devices: a systematic review of 200 published prospective studies. Mayo Clinic Proceedings 2006;81:1159-71

97. Chopra V, O'Horo JC, Rogers MAM, Maki DG, Safdar N. The risk of bloodstream infection associated with peripherally inserted central catheters compared with central venous catheters in adults: a systematic review and meta-analysis. Infect Control Hosp Epidemiol 2013;34:908-18

98. Gao Y, Liu Y, Ma X, Wei L, Chen W, Song L. The incidence and risk factors of peripherally inserted central catheter-related infection among cancer patients. Ther Clin Risk Manag 2015;11:863-71

99. Kang J, Chen W, Sun W, et al. Peripherally inserted central catheter-related complications in cancer patients: a prospective study of over 50,000 catheter days. J Vasc Access 2017;18:153-7

100. Mollee P, Jones M, Stackelroth J, et al. Catheter-associated bloodstream infection incidence and risk factors in adults with cancer: a prospective cohort study. J Hosp Infect 2011;78:26-30

101. Ahn DH, Illum HB, Wang DH, Sharma A, Dowell JE. Upper extremity venous thrombosis in patients with cancer with peripherally inserted central venous catheters: a retrospective analysis of risk factors. Journal of Oncology Practice 2013;9:8-12

102. Safdar N, Maki DG. The pathogenesis of catheter-related bloodstream infection with noncuffed short-term central venous catheters. Intensive Care Med 2004;30:62-7

103. Mermel LA, Allon M, Bouza E, et al. Clinical practice guidelines for the diagnosis and management of intravascular catheter-related infection: 2009 Update by the Infectious Diseases Society of America. Clin Infect Dis 2009;49:1-45

104. Slobbe L, Barzouhi el A, Boersma E, Rijnders BJA. Comparison of the Roll Plate Method to the Sonication Method To Diagnose Catheter Colonization and Bacteremia in Patients with Long-Term Tunnelled Catheters: a Randomized Prospective Study. Journal of Clinical Microbiology 2009;47:885-8

105. Sautter RL, Bills AR, Lang DL, Ruschell G, Heiter BJ, Bourbeau PP. Effects of delayed-entry conditions on the recovery and detection of microorganisms from BacT/ALERT and BACTEC blood culture bottles. Journal of Clinical Microbiology 2006;44:1245-9

106. Safdar N, Fine JP, Maki DG. Meta-analysis: methods for diagnosing intravascular device-related bloodstream infection. Ann Intern Med 2005;142:451-66

107. Safdar N, Maki DG. Risk of Catheter-Related Bloodstream Infection With Peripherally Inserted Central Venous Catheters Used in Hospitalized Patients. Chest 2005;128:489-95

108. Pinelli F, Cecero E, Degl'Innocenti D, et al. Infection of totally implantable venous access devices: A review of the literature. J Vasc Access 2018;163:1-13 
109. Fernández-Hidalgo N, Almirante B, Calleja R, et al. Antibiotic-lock therapy for longterm intravascular catheter-related bacteraemia: results of an open, non-comparative study. J Antimicrob Chemother 2006;57:1172-80

110. Tribler S, Brandt CF, Petersen AH, et al. Taurolidine-citrate-heparin lock reduces catheter-related bloodstream infections in intestinal failure patients dependent on home parenteral support: a randomized, placebo-controlled trial. Am J Clin Nutr 2017;106:839-48

111. Tribler S, Brandt CF, Fuglsang KA, et al. Catheter-related bloodstream infections in patients with intestinal failure receiving home parenteral support: risks related to a catheter-salvage strategy. Am J Clin Nutr 2018;107:743-53

112. Tribler S, Brandt CF, Hvistendahl M, et al. Catheter-Related Bloodstream Infections in Adults Receiving Home Parenteral Nutrition: Substantial Differences in Incidence Comparing a Strict Microbiological to a Clinically Based Diagnosis. JPEN J Parenter Enteral Nutr 2018;42:393-402

113. Mimoz O, Lucet J-C, Kerforne T, et al. Skin antisepsis with chlorhexidine-alcohol versus povidone iodine-alcohol, with and without skin scrubbing, for prevention of intravascular-catheter-related infection (CLEAN): an open-label, multicentre, randomised, controlled, two-by-two factorial trial. Lancet 2015;386:2069-77

114. Kampf G. Acquired resistance to chlorhexidine - is it time to establish an 'antiseptic stewardship' initiative? J Hosp Infect 2016;94:213-27

115. Mermel LA. Prevention of Intravascular Catheter-Related Infections. Ann Intern Med 2000;132:391-402

116. Dentali F, Gianni M, Agnelli G, Ageno W. Association between inherited thrombophilic abnormalities and central venous catheter thrombosis in patients with cancer: a meta-analysis. J Thromb Haemost 2008;6:70-5

117. Kerner JA, Garcia-Careaga MG, Fisher AA, Poole RL. Treatment of catheter occlusion in pediatric patients. JPEN J Parenter Enteral Nutr 2006;30:S73-81

118. McHugh GJ, Wild DJ, Havill JH. Polyurethane central venous catheters, hydrochloric acid and 70\% ethanol: a safety evaluation. Anaesth Intensive Care 1997;25:350-3

119. Mirza B, Vanek VW, Kupensky DT. Pinch-off syndrome: case report and collective review of the literature. Am Surg 2004;70:635-44

120. Aitken DR,. The 'pinch-off sign': a warning of impending problems with permanent subclavian catheters. The American Journal of Surgery 1984;148:633-636

121. Zawacki WJ, Walker TG, DeVasher E, et al. Wound dehiscence or failure to heal following venous access port placement in patients receiving bevacizumab therapy. $J$ Vasc Interv Radiol 2009;20:624-7

122. Erinjeri JP, Fong AJ, Kemeny NE, Brown KT, Getrajdman GI, Solomon SB. Timing of administration of bevacizumab chemotherapy affects wound healing after chest wall port placement. Cancer 2011;117:1296-301 
123. Kurul S, Saip P, Aydin T. Totally implantable venous-access ports: local problems and extravasation injury. The Lancet Oncology 2002;3:684-92

124. Schulmeister L. Extravasation management: clinical update. Semin Oncol Nurs 2011;27:82-90

125. Pérez Fidalgo JA, García Fabregat L, Cervantes A, et al. Management of chemotherapy extravasation: ESMO-EONS Clinical Practice Guidelines. Ann Oncol 2012;23:167-73

126. Kang J, Chen W, Sun W, et al. Health-Related Quality of Life of Cancer Patients with Peripherally Inserted Central Catheter: A Pilot Study. J Vasc Access 2017;18:396-401

127. Bortolussi R, Zotti P, Conte M, et al. Quality of Life, Pain Perception, and Distress Correlated to Ultrasound-Guided Peripherally Inserted Central Venous Catheters in Palliative Care Patients in a Home or Hospice Setting. J Pain Symptom Manage 2015;50:118-23

128. Parás-Bravo P, Paz-Zulueta M, Santibañez M, et al. Living with a peripherally inserted central catheter: the perspective of cancer outpatients-a qualitative study. Support Care Cancer 2018;26:441-9

129. Krein SL, Saint S, Trautner BW, et al. Patient-reported complications related to peripherally inserted central catheters: a multicentre prospective cohort study. $B M J$ Qual Saf 2018;0:1-8

130. Patel GS, Jain K, Kumar R, et al. Comparison of peripherally inserted central venous catheters (PICC) versus subcutaneously implanted port-chamber catheters by complication and cost for patients receiving chemotherapy for non-haematological malignancies. Support Care Cancer 2014;22:121-8

131. Lorenzoni L, Koechlin F. International Comparisons of Health Prices and Volumes [Internet] www.oecd.org/health/health-systems/international-comparisons-of-healthprices-and-volumes-new-findings-pdf 2017:1-11

132. Rotzinger R, Gebauer B, Schnapauff D, et al. Placement of central venous port catheters and peripherally inserted central catheters in the routine clinical setting of a radiology department: analysis of costs and intervention duration learning curve. Acta Radiol 2017;58:1468-75

133. Viart H, Combe C, Martinelli T, Thomas J, Hida H. Comparison between implantation costs of peripherally inserted central catheter and implanted subcutaneous ports. Ann Pharm Fr 2015;73:239-44

134. LaRoy JR, White SB, Jayakrishnan T, et al. Cost and Morbidity Analysis of Chest Port Insertion: Interventional Radiology Suite Versus Operating Room. J Am Coll Radiol 2015;12:563-71

135. Wu O, Boyd K, Paul J, et al. Hickman catheter and implantable port devices for the delivery of chemotherapy: a phase II randomised controlled trial and economic evaluation. Br J Cancer 2016;114:979-85 
136. Biffi R, Pozzi S, Bonomo G, et al. Cost effectiveness of different central venous approaches for port placement and use in adult oncology patients: evidence from a randomized three-arm trial. Ann Surg Oncol 2014;21:3725-31

137. Ng F, Mastoroudes H, Paul E, et al. A comparison of Hickman line- and Port-a-Cathassociated complications in patients with solid tumours undergoing chemotherapy. Clin Oncol (R Coll Radiol) 2007;19:551-6

138. Shen-Gunther J, Mannel RS, Walker JL, Gold MA, Johnson GA. Outpatient implantation of a central venous access system in gynecologic oncology patients. $J$ Reprod Med 2003;48:875-81

139. Pernar LIM, Wolf LL, Seshadri A, Patel V. Impact of a Surgeon-Led Peripherally Inserted Central Venous Catheter Team on Peripherally Inserted Central Venous Catheter-Related Complications and Costs. Surg Infect (Larchmt) 2016;17:352-6

140. Walker G, Todd A. Nurse-led PICC insertion: is it cost effective? Br J Nurs 2013;22:S9-15

141. Hernández PR, López JLG, Martín JG, Eguía BR. Care and cost-utility indicators for high-flow PICC catheters: a study. Br J Nurs 2011;20:22-7

142. Periard D, Monney P, Waeber G, et al. Randomized controlled trial of peripherally inserted central catheters vs. peripheral catheters for middle duration in-hospital intravenous therapy. J Thromb Haemost 2008;6:1281-8

143. Cowl CT, Weinstock JV, Al-Jurf A, Ephgrave K, Murray JA, Dillon K. Complications and cost associated with parenteral nutrition delivered to hospitalized patients through either subclavian or peripherally-inserted central catheters. Clin Nutr 2000;19:237-43

144. O'Grady NP, Alexander M, Dellinger EP, et al. Guidelines for the prevention of intravascular catheter-related infections. Centers for Disease Control and Prevention. MMWR 2002;51:1-29

145. Fraenkel DJ, Rickard C, Lipman J. Can we achieve consensus on central venous catheter-related infections? Anaesth Intensive Care 2000;28:475-90

146. Hammarskjöld F, Wallén G, Malmvall B-E. Central venous catheter infections at a county hospital in Sweden: a prospective analysis of colonization, incidence of infection and risk factors. Acta Anaesthesiol Scand 2006;50:451-60

147. König C, Simmen H-P, Blaser J. Bacterial concentrations in pus and infected peritoneal fluid--implications for bactericidal activity of antibiotics. $J$ Antimicrob Chemother 1998;42:227-32

148. Hopewell S, Clarke M, Moher D, et al. CONSORT for reporting randomised trials in journal and conference abstracts. The Lancet 2008;371:281-3

149. Bertoglio S, Faccini B, Lalli L, Cafiero F, Bruzzi P. Peripherally inserted central catheters (PICCs) in cancer patients under chemotherapy: A prospective study on the incidence of complications and overall failures. J Surg Oncol 2016;113:708-14 
150. Aw A, Carrier M, Koczerginski J, McDiarmid S, Tay J. Incidence and predictive factors of symptomatic thrombosis related to peripherally inserted central catheters in chemotherapy patients. Thromb Res 2012;130:323-6

151. Catalano O, de Lutio di Castelguidone E, Sandomenico C, et al. Central venous device-related thrombosis as imaged with MDCT in oncologic patients: prevalence and findings. Acta Radiol 2011;52:148-54

152. Chopra V, Kaatz S, Conlon A, et al. The Michigan Risk Score to predict peripherally inserted central catheter-associated thrombosis. J Thromb Haemost 2017;15:1951-62

153. Forauer AR, Theoharis CGA, Dasika NL. Jugular vein catheter placement: histologic features and development of catheter-related (fibrin) sheaths in a swine model. Radiology Radiological Society of North America; 2006;240:427-34

154. Nifong TP, McDevitt TJ. The effect of catheter to vein ratio on blood flow rates in a simulated model of peripherally inserted central venous catheters. Chest 2011;140:48-53

155. Chopra V, Anand S, Krein SL, Chenoweth C, Saint S. Bloodstream infection, venous thrombosis, and peripherally inserted central catheters: reappraising the evidence. $\mathrm{Am}$ $J$ Med 2012;125:733-41

156. Hammarskjöld F, Wallen G, Malmvall B-E. Central venous catheter infections at a county hospital in Sweden: a prospective analysis of colonization, incidence of infection and risk factors. Acta Anaesthesiol Scand 2006;50:451-60

157. Hammarskjöld F, Berg S, Hanberger H, Malmvall B-E. Low incidence of arterial catheter infections in a Swedish intensive care unit: risk factors for colonisation and infection. J Hosp Infect 2010;76:130-4

158. Hammarskjöld F, Berg S, Hanberger H, Malmvall B-E. Sustained low incidence of central venous catheter-related infections over six years in a Swedish hospital with an active central venous catheter team. Am J Infect Control 2014;42:122-8

159. Teichgräber UKM, Kausche S, Nagel SN. Evaluation of radiologically implanted central venous port systems explanted due to complications. $J$ Vasc Access 2011;12:306-12

160. Barbetakis N, Asteriou C, Kleontas A, Tsilikas C. Totally implantable central venous access ports. Analysis of 700 cases. J Surg Oncol 2011;104:654-6

161. Lefebvre L, Noyon E, Georgescu D, et al. Port catheter versus peripherally inserted central catheter for postoperative chemotherapy in early breast cancer: a retrospective analysis of 448 patients. Support Care Cancer 2016;24:1397-403

162. Heibl C, Trommet V, Burgstaller S, et al. Complications associated with the use of Port-a-Caths in patients with malignant or haematological disease: a single-centre prospective analysis. Eur J Cancer Care 2010;19:676-81 
163. Peris A, Zagli G, Bonizzoli M, et al. Implantation of 3951 long-term central venous catheters: performances, risk analysis, and patient comfort after ultrasound-guidance introduction. Anesthesia \& Analgesia 2010;111:1194-201

164. Taxbro K, Hammarskjöld F, Thelin B, et al. Clinical impact of peripherally inserted central catheters vs implanted port catheters in patients with cancer: an open-label, randomised, two-centre trial. British Journal of Anaesthesia 2019;122:734-41

165. Johansson E, Hammarskjöld F, Lundberg D, Heibert Arnlind M. A survey of the current use of peripherally inserted central venous catheter (PICC) in Swedish oncology departments. Acta Oncol 2013;52:1241-2

166. Chopra V, Flanders SA, Saint S. The problem with peripherally inserted central catheters. JAMA 2012;308:1527-8

167. Rotzinger R, Gebauer B, Schnapauff D, et al. Placement of central venous port catheters and peripherally inserted central catheters in the routine clinical setting of a radiology department: analysis of costs and intervention duration learning curve. Acta Radiol 2017;58:1468-75 


\section{Papers}

The papers associated with this thesis have been removed for copyright reasons. For more details about these see:

http://urn.kb.se/resolve?urn=urn:nbn:se:liu:diva-159085 


\section{FACULTY OF MEDICINE AND HEALTH SCIENCES}

Linköping University Medical Dissertation No. 1693, 2019 Department of Medical and Health Sciences (IMH)

Division of Cardiovascular Medicine (KVM)

Linköping University

SE-581 83 Linköping, Sweden

www.liu.se 